\title{
ADSORÇÃO DE COBRE EM LATOSSOLOS ÁCRICOS PAULISTAS
}

\author{
Maria Lucia Azevedo Silveira \\ Engenheira Agrônoma
}

Orientador : Prof. Dr. LUÍS REYNALDO FERRACCIÚ ALLEONI

Dissertação apresentada à Escola Superior de Agricultura "Luiz de Queiroz", Universidade de São Paulo, para obtenção do título de Mestre em Agronomia, Área de Concentração: Solos e Nutrição de Plantas.

\section{PIRACICABA}

Estado de São Paulo - Brasil

Maio - 1999 
DIVISÃo DE BIBLIOTECA E DOCUMENTAÇÃO - Campus "Luiz de Queiroz"/USP

\section{Silveira, Maria Lúcia Azevedo}

Adsorção de cobre em latossolos ácricos paulistas / Maria Lúcia Azevedo Silveira. . . Piracicaba, 1999.

$91 \mathrm{p}$.

Dissertação (mestrado) -. Escola Superior de Agricultura Luiz de Queiroz, 1999. Bibliografia.

1. Adsorção 2. Cobre 3. Latossolo 4. Química do solo 5. Terra roxa I. Título

CDD 631.41 
SILVEIRA, Maria Lucia Azevedo. Adsorção de cobre em latossolos ácricos paulistas. Piracicaba, 1999. 91 p. Dissertação (Mestrado) - Escola Superior de Agricultura "Luiz de Queiroz", Universidade de São Paulo.

\section{ERRATA}

p. linha onde se lê leia-se

$\begin{array}{llll}38 & \text { oitava } & (\mathrm{ki}>0,75 \text { e } \mathbf{k}<0,75) & (\mathrm{ki}>0,75 \text { e } \mathrm{k}>0,75) \\ 38 & \text { nona } & \mathrm{LR}: & \mathrm{LR} \text { e LU : } \\ 38 & \text { décima } & \text { LU : gibsítico ... } & \text { (eliminar o período) }\end{array}$




\section{OFERECIMENTO}

Aos meus pais, Lourdes e José Waldir, pelo apoio e compreensão; à minha irmã Maria Cristina

\section{DEDICAÇÃO}

ao meu irmão José Waldir (in memorian) pela sua lição de vida 


\section{AGRADECIMENTOS}

Ao Dr. Luís Reynaldo Ferracciú Alleoni, pela sua orientação e, acima de tudo, pelo apoio em todos os momentos;

À Fundação de Amparo à Pesquisa do Estado de São Paulo (FAPESP) e à CAPES, pela concessão da Bolsa de estudo;

À coordenação do Curso de Pós-Graduação em Solos e Nutrição de Plantas, na pessoa do Prof. Dr. Francisco A. Monteiro, pela oportunidade oferecida;

Aos pesquisadores Dr. Otávio A. de Camargo (Instituto Agronômico de Campinas) e Dr. José Carlos Casagrande (Universidade Federal de São Carlos) pelo apoio técnico;

Aos professores do Departamento de Solos e Nutrição de Plantas que contribuíram com o estudo, em especial ao Prof. Dr. Jorge de Castro Kiehl e Prof. Dr. Luís Ignácio Prochnow;

Ao professor Dr. Luiz Roberto G. Guilherme (Universidade Federal de Lavras), pelas sugestões;

Aos funcionários do Departamento de Solos e Nutrição de Plantas, pelo auxílio nas análise laboratoriais;

Aos colegas de curso, em especial ao João Maurício B. Vendramini, pela amizade e convivência. 


\section{SUMÁRIO}

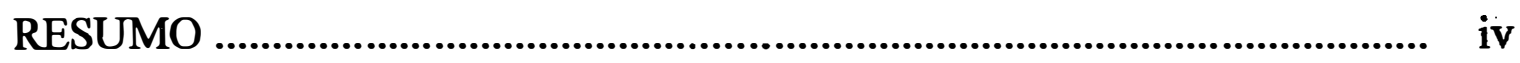

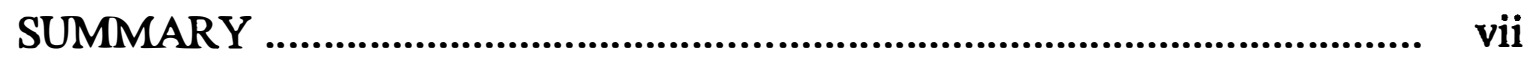

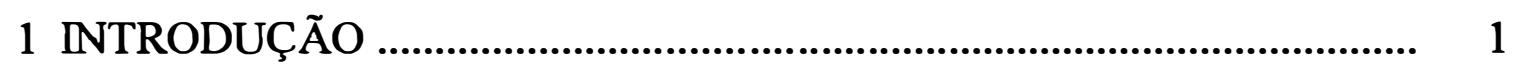

2 REVISÃO DE LITERATURA .............................................................. 4

2.1 Geoquímica do cobre ........................................................................ 4

2.2 Reações que controlam a solubilidade do cobre em solo.......................... 6

2.2.1 Troca iônica ............................................................................. 7

2.2.2 Adsorção química na superficie dos componentes do solo ......... 9

2.2.2.1 Matéria orgânica .................................................................... 11

2.2.2.2 Óxidos .................................................................... 13

2.2.2.3 Descrição da adsorção ......................................................... 16

2.2.3 Precipitação/Dissolução .......................................................... 19

2.2.4 Influência do $\mathrm{pH}$ na adsorção de cobre pelo solo ...................... 20

2.3 Solos ácricos ............................................................................... 22

2.3.1 Definição e ocorrência no Estado de São Paulo ......................... 22

2.3.2 Atributos químicos, físicos e mineralógicos ............................... 24

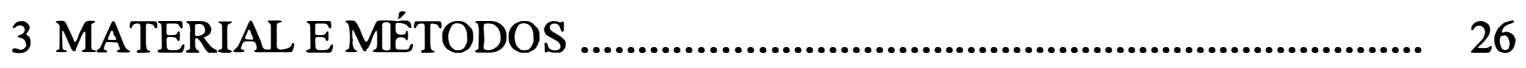

3.1 Solos utilizados .......................................................................... 26

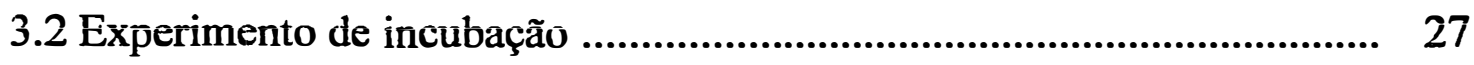

3.3 Caracterização química, fisica e mineralógica ....................................... 27

3.4 Curvas e isotermas de adsorção de cobre ............................................. 32 
3.5 Variação do $\mathrm{pH}$....................................................................................... 33

3.6 Análise de regressão....................................................................... 34

3.7 Análises estatísticas ....................................................................... 34

4 RESULTADOS E DISCUSSÃO _........................................................ 35

4.1 Atributos químicos ........................................................................ 35

4.2 Experimento de incubação com $\mathrm{CaCO}_{3} \mathrm{e} \mathrm{HCl}$........................................ 41

4.3 Atributos físicos ........................................................................... 42

4.4 Análise mineralógica e análise térmica diferencial .............................. 44

4.5 Curvas e isotermas de adsorção ............................................................. 45

4.5.1 Curvas de adsorção ..................................................................... 45

4.5.2 Os parâmetros de Langmuir e Freundlich ....................................... 49

4.5.3 Correlações entre os parâmetros e os atributos dos solos ............... 52

4.6 Energia livre das reações de adsorção de cobre ...................................... 57

4.7 Efeito da variação do pH na adsorção de cobre ....................................... 59

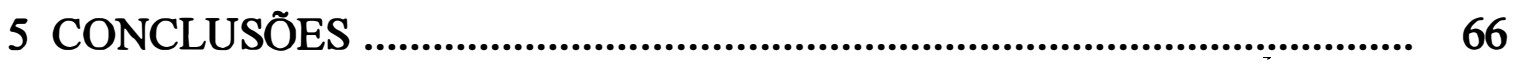

REFERÊNCIAS BIBLIOGRÁFICAS .................................................... 67

APÊNDICES 83

A1 - Curvas de adsorção de cobre nas amostras de terra com pH original dos solos

A2 - Coeficientes de correlação simples entre os atributos do solo e parâmetros dos modelos

A3 - Coeficientes de correlação múltipla dos atributos do solos utilizados nas regressões

A5 - Adsorção de cobre nas amostras de terra incubadas com carbonato de cálcio e ácido clorídrico 


\title{
ADSORÇÃO DE COBRE EM LATOSSOLOS ÁCRICOS PAULISTAS
}

\author{
Autora : MARIA LUCIA AZEVEDO SILVEIRA \\ Orientador : Prof. Dr. LUÍS REYNALDO FERRACCIÚ ALLEONI
}

\section{RESUMO}

O cobre, embora essencial à nutrição de plantas, pode apresentar caráter tóxico, quando presente em altas concentrações na solução do solo. Esse elemento está presente em resíduos municipais e industriais, em compostos organo-metálicos, como agroquímicos largamente utilizados na agricultura, em fertilizantes e na ração animal. As reações que controlam a disponibilidade do cobre no sistema agroecológico são complexas, sendo que o mesmo pode se encontrar ligado nas frações orgânica e inorgânica do solo. Os objetivos deste estudo foram estudar a adsorção do cobre nos horizontes superficiais $(0-20 \mathrm{~cm})$ e subsuperficiais (na maior expressão do horizonte B) de três solos do Estado de São Paulo: Latossolo Roxo ácrico textura muito argilosa, Latossolo variação Una ácrico textura média e Terra Roxa Estruturada, em seus valores de $\mathrm{pH}$ naturais e averiguar se ela pode ser estimada por seus atributos químicos, Iísicos e mineralógicos. As amostras foram suspensas em $20 \mathrm{~mL}$ de solução $0,0025 \mathrm{~mol}$ $\mathrm{L}^{-1}$ de $\mathrm{Ca}\left(\mathrm{NO}_{3}\right)_{2}$ contendo $\mathrm{Cu}\left(\mathrm{NO}_{3}\right)_{2}$, nas concentrações de $0 ; 5 ; 10 ; 20 ; 50 ; 100$; 
200; 300; 400; 600 e $800 \mathrm{mg} \mathrm{kg}{ }^{-1}$ de cobre. Após agitação por 24 horas realizaram-se as determinações de cobre no extrato, com auxílio de espectrofotômetro de absorção atômica. A partir desses resultados, foram obtidas as isotermas de adsorção e os coeficientes das equações de Freundlich e Langmuir. Numa segunda etapa, avaliou-se o efeito do $\mathrm{pH}$ na adsorção do cobre em amostras de terra incubadas com carbonato de cálcio ou ácido clorídrico, dentro de uma faixa de variação de $\mathrm{pH}$ de 4 a 7 . Adicionaram-se $100 \mathrm{mg} \mathrm{kg}^{-1} \mathrm{de}$ Cu e seguiu-se o mesmo procedimento descrito na primeira etapa.

Observou-se aumento na adsorção de cobre com o aumento da dose adicionada, porém o incremento foi menos acentuado nas doses mais altas do metal, possivelmente pela saturação dos sítios de adsorção. Os horizontes superficiais adsorveram maiores quantidades de cobre em relação ao horizontes subsuperficiais, evidenciando a influência da matéria orgânica nas reações. A adsorção de cobre foi significativa nos horizontes subsuperficiais dos Latossolos, apesar do balanço positivo de cargas, demostrando a existência de mecanismos de adsorção específica, relacionados principalmente com a predominância dos óxidos de ferro e alumínio na fração mineral desses solos. Houve efeito do $\mathrm{pH}$ da solução do solo na adsorção de cobre, pois elevando-se seu valor houve correspondente aumento nas quantidades adsorvidas. A TE apresentou maior capacidade de adsorção de cobre, porém as quantidades adsorvidas do elemento não foram estatisticamente diferentes para os três solos estudados em valores de 
$\mathrm{pH}$ próximos a 6,0. A CTC, influenciada pelos teores de matéria orgânica e argila, e os teores de óxidos e hidróxidos de ferro e alumínio foram os principais atributos do solo que correlacionaram-se com os parâmetros dos modelos de Langmuir e Freundlich. 


\title{
COPPER ADSORPTION ON ACRIC OXISOLS FROM THE STATE OF
}

\section{SÃO PAULO}

\author{
Author : MARIA LUCIA AZEVEDO SILVEIRA \\ Adviser : Prof. Dr. LUÍS REYNALDO FERRACCIÚ ALLEONI
}

\section{SUMMARY}

Although essential to plant nutrition, copper may also display a toxic feature at high concentrations in the soil solution. This element is found in municipal and industrial wastes, in organometalic compounds, such as widely used agrochemicals, in fertilizers, and animal rations. Many reactions control copper availability in the agroecological system, and the element can be found complex with both the organic and inorganic fraction. The objects of this study were to study copper adsorption in the surface $(0-20 \mathrm{~cm})$ and subsurface horizons (in the B horizon) of three soils from the State of São Paulo, Brazil: Rhodic Kandiudalf (RK), Anionic "Rhodic" Acrudox (RA) and Anionic "Xanthic" Acrudox (XA). Natural $\mathrm{pH}$ values were used and we assessed whether $\mathrm{Cu}$ adsorption can be estimated by chemical, physical and mineralogical attributes. Samples were suspended in $20 \mathrm{~mL}$ of a $\mathrm{Ca}\left(\mathrm{NO}_{3}\right)_{2} \quad 0,0025 \mathrm{~mol} \mathrm{~L}^{-1}$ solution, containing $\mathrm{Cu}\left(\mathrm{NO}_{3}\right)_{2}$ at concentrations of $0 ; 5 ; 10 ; 20 ; 50 ; 100 ; 200 ; 300 ; 400$; 
600 e $800 \mathrm{mg} \mathrm{kg}^{-1}$ of copper. After 24-hours, copper was determined in the extract by atomic adsorption spectrophotometer. From the results, adsorption isotherms and Freundlich and Langmuir equation coefficients were estimated. In a second stage, the samples were incubated with either calcium carbonate or chloridric acid with a $\mathrm{pH}$ ranging from 4 to $7 . \mathrm{A} 100 \mathrm{mg} \mathrm{kg}^{-1} \mathrm{Cu}$ was added to the soil and then the same procedure as described in first stage was performed.

Copper adsorption increased as the addition of $\mathrm{Cu}$ increased. However, the adsorption increment was less marked in the more concentrated $\mathrm{Cu}$ levels, probably due to saturation of the adsorption sites. Surface horizons adsorbed greater amounts of copper in relation to the subsurface horizons, thus showing the influence of organic matter. Copper adsorption was significant in subsurface horizons of RA and XA, in spite of positive net of charges, which showed that a specific adsorption mechanism was involved. It is likely that this is due mainly to the predominance of iron and aluminun oxides in mineral fraction. A pH effect on $\mathrm{Cu}$ adsorption was observed, since a higher $\mathrm{pH}$ increased the amounts of $\mathrm{Cu}$ adsorbed. RK had a higher $\mathrm{Cu}$ adsorption capacity; however, the amounts of adsorbed $\mathrm{Cu}$ were similar for all three soils as the $\mathrm{pH}$ increased to 6.0. The $\mathrm{CEC}$, influenced by organic matter and clay, as well as iron and aluminum sesquioxide contents, were the main soil attributes, which correlated with the parameters of Langmuir and Freundlich. 


\section{INTRODUÇĀO}

A disposição de resíduos municipais e industriais nos solos tem se tornado prática comum em nosso meio nos últimos anos. Além disso, diversos compostos organometálicos, como agroquímicos, são longa e largamente utilizados em nossa agricultura. Tanto os primeiros como os últimos podem ser ricos em cobre.

A quantidade de metal presente em determinado resíduo depende da origem desse material, podendo atingir valores próximos a $8.000 \mathrm{mg} \mathrm{kg}^{-1}$ no lodo de esgoto. $\mathrm{O}$ cobre pode estar presente nos corretivos agrícolas, adubos fosfatados e na cama de frango. Estima-se que a mobilização de metais pesados induzida pela atividade humana para a biosfera alcança valores próximos a 150 t/ano de $\mathrm{Cu}$ (Amaral Sobrinho, 1996).

O uso continuado destes componentes na agricultura pode causar acúmulo do elemento no solo. Ainda, a suplementação da ração animal com alguns metais, dentre eles o cobre, principalmente na criação de suínos, também auxilia nesse processo. Nos Estados Unidos, a USEPA (Agência Federal de Proteção Ambiental) regula as taxas de metais presentes nos resíduos ou outras fontes que podem ser aplicadas, bem como os níveis críticos de cada elemento no solo. Por muitos anos esses valores foram baseados na capacidade de troca de cátions do solo (CTC), porém, atualmente, criaram-se novas diretrizes, que se baseiam em critérios de risco e trabalhos científicos de curta duração. De modo geral, a legislação americana é mais tolerante do que outros países nos níveis máximos dos elementos aplicados ao solo. Para o cobre, especificamente, a USEPA tolera 
até $1.500 \mathrm{~kg} \mathrm{ha}^{-1}$, enquanto as entidades da Alemanha, Nova Zelândia toleram até $200 \mathrm{~kg} \mathrm{ha}^{-1}$ e o Canadá $150 \mathrm{~kg} \mathrm{ha}^{-1}$.

O cobre faz parte dos elementos químicos considerados micronutrientes, está incluído no ciclo bioecológico e apresenta papel essencial na nutrição das plantas. Porém, sua alta concentração na solução do solo pode torná-lo tóxico às plantas, aos animais e ao homem. Ele é considerado metal pesado, pois possui densidade superior a $6 \mathrm{~g} \mathrm{~cm}^{-3}$, mais especificamente $8,96 \mathrm{~g} \mathrm{~cm}^{-3}$ (King, 1996).

Suas reações com constituintes do solo são complexas, e o elemento pode estar complexado com a fração orgânica e a inorgânica. Diversos compostos são capazes de reagir com o cobre, sendo sua concentração na fase líquida determinada pela solubilidade da forma menos solúvel presente no sistema.

As reações que controlam a disponibilidade de metais pesados em solos compreendem adsorção/dessorção, precipitação e complexação. Certas reações no solo podem ser deduzidas de suas propriedades já conhecidas e bem estabelecidas. Por exemplo, o cobre é um cátion e em menor ou maior intensidade é adsorvido pelo complexo de troca. O grau de adsorção dependerá da eletronegatividade das partículas do solo e do potencial de ionização dos íons adsorvidos. Outra propriedade conhecida é que o cobre combina com ligantes para formar complexos e quelatos estáveis, sendo, portanto, passível de formá-los com os radicais orgânicos da matéria orgânica do solo. Ainda, em valores de $\mathrm{pH}$ elevado, o cobre pode formar hidróxidos e se precipitar.

No caso de solos muito intemperizados, com predominância de mineralogia oxídica na fração argila, as reações de adsorção de cobre têm características distintas de solos com argilominerais do tipo 2:1. Mesmo quando os óxidos e hidróxidos de ferro e alumínio estão presentes em baixas porcentagens no solo, os mesmos proporcionam substancial efeito na adsorção de cobre, haja vista a acentuada afinidade do metal pela superficie reativa desses componentes. Porém, constata-se na literatura a escassez de trabalhos que 
discorrem sobre o assunto. A maioria das informações é restrita a solos de clima temperado e, sobretudo, aos horizontes superficiais. Além do mais, os resultados obtidos são de difícil comparação, uma vez que os estudos de adsorção de metais são conduzidos em condições experimentais distintas, como relação solo:solução, concentração do metal, força iônica, $\mathrm{pH}$, temperatura e tempo de equilíbrio.

Considerando que os solos são heterogêneos na sua constituição e que seus atributos influenciam os fenômenos de adsorção de maneira muito complexa, é importante que se conheçam algumas interações do cobre com o solo, para um melhor entendimento de como, quando e onde o cobre é retido no sistema, uma vez que esses mecanismos de retenção controlam seu destino no sistema agroecológico.

Nesse contexto, os principais objetivos desse trabalho são :

a) Estudar a adsorção do cobre em amostras superficiais $(0-20 \mathrm{~cm})$ e subsuperficiais (na maior expressão do horizonte B) de três solos do Estado de São Paulo : Latossolo Roxo ácrico textura muito argilosa, Latossolo variação Una ácrico textura média e Terra Roxa Estruturada, utilizada como referência, por apresentar carga líquida negativa ao longo de todo o perfil; e obter as correlações entre cobre adsorvido e os atributos químicos, físicos e mineralógicos dos solos;

b) Avaliar a interação do cobre com a matéria orgânica e com os óxidos do solo;

c) Avaliar o efeito do pH na adsorção do cobre.

Hipótese: a adsorção de cobre é maior nos solos de textura argilosa e a valores mais altos de $\mathrm{pH}$, sendo que a matéria orgânica e os óxidos, principalmente nas formas amorfas, tem efeito acentuado na adsorção de cobre, notadamente na camada superficial e nos solos com maior teor de ferro. 


\section{REVISÃO DA LITERATURA}

2.1 Geoquímica do cobre

O cobre é considerado micronutriente essencial à nutrição de plantas, mostrando alto potencial de ionização (Cotton \& Wilkinson, 1972). Ele pode ser encontrado com número de oxidação $2+\mathrm{e}$ em menor escala com $1+$ em certos sulfetos, sendo muito dificil de se estimar o número de oxidação em muitos minerais (Krauskopf, 1972). Pode aparecer freqüentemente como calcopirita $\left(\mathrm{CuFeS}_{2}\right)$, sendo largamente encontrada dispersa em rochas e concentrada nas maiores jazidas de cobre do mundo (Cox, 1979). Outros minerais comuns são a calcosita $\left(\mathrm{Cu}_{2} \mathrm{~S}\right)$, a covelita $(\mathrm{CuS})$ a bornita $\left(\mathrm{Cu}_{5} \mathrm{FeS}_{4}\right)$, a cuprita $\left(\mathrm{Cu}_{2} \mathrm{O}\right)$, a tenorita (CuO), a malaquita $\mathrm{Cu}_{2}(\mathrm{OH})_{2} \mathrm{CO}_{3}$, a azurita $\mathrm{Cu}_{3}(\mathrm{OH})_{2}\left(\mathrm{CO}_{3}\right)_{2}$, crisocola $\mathrm{CuSiO}_{3} \cdot 2 \mathrm{H}_{2} \mathrm{O}$, brochantita $\mathrm{Cu}_{4}(\mathrm{OH})_{6} \mathrm{SO}_{4}$ e atacanita $\mathrm{Cu}_{2}(\mathrm{OH})_{3} \mathrm{Cl}$ (McBride, 1981). Nos minerais primários, o cobre está frequentemente associado ao enxofre, em virtude da grande afinidade existente entre ambos, formando compostos insolúveis (Ferreira \& Cruz, 1991).

O teor médio de cobre no solo é de aproximadamente $35 \mathrm{mg} \mathrm{kg}^{-1}$, sendo $45 \mathrm{mg} \mathrm{kg}^{-1}$ na litosfera. Em solos do Estado de São Paulo, Valadares (1975) determinou valores que variaram, em média, de $187,7 \mathrm{mg} \mathrm{kg}^{-1}$ para solos derivados de rochas básicas até $8,7 \mathrm{mg} \mathrm{kg}^{-1}$ para solos derivados do arenito Bauru e 7,0 $\mathrm{mg} \mathrm{kg}^{-1}$ para solos derivados de sedimentos arenosos (Quadro 1). O material de origem foi preponderante na determinação desses teores, sendo que nos magmáticos, de maneira geral, a riqueza é devido a sua associação com sulfetos e 
Quadro 1. Teores médios, ponderados, de cobre total no horizonte superficial de solos do Estado de São Paulo.

\begin{tabular}{cc}
\hline Solos & Cobre Total \\
\hline $\mathrm{mg} \mathrm{kg}^{-1}$
\end{tabular}

Derivados de rochas básicas

Solo Litólico

$156,9-251,7$

Terra Roxa Estruturada

$161,2-334,7$

Latossolo Roxo eutrófico

$204,9-218,5$

Latossolo Roxo distrófico

$89,0-98,9$

Derivados de materiais aluviais e coluviais

Solos Hidromórficos

$25,6-28,8$

Derivados de sedimentos modernos

Latossolo Vermelho-Escuro

$18,3-37,9$

Latossolo Vermelho-Amarelo

$18,0-19,5$

Latossolo Vermelho-Amarelo Húmico

$6,3-11,6$

Podzólico Vermelho-Amarelo

$18,8-49,2$

Derivados do arenito Baurú

Podzólico Vermelho-Amarelo (var. Lins)

$5,1-6,9$

Podzólico Vermelho-Amarelo (var. Marília)

$3,4-5,5$

Derivados de sedimentos arenosos

Latossolo Vermelho-Escuro textura média/arenosa

$9,6-10,8$

Latossolo Vermelho-Amarelo textura média/ arenosa

$11,8-12,8$

Regossolo

$1,6-1,8$

Fonte : Valadares (1975), com atualização na monenclatura, segundo Prado (1997). 
a pobreza nos sedimentos se deve ao fato de serem sujeitos a intensa meteorização e ciclos sucessivos de transporte e deposição.

O cobre pode ainda estar presente em diversos resíduos e em diferentes concentrações. $\mathrm{O}$ teor de cobre, em média, é de $8.000 \mathrm{mg} \mathrm{kg}^{-1}$ no lodo de esgoto, $266 \mathrm{mg} \mathrm{kg}^{-1}$ na cama de frango e $41 \mathrm{mg} \mathrm{kg}^{-1}$ nos fertilizantes fosfatados (Pezzarrossa et al.1990). Considerando diversos países, as quantidades de cobre presentes no logo de esgoto são contrastantes. Bridges (1989) observou que nos Estados Unidos são atingidas concentrações de cobre no lodo de esgoto variando entre 84 a $10.400 \mathrm{mg} \mathrm{kg}^{-1}$, representando os maiores teores em relação a outros países. Já a Austrália possui os menores teores de cobre em seu resíduo proveniente de lodo de esgoto, variando entre 250 a $2500 \mathrm{mg} \mathrm{kg}^{-1}$, seguido do Canadá e Suíça, com valores entre 160 a $3000 \mathrm{mg} \mathrm{kg}^{-1}$ e 52 a $3300 \mathrm{mg} \mathrm{kg}^{-1}$, respetivamente. No Quadro 2 verificam-se as quantidades médias de cobre presentes em alguns corretivos e fertilizantes.

\subsection{Reações que controlam a solubilidade do cobre em solo}

O cobre, assim como outros elementos, tem sua solubilidade controlada por um conjunto de reações químicas que ocorrem no solo. Essas interações influenciam a partição do metal nas fases líquida e sólida do solo e são responsáveis pela sua mobilidade e biodisponibilidade no sistema. A Figura 1 representa as interações que ocorrem no solo entre suas fases sólida e líquida e o cobre. 
Quadro 2. Quantidade de metais pesados incorporados por hectare de solo pela aplicação de fertilizantes e corretivos.

\begin{tabular}{lc}
\hline \multicolumn{1}{c}{ Produtos } & Cobre \\
\hline Calcário Unaí (MG) & $\mathrm{mg} \mathrm{kg}^{-1}$ \\
Calcário Arcos (MG) & 4,8 \\
Calcário Italva (RJ) & 2,6 \\
Calcário Poté (MG) & 4,3 \\
Calcário Coromandel (MG) & 11,0 \\
Calcário Bocaiuva (MG) & 4,8 \\
Calcário Formiga (MG) & 2,6 \\
Corretivo-Resíduo-Paracatú (MG) & 2,5 \\
Fórmula NPK+Zn (0-30-15+0,2\%Zn) & 121,7 \\
Fórmula NPK+Zn (0-20-20+0,4\%Zn) & 32,6 \\
Fórmula NPK+Zn (2-28-08+0,5\%Zn) & 33,6 \\
Termofosfato Yoorin & 72,9 \\
Apatita de Araxá & 44,1 \\
Superfosfato triplo + Cu & 72,1 \\
\hline
\end{tabular}

Fonte : Amaral Sobrinho et al. (1996).

\subsubsection{Troca iônica}

Os sítios de carga permanente nos argilominerais retêm cátions por forças eletrostáticas não específicas (Matos et al., 1996) e, em condições que não favoreçam hidrólise ( $\mathrm{pH}$ alto), os metais pesados, incluindo o cobre, mostram comportamento típico de troca iônica em minerais silicatados (McBride, 1976; 1980). Tanto os colóides minerais quanto os orgânicos estão envolvidos nesse 


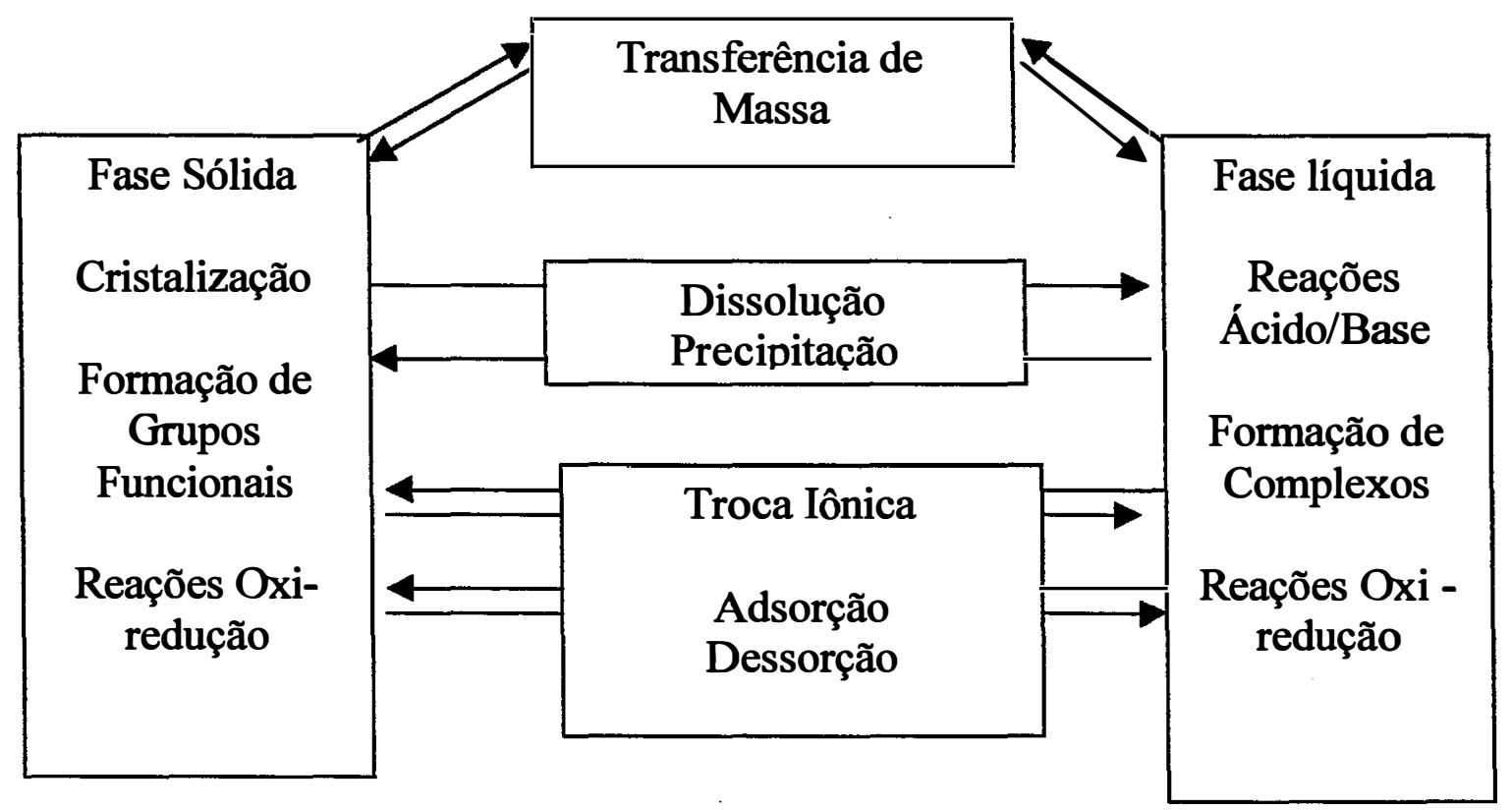

Figura 1. Interações entre as fases líquida e sólida do solo que influenciam o comportamento de cobre nos solos. Adaptado de Mattigod \& Page (1983).

tipo de reação, porém esta forma de adsorção, envolvendo forças eletrostáticas, constitui uma fração muito pequena em relação à quantidade total do cobre, mas é uma fonte importante do elemento para a solução do solo e, consequentemente, para as plantas.

A preferência dos argilominerais por cátions com cargas mais elevadas não vem de nenhum mecanismo especial, além da conseqüência da forma matemática da equação de troca iônica. No ambiente pedológico, $\mathrm{o}^{2+}$ tem de competir com íons abundantes como cálcio, por exemplo. Entretanto, neste caso específico, não se espera grande partição entre os dois pelos lugares de troca, tendo sido encontrado um coeficiente de seletividade perto da unidade para a troca $\mathrm{Cu}^{2+} / \mathrm{Ca}^{2+}$ em condições de reação ácida (El-Sayed et al., 1970), como mostra a (equação 1). 


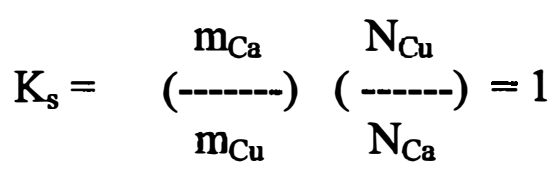

em que $\mathbf{m}$ representa a concentração dos metais na solução e $\mathbf{N}$ representa a fração de lugares de troca ocupada pelos íons. McBride (1989) mostra, no entanto, que a concentração de cobre em solução, usando dados de Johnson \& Chu (1983) e Sanders (1982), é na realidade menor que a estimada, mostrando que se necessitam de mecanismos mais específicos que a troca iônica para melhor avaliação. Basicamente, o que se pode concluir de diversas evidências mostradas na literatura é que é improvável que lugares de troca limitem a solubilidade do cobre em solo, indicando que há mecanismos muito mais seletivos para demonstrar a sua baixa solubilidade e difícil extração.

\subsubsection{Adsorção química na superfície dos componentes do solo}

O cobre pode estar presente na solução do solo como íon livre $\left(\mathrm{Cu}^{2+}\right)$ ou formando complexos inorgânicos, tais como $\mathrm{Cu}(\mathrm{OH})^{+}, \mathrm{CuSO}_{4}{ }^{0}$ ou complexos orgânicos solúveis, sendo que a concentração total dissolvida é calculada pela soma das diferentes formas presentes na solução (Salam \& Helmke, 1990). Cobre livre $\left(\mathrm{Cu}^{2+}\right)$ é considerada a espécie mais prontamente biodisponível (Temminghoff et al., 1994), sendo que, sua determinação é de fundamental importância, pois reflete o equilíbrio entre as diferentes formas do metal em solução (Sanders, 1982).

As reações entre o cobre e os constituintes do solo podem se dar por meio de um conjunto de processos que ocorrem nas superfícies. Numa definição simplista, a reação entre um íon qualquer e a superfície dos constituintes do solo constitui uma adsorção (Ferreira \& Cruz, 1991). Porém, além das reações de adsorção, podem ocorrer, concomitantemente, outros fenômenos de superfície, 
tais como reações de precipitação e polimerização (Sparks, 1995). Os metais pesados no solo, quando presentes em concentrações muito baixas, são retidos de maneira significativa em forma não trocável. McLaren \& Crawford (1973); Jenne (1976); Korte et al. (1976); Petronio et al. (1996); McBride et al. (1997) e Salam \& Helmke (1998) mostraram que as reações de adsorção que ocorrem na interface sólido-líquido são um importante mecanismo controlador da atividade desses metais não apenas na solução do solo, mas, também, em corpos de águas naturais.

As reações de adsorção ocorrem normalmente na fração argila do solo, sendo que os óxidos de alumínio, ferro e manganês e os grupos funcionais ácidos da matéria orgânica são as superfícies reativas mais representativas. Estes componentes apresentam as maiores superficies específicas e, portanto, os maiores pontos de contato com a solução do solo. Pela adição de $\mathrm{H}^{+}$ou $\mathrm{OH}^{-}$pode ocorrer a protonação ou desprotonação da superficie dos grupos funcionais, alterando suas características adsortivas (Sparks, 1995). Muitas vezes, mesmo que sua concentração não seja muito alta, estes componentes podem estar dispersos na superficie dos minerais de argila e areias exercendo, assim, um controle considerável sobre as reações. Para McLaren \& Crawford (1973), o óxido de manganês e a matéria orgânica foram os constituintes do solo de contribuição mais expressiva para o fenômeno de adsorção, seguidos dos óxidos de ferro e dos minerais de argila.

Devido à expressiva afinidade do cobre por determinados grupos funcionais de superficie, há formação de moléculas estáveis, ou seja, complexos de esfera interna, que correspondem à adsorção específica, com alta energia de ligação. Esse tipo de complexação ocorre mais lentamente, e os complexos são mais estáveis do que os de esfera externa (Sparks, 1995).

Com o tempo, metais inicialmente adsorvidos na superficie externa tendem a se difundir para sítios de adsorção no interior da partícula, dificultando posterior dessorção (Barrow, 1985). Embora tanto a adsorção específica quanto a não 
específica de cobre ( $\mathrm{Cu}$ trocável) ocorram nas superfícies heterogêneas das partículas de solo, a dessorção do cobre adsorvido especificamente tende a ser lenta e/ou incompleta (Guilherme \& Anderson, 1997).

\subsubsection{Matéria orgânica}

A matéria orgânica parece ser o componente mais importante na retenção do cobre (Singh, 1971; McLaren \& Crawford, 1973; McLaren et al., 1981; Borah et al., 1992; Holgrem et al., 1993; Bibak, 1994). Ânions orgânicos como citratos, oxalatos e tartaratos, e também os ácidos húmicos formam complexos com o cobre com diferentes graus de estabilidade (Schnitzer \& Skinner, 1966). Dependendo da solubilidade destes complexos formados, eles estarão na fase líquida (solúveis) ou na fase sólida do solo. No primeiro caso, o metal permanece em solução e pode ser facilmente transportado e estar disponível à planta, enquanto que no segundo caso, o metal será imobilizado.

A fração orgânica solúvel do solo representa um sistema complexo de moléculas com diferentes pesos moleculares. $\mathrm{O}$ ácido húmico possui maior número de cadeias alifáticas e suporta maior condensação e adsorção de cobre do que o ácido fúlvico (Temminghoff et al., 1994). Segundo Stevenson \& Fitch (1981), o ácido húmico liga-se mais fortemente ao íon cobre do que o fúlvico e tem implicação importante nos mecanismos pelos quais o cobre é mantido em forma solúvel no solo. Bibak (1994), em estudos com óxidos de ferro e alumínio e ácido húmico sintéticos, concluiu que a adsorção de cobre foi maior para o ácido húmico, sendo que o ion $\mathrm{Cu}^{+2}$ estava imobilizado por complexos de esfera interna, principalmente pelos grupos carboxílico e fenólico. A estabilidade dos complexos formados pelo ácido fúlvico e o cobre é maior do que se comparada a outros íons como o $\mathrm{Zn}$, por exemplo (Duquette \& Hendershot, 1990). 
$\mathrm{Na}$ literatura, parece não haver um consenso sobre a sequência de estabilidade das ligações entre os metais e o ácido húmico. Características como a concentração do metal, $\mathrm{pH}$ da solução de equilíbrio e quantidade de ácido húmico presente, podem afetar as reações de adsorção de cobre (Kerndorff \& Schnitzer, 1980). Ferreira \& Cruz (1991) propuseram que a sequência de estabilidade dos complexos formados entre ácido húmico $\mathrm{e}$ cátions divalentes é $\mathrm{Cu}>\mathrm{Ni}>\mathrm{Co}>\mathrm{Zn}>\mathrm{Fe}>\mathrm{Mn}$. Discordando dessa informações Kerndorff \& Schnitzer (1980) sugeriram as sequências de adsorção de metais nos ácidos húmicos descritas abaixo, em função do $\mathrm{pH}$ :

$$
\begin{aligned}
& \mathrm{pH}=2,4: \mathrm{Hg}>\mathrm{Fe}>\mathrm{Pb}>\mathrm{Cu}=\mathrm{Al}>\mathrm{Ni}>\mathrm{Cr}=\mathrm{Zn}=\mathrm{Cd}=\mathrm{Co}=\mathrm{Mn} \\
& \mathrm{pH}=3,7: \mathrm{Hg}=\mathrm{Fe}>\mathrm{Al}>\mathrm{Pb}>\mathrm{Cu}>\mathrm{Cr}>\mathrm{Cd}=\mathrm{Zn}=\mathrm{Ni}>\mathrm{Co}>\mathrm{Mn} \\
& \mathrm{pH}=4,7: \mathrm{Hg}=\mathrm{Fe}=\mathrm{Pb}=\mathrm{Cu}=\mathrm{Al}=\mathrm{Cr}>\mathrm{Cd}=\mathrm{Ni}=\mathrm{Zn}>\mathrm{Co}>\mathrm{Mn} \\
& \mathrm{pH}=5,8: \mathrm{Hg}=\mathrm{Fe}=\mathrm{Pb}=\mathrm{Al}=\mathrm{Cr}=\mathrm{Cu}>\mathrm{Cd}>\mathrm{Zn}>\mathrm{Ni}>\mathrm{Co}>\mathrm{Mn}
\end{aligned}
$$

Essas sequências de adsorção encontradas pelos pesquisadores não se correlacionaram com os respectivos números e pesos atômicos, valência e raio iônico hidratado dos metais.

O alto grau de seletividade mostrado pela matéria orgânica com o cobre é causado pela formação de complexos de esfera interna, também referidos como adsorção específica (Guilherme \& Anderson, 1998). Em concentrações baixas de cobre na solução, o cobre será imobilizado pelos ácidos húmicos. Entretanto, à medida que os sítios de ligação forte vão sendo saturados, uma quantidade maior de cobre será solubilizada pelos ácidos fúlvicos ou compostos orgânicos mais simples. A tendência de o $\mathrm{Cu}$ formar complexo com o ácido húmico depende do pH, sendo que Wang \& Stumm (1987) mostraram que a amplitude da ação complexamente se estende por várias unidades de $\mathrm{pH}$ (50\% a partir de $\mathrm{pH} 6$ ), proporcionando tamponamento do íon metálico. Para valores de $\mathrm{pH}$ inferiores a 4,4 demostrou-se que o cobre estava predominantemente ligado à fração fúlvica, 
enquanto que para valores de $\mathrm{pH}$ acima de 5,7 a ligação era com a fração húmica (Temminghoof, 1994). Taga et al. (1991) observaram que os lugares de troca com alta energia na ligação do cobre pelo ácido húmico eram fornecidos pelo grupo carboxila, enquanto os de ligação fraca eram fornecidos pelos grupos amino e fenol.

\subsubsection{2 Óxidos}

Algumas evidências para a formação de ligações fortes entre as superfícies dos óxidos cristalinos ou microcristalinos com metais pesados têm sido levantadas, tais como liberação de até dois íons $\mathrm{H}^{+}$para cada $\mathrm{M}^{2+}$ adsorvido (Forbes et al., 1976; McKenzie, 1980), alto grau de especificidade mostrado por certos óxidos com relação a determinados metais (Kinniburgh et al., 1976) e alterações das propriedades de carga superficial do óxido como resultado da adsorção (Stumm \& Morgan, 1981). Com respeito a esta última interação, pode haver aumento da carga positiva superficial desenvolvida no decorrer da adsorção química (equação 2).

$$
-\mathrm{Fe}-\mathrm{OH}+\mathrm{M}\left(\mathrm{H}_{2} \mathrm{O}\right)^{2+}{ }_{6} \rightarrow-\mathrm{Fe}-\mathrm{OM}\left(\mathrm{H}_{2} \mathrm{O}\right)^{+}{ }_{5}+\mathrm{H}_{3} \mathrm{O}
$$

Constatações mais diretas da coordenação de superficie dos metais têm sido obtidas com ressonância de spin eletrônico e estudos do espectro UV-visível (Martini et al., 1980; Mc Bride, 1985 e Bleam \& McBride, 1986). Os espectros UV-visível dos metais de transição são sensíveis à formação de complexos de esfera interna com ligantes, porque a substituição da $\mathrm{H}_{2} \mathrm{O}$ no complexo aquometal por outro ligante altera a energia de campo do cristal no elétron do orbitald. 
Está bem demonstrado também por ressonância de spin eletrônico que os metais adsorvidos na superfície dos óxidos o fazem em sítios isolados, a baixas concentrações, e estão fortemente ligados se comparados com os íons adsorvidos a lugares de troca de argilominerais (Clark \& McBride, 1984).

Para a caulinita, a troca iônica (complexos de esfera externa) pode ser mais importante em baixos valores de $\mathrm{pH}$ e força iônica, entretanto, o aumento em ambos favorece a adsorção específica nas superfícies anfóteras das hidroxilas (Schindler et al. 1987).

Há muito tempo já se sabe da importância do óxido de manganês na retenção do cobre (McLaren \& Crawford, 1973; Burau, 1973), sendo que em determinados estudos foi demonstrado que os metais pesados foram mais intensamente adsorvidos nestes óxidos do que nos de ferro (McLaren \& Crawford, 1973; McKenzie, 1980; Fu et al., 1991).

A importância dos óxidos de ferro e alumínio na adsorção do cobre também tem sido relatada com freqüência (Forbes et al., 1976; Hem, 1977; Barrow et al., 1981; Okazaki et al., 1986; Msaky \& Calvet, 1990; Bibak, 1994; Matos et al., 1996). Porém, dependendo das condições do meio, principalmente $\mathrm{pH}$, a quantidade de cobre retida por esses óxidos é diferenciada. Bibak (1994), estudando a adsorção de cobre em óxidos e hidróxidos de ferro e alumínio sintéticos, concluiu que, para um mesmo valor de $\mathrm{pH}$, o óxido de alumínio foi capaz de reter maiores quantidades de cobre em relação aos demais, porém a inclinação da curva de adsorção era semelhante a do ácido húmico, sugerindo que esses seriam os principais componentes do solo que interferem no fenômeno de adsorção de cobre (Figura 2).

Em estudo semelhante, porém utilizando óxidos sintéticos de magnésio e ferro, McKenzie (1980) concluiu que, para uma faixa de variação de $\mathrm{pH}$ entre $3 \mathrm{e}$ 7,0, o cobre foi mais fortemente adsorvido pelos óxidos de magnésio e, ainda, dentre os óxidos de ferro, a goetita foi capaz de reter maiores quantidades de 


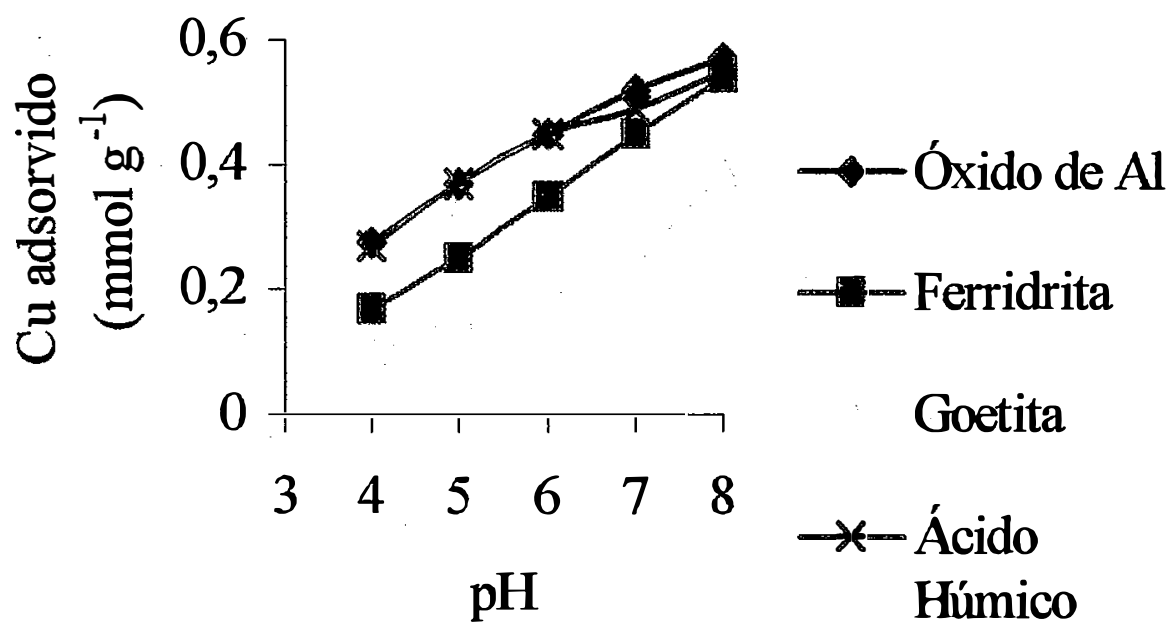

Figura 2. Adsorção máxima de cobre adsorvido por óxido de alumínio, ferridrita, goetita e ácido húmico, em função do pH (Bibak, 1994).

cobre do que a hematita, devido principalmente à sua maior superficie específica (superficies específicas da goetita e hematita iguais a 75 e $20 \mathrm{~m}^{2} \mathrm{~g}^{-1}$, respectivamente). Discordando dos resultados anteriores, para alguns autores, dentre os óxidos de ferro, manganês e alumínio envolvidos na adsorção de cobre, embora este último represente um mecanismo de adsorção significativo, foi o menos importante (Cavallaro \& McBride, 1984; Msaky \& Calvet, 1990; Schulthess \& Huang, 1990).

Coutinho \& Grove (1997) observaram, em estudos conduzidos nos Estados Unidos, que a maior parte do cobre adsorvido no solo se encontrava nas frações residual $(31,1 \%$ total) e óxido de ferro cristalino ( $27 \%$ total), além de grande quantidade associada à fração orgânica (19,1\% total). Concordando com essas informações, Gomes et al. (1997), estudando fracionamento de metais, constataram que, dentre eles, $\mathrm{Cd}, \mathrm{Cr}, \mathrm{Ni} \mathrm{Pb}$ e $\mathrm{Zn}$, o $\mathrm{Cu}$ foi o que apresentou maior afinidade pela fração óxido de ferro (67,5 e 39,1 \% total nos horizontes A e B, respectivamente). Constatou-se também nesse trabalho a redução nos valores de 
cobre extraídos na fração óxido de ferro nos horizontes subsuperficiais, possivelmente, devido à energia de ligação de cobre à fase sólida ser maior no horizonte $\mathrm{B}$ (menor poder tampão ocasionando maior elevação do $\mathrm{pH}$ durante o processo de fracionamento do que horizonte A), além da maior quantidade de óxidos mal cristalizados. Estudos desta natureza levam a conclusão que a adsorção química depende da natureza do óxido, do seu grau de cristalinidade e da morfologia da superfície.

O envelhecimento dos óxidos é muito importante, porque ele determina não somente o número de sítios de adsorção, como o tipo do sítio, mudando não só a intensidade da reação, como a seletividade (Kinniburgh et al., 1976). Okazaki et al. (1986) constataram que óxidos e hidróxidos de ferro e alumínio hidratados, amorfos aos raios $\mathrm{X}$, com baixa cristalinidade, exibiram capacidade adsortiva maior aos metais pesados que aqueles de alta cristalinidade.

Um fator que pode dificultar as reações metal/óxido é a presença de ligantes, que são representados por radicais orgânicos (EDTA, glicina etc.) ou inorgânicos $\left(\mathrm{Cl}^{-}, \mathrm{PO}_{4}{ }^{3-}, \mathrm{SO}_{4}{ }^{2-}\right.$ etc). Dependendo da natureza desse ligante, ele poderá formar ligações que possam não influir (Bourg \& Schindler, 1979; Elliot \& Huang, 1979; Alva \& Obreza, 1994), aumentar (Davies \& Leckie, 1978; Guilherme \& Anderson, 1998) ou diminuir (Davies \& Leckie, 1978) a adsorção do metal pela superfície dos óxidos. Em estudos realizados com aplicação de fosfato, demostrou-se que a quantidade de cobre adsorvida foi maior, após a adição de $\mathrm{P}$, principalmente no horizonte $\mathrm{B}$ (Guilherme et al., 1995).

\subsubsection{Descrição da adsorção}

Isotermas de adsorção descrevem a relação entre a massa da substância adsorvida (adsorvato) pelo sólido (adsorvente) e a concentração da substância na 
solução (mais propriamente atividade) em equilíbrio. Estes dados normalmente ajustam-se a modelos dos quais os mecanismos de adsorção são inferidos.

Um modelo usado para descrever os dados de adsorção de elementos é a equação de Freundlich (equação 3).

$\mathbf{x}$

$-\cdots=\mathrm{KC}^{\mathrm{n}}$

m

na qual $\mathbf{x}=$ massa do elemento adsorvido; $\mathbf{m}=$ massa da fase sólida adsorvente; $\mathbf{C}$ = concentração de equilíbrio do adsorvato em solução e $\mathbf{K}$ e $\mathbf{n}$ são constantes determinadas empiricamente (Garcia-Miragaya \& Page, 1976; Bowman et al., 1981).

Inicialmente a equação de Freundilch foi utilizada para descrever adsorção da fase gasosa e solutos. Sua maior desvantagem é não predizer a adsorção máxima e, em alguns caso, podem-se obter várias inclinações da curva, sugerindo diferentes sítios de ligação (Sparks, 1995). Outra desvantagem é que o modelo não fornece informações sobre os processos envolvidos e o mecanismo de retenção (Buchter et al., 1989).

Outro modelo usado para descrever a adsorção de metais é a equação de Langmuir. Quando aplicada a minerais, sedimentos e solos ela é usada na forma:

$$
\begin{array}{cc}
\mathrm{x} & \mathrm{KbC} \\
--- & ----- \\
\mathrm{m} & 1+\mathrm{KC}
\end{array}
$$

na qual $\mathbf{K}=$ parâmetro ligado à afinidade do adsorvente pelo adsorvato e $\mathbf{b}=$ adsorção máxima. 
Assim como o modelo de Freundlich, a equação de Langmuir descreve melhor a adsorção na superfície dos colóides em baixas concentrações do elemento.

O modelo de Langmuir supõe algumas afirmações, tais como: a) não há movimentação lateral de moléculas na superfície; b) as superfícies são homogêneas e não se interagem; c) a adsorção ocorre em uma única camada, com número fixo de sítios de adsorção, os quais só podem adsorver uma única molécula e d) a adsorção é reversível. Portanto, a equação de Langmuir deve ser utilizada para descrever o fenômeno de apenas de forma qualitativa, uma vez que suas hipóteses não são válidas para superfícies heterogêneas encontradas no solo (Sparks, 1995).

Apesar de suas limitações, os modelos de Freundlich e Langmuir são utilizados em diversos estudos de adsorção de cobre (Petruzzelli et al., 1985; Pombo \& Klamt, 1986; Bibak, 1994; Temminghoff et al., 1994; Saha et al., 1995; Atanassova \& Okazaki, 1997; Yuan \& Lavkulich, 1997). Os coeficientes de correlação obtidos nesses trabalhos variam entre 0,83 a 0,99 , indicando que esses modelos de adsorção se ajustam em diversas condições de solos e concentrações do metal. Ainda, o parâmetro de adsorção máxima (Langmuir) pode ser utilizado como indicativo para comparar solos com características diferentes, além dos efeitos do $\mathrm{pH}$ e matéria orgânica na adsorção do metal.

Outras inferências podem ser feitas a partir dos resultados de adsorção do elemento, como por exemplo o cálculo termodinâmico da energia livre das reações $\left(\Delta G_{0}\right)$. As mudanças que ocorrem quando um elemento é adsorvido podem servir como medida da extensão ou da força que guia determinada reação (Singh, 1971). Seu sinal indica se, em um sistema fechado, a temperatura e pressão constantes, a reação é espontânea ou não. Valores de $\Delta G_{o}$ negativo indicam que a reação é exergônica e espontânea e, ao contrário, valores positivos 
indicam que a reação é endergônica e não pode ser espontânea. Seu valor indica quão distante do equilíbrio está o estado inicial do sistema. Quando consideramos doses crescentes de cobre adicionadas ao solo, o valor da energia livre pode revelar a magnitude da força da reação entre o metal e a superficie do adsorvente. Quanto maior seu valor, maior será a força de determinada reação. Alleoni \& Camargo (1998), estudando a adsorção de boro em cinco solos do Estado de São Paulo, abordaram essas reações considerando os valores de energia livre.

\subsubsection{Precipitação / Dissolução}

Quando se faz um experimento de adsorção, é difícil separar o que é adsorção química daquilo caracterizado como precipitação. Quando os mecanismos de retenção não são conhecidos define-se o termo sorção como o conjunto de reações de adsorção, precipitação e polimerização (Sparks, 1995)

No caso do cobre, esse mecanismo só passa a ser importante em concentrações muito mais altas do que as normalmente encontradas em solos, mesmo quando estes receberam dose elevada do elemento.

Entretanto, se essas concentrações forem atingidas, os processos de precipitação e dissolução podem governar a atividade do elemento na solução do solo. Essas reações são descritas normalmente pelo produto de solubilidade, nas quais os sólidos dissolvem-se para formar constituintes solúveis.

Há, no entanto, um consenso geral que a solubilidade de metais pesados e de transição em solo, com exceção de Fe e Mn, não é controlada pelo produto de

solubilidade da fase sólida (Brümmer et al., 1983). Uma razão para isso é que, a baixas concentrações nos sólidos do solo, o processo de adsorção é suficientemente capaz de manter a solubilidade a um nível tão baixo que evita a precipitação. Abd-Elfattah \& Wada (1981) observaram uma relação entre a facilidade que o metal se hidroliza e sua sequência de seletividade com os sítios 
ativos de adsorção. Para o $\mathrm{Cu}^{2+}$, o valor da constante de hidrólise $\left(\mathrm{pK}_{1}\right)$ varia entre 7,3 e 8,0. Esse valor é inferior a outros metais como o $\mathrm{Zn}^{2+}\left(\mathrm{pK}_{1}=9,0-\right.$ $9,4), \mathrm{Co}^{2+}\left(\mathrm{pK}_{1}=7,6-12,2\right)$ e $\mathrm{Cd}^{2+}\left(\mathrm{pK}_{1}=7,6-11,6\right)$, e inversamente proporcional ao produto de solubilidade $\left(\mathrm{pK}_{\mathrm{s}}\right)$ dos metais, que aumenta na seguinte ordem : Cd $(13,6-14,6)<\operatorname{Co}(14,2-15,7)<\operatorname{Zn}(15,7-17,4)<\mathrm{Pb}$ $(15,1-20,0)<\mathrm{Cu}(19,7-19,9)$. Com isso, os autores sugerem que o cobre, assim como o chumbo $\left(\mathrm{pK}_{1}=7,8-7,9\right)$, são mais facilmente hidrolizados e, portanto, retidos em maiores quantidades, reduzindo a ocorrência do fenômeno de precipitação para esses elementos.

\subsubsection{Influência do $\mathrm{pH}$ na adsorção de cobre pelo solo}

Alguns fatores ligados diretamente com o ambiente são importantes nas reações de adsorção, destacando-se o pH do meio (King, 1996; Camargo, 1997). A adsorção de cátions metálicos apresentam grande dependência ao $\mathrm{pH}$ da solução e isso é caracterizado por uma estreita faixa de $\mathrm{pH}$, na qual a adsorção pode ter seu valor duplicado (Sparks, 1995). Elevando-se apenas uma unidade de pH, pode haver considerável efeito na adsorção de cobre (Barrow et al., 1981). Para o cobre, não apenas a quantidade adsorvida é aumentada com a elevação do pH, mas também a inclinação das isotermas de adsorção do metal (Msaky \& Calvet, 1990). Dentre os metais pesados, o aumento no $\mathrm{pH}$ afeta de maneira mais significativa a adsorção do cobre e chumbo, em relação ao cádmio, zinco e cobalto (Abd-Elfattah \& Wada, 1981).

$\mathrm{O} \mathrm{pH}$ do solo pode afetar a quantidade de cargas na superfície, além da forma dos ions presentes e, por essa razão, pode exercer importante influência na adsorção de cátions pelo solo, quer seja por mecanismos de adsorção específica como não específica ou eletrostática (Yu, 1997). Normalmente, aumentando-se o pH, aumenta a adsorção do $\mathrm{Cu}$ em solução, diminuindo sua disponibilidade para 
as plantas (Singh, 1971; Temminghoff, 1994; King, 1996; Salam \& Helmke, 1998). Ao se elevar o $\mathrm{pH}$, há formação de produtos de hidrólise que têm diferentes afinidades pelos lugares de troca permanente, além de alterar a natureza do $\mathrm{Al}^{3+}$ que ocupa estes lugares, precipitando-o e liberando sítios de troca (Kuo \& Barber, 1980). Em solos incubados com lodo de esgoto, a concentração e a atividade de íon cobre foi diminuída com a elevação do $\mathrm{pH}$, pois a capacidade adsortiva do solo foi aumentada, principalmente pela desprotonação dos sítios de carga variável (Salam \& Helmke, 1998). Cavallaro \& McBride (1984) e Pombo (1997) encontraram aumento na adsorção de $\mathrm{Cu}$ a pH entre 4,5 e 7,5. Para solos do Estado de São Paulo, Camargo et al. (1982) encontraram correlação negativa entre o $\mathrm{pH}$ e o Cu solúvel em DTPA. Em valores de $\mathrm{pH}$ mais elevados, após um período de tempo, verificou-se a passagem de formas mais solúveis dos metais pesados para formas de menor solubilidade (Amaral Sobrinho et al., 1997). Em geral, valores de $\mathrm{pH}$ acima de 6,5 miniminizam a mobilidade e toxicidade do cobre (Ellis \& Knezek,1977).

Dependendo da constituição mineralógica do solo, a variação do $\mathrm{pH}$ da solução pode alterar, de maneira diferenciada, a afinidade dos sítios de troca pelo metal. Msaky \& Calvet (1990), estudando solos com características mineralógicas distintas, ou seja, Brown Silty Soil (arenoso, mineralogia tipo 2:1) e Oxisol (argiloso), ambos com predominância de esmectita e caulinita/goetita, respectivamente, constataram que o efeito do $\mathrm{pH}$ modificou a inclinação das curvas de adsorção de cobre para esses solos (Figura 3). Conclui-se que, para solos com mineralogia 2:1, a adsorção de cobre envolve tanto reações de troca iônica como de formação de complexos, enquanto nos solos oxídicos o mecanismo de complexação parece ser o principal (Msaky \& Calvet, 1990). Padmanabhan (1983) estudando a adsorção de cobre, zinco, cobalto e ferro na superficie de uma goetita sintetizada, em valores de $\mathrm{pH}$ inferiores ao PESN do mineral, observou que a adsorção desses metais se correlacionava com suas 


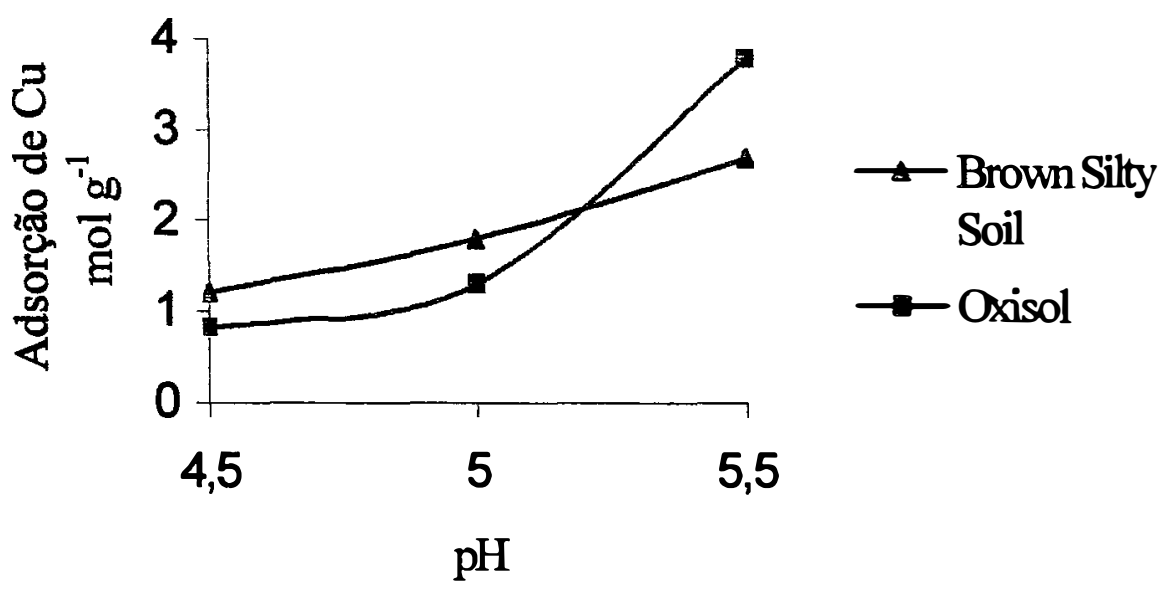

Figura 3. Adsorção de cobre em dois solos. (Msaky \& Calvet, 1990)

respectivas constantes de hidrólise, identificando que o cobre apresentou maior afinidade pelos sítios de adsorção, sendo capaz de competir com altas concentrações de prótons em solução.

\subsection{Solos ácricos}

\subsubsection{Definição e ocorrência no Estado de São Paulo}

A palavra ácrico origina-se do grego "akros", que significa "na ponta" ou "no fim" (Uehara, 1988). Esses solos caracterizam-se pelo intenso processo de intemperismo e dessilicatização, resultando no acúmulo de óxidos de ferro (hematita e goetita) e alumínio (gibsita), além da caulinita (mineral de argila do tipo 1:1). Os solos ácricos encontram-se na posição de máximo de acúmulo de minerais oxídicos (Figura 4). 


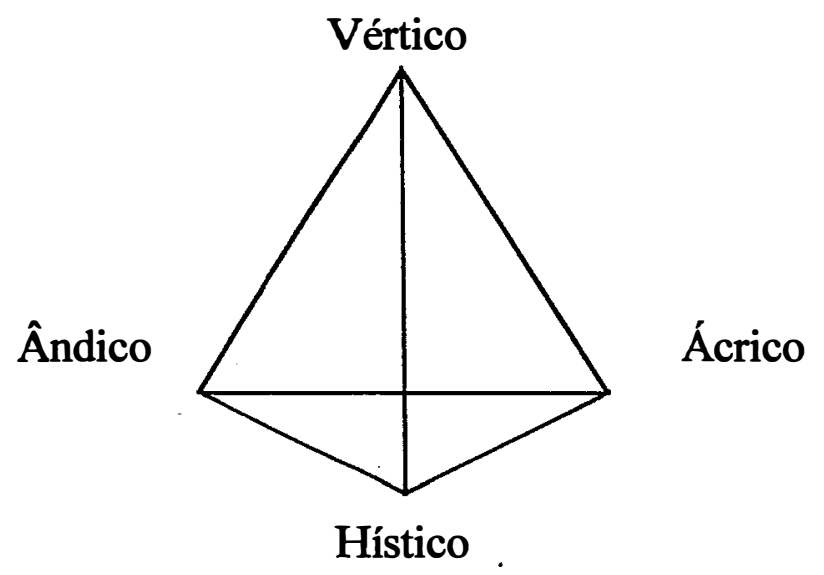

Figura 4. Os quatros extremos taxonômicos (Uehara, 1988)

Embora a classificação brasileira de solos não contemple o caráter ácrico, este pode ser definido, segundo a FAO (1989), quando o solo apresenta uma CTC efetiva menor que $15 \mathrm{mmolc} \mathrm{kg}^{-1}$ de argila e $\mathrm{pH}\left(\mathrm{KCl} 1 \mathrm{~mol} \mathrm{~L}^{-1}\right)$ maior ou igual a 5,0 ; ou $\Delta \mathrm{pH}\left(\mathrm{pH} \mathrm{KCl}-\mathrm{pH} \mathrm{H}_{2} 0\right)$, maior ou igual a 0,1 , em uma profundidade de $125 \mathrm{~cm}$.

No Estado de São Paulo, esses solos localizam-se, principalmente, na Região Norte, sendo que $26 \%$ do total da quadrícula de Ribeirão Preto, ou seja, o equivalente a $74.264,5$ ha é composto por solos. Na Região de Guaíra foram registrados 95.200 ha de solos ácricos, representando a maior ocorrência de Latossolos ácricos mapeadas no Estado de São Paulo, porém acredita-se que essa mesma tendência deve se extender nas área contíguas, ao Sul do Estado de Minas Gerais (Oliveira \& Prado, 1991).

Deve-se ressaltar a importância econômica desses solos na região norte do Estado de São Paulo, uma vez que suportam uma agricultura intensiva baseada na cultura da cana-de açucar e em lavouras irrigadas altamente tecnificadas. 


\subsubsection{Atributos químicos, físicos e mineralógicos}

Os solos ácricos são caracterizados, de ponto de vista químico, pela baixa retenção de cátions, baixos valores de alumínio trocável e proximidade entre o $\mathrm{pH}$ do solo e seu PCZ, sendo que, em alguns casos, o valor do PCZ pode ser superior ao $\mathrm{pH}$ do solo, conferindo uma carga líquida positiva (Alleoni \& Camargo, 1994b). Esse fenômeno de reversão no balanço de cargas é mais comum em profundidades superiores a $0,50 \mathrm{~m}$, devido à menor influência da matéria orgânica, cujo valor de PCZ é próximo a 2,0 (Uehara, 1988). Os valores de potencial elétrico superficial são reduzidos, devido a proximidade do $\mathrm{pH}$ do solo de seu PCZ. Para solos com carga com carga variável, o potencial elétrico superficial ( $\Psi 0)$ é controlado pelos íons determinadores de potencial e é controlada pela atividade dessas espécies na solução de equilíbrio e é independente da presença de eletrólitos suporte (Yu, 1997). Deve-se ressaltar que, para colóides com interface reversível, o potencial na superficie, em determinado $\mathrm{pH}$, é independente da concentração do eletrólito (Alleoni, 1992).

A mineralogia da fração argila deferrificada dos solos ácricos é constituída predominantemente por altas porcentagens de caulinita e gibsita, o que confere a esses solos características próprias.

Devido seu intenso processo de intemperismo, geralmente são solos profundos, com microagregação estável devido à ação cimentante dos óxidos de ferro nas argilas. $\mathrm{O}$ desenvolvimento de uma forte microagregação resulta em baixos teores de água disponível, pois confere ao solos movimento e armazenamento de água similar aos de solos arenosos (Alleoni \& Camargo, 1994a).

Os valores de superficie específica dos solos ácricos são baixos (40 a 100 $\mathrm{m}^{2} \mathrm{~g}^{-1}$ ), notadamente nos horizontes subsuperficiais, como consequência da predominância de minerais cauliníticos e oxídicos na fração argila, além do 
menor conteúdo de matéria orgânica (Alleoni \& Camargo, 1995). A densidade de cargas é reduzida, sendo que seu valor indica a quantidade de carga elétrica por unidade de área. Porém, devido a heterogeneidade na composição mineralógica e na composição e forma dos recobrimentos orgânicos e inorgânicos, a distribuição da densidade de cargas superficial nas superficies das partículas de solo é descontínua, sendo que a densidade de cargas indica um valor médio (Sparks, 1995).

A quantidade de argila dispersa em água desses solos é baixa, principalmente em profundidade, devido aos menores valores de $\Delta \mathrm{pH}$, balanço de cargas e potencial elétrico (Alleoni \& Camargo, 1994a). 


\section{MATERIAL E MÉTODOS}

O experimento, conduzido no Laboratório de Química do Solo, do Departamento de Solos e Nutrição de Plantas, da Escola Superior de Agricultura "Luiz de Queiroz", dividiu-se em duas etapas. Na etapa inicial, estudou-se o efeito de doses crescentes de cobre na adsorção do elemento em amostras de terra, superficiais e subsuperficiais, correspondentes ao $\mathrm{pH}$ natural. Posteriormente, baseado nesse estudo preliminar, foi escolhida uma dose de cobre e avaliou-se o efeito da variação do pH na adsorção de cobre.

\subsection{Solos utilizados}

Foram utilizadas amostras superficiais $(0-20 \mathrm{~cm})$ e subsuperficiais, na maior expressão do $\mathrm{B}$, dos seguintes solos:

1) Latossolo Roxo (LR), ácrico, textura muito argilosa, localizado no município de Ribeirão Preto-SP;

2) Latossolo variação Una (LU), ácrico, textura média, localizado em Guaíra-SP;

3) Terra Roxa Estruturada (TE), textura muito argilosa, município de Ribeirão Preto-SP.

Os Latossolos são oxídicos, muito intemperizados, enquanto a Terra Roxa Estruturada apresenta estádio menos avançado de intemperismo, servindo assim como comparação. Ainda, os Latossolos escolhidos apresentam texturas 
contrastantes, para melhor caracterizar a adsorção do metal em diferentes conteúdos de argila.

Após a coleta, os solos foram secos ao ar e, posteriormente, peneirados com peneira de plástico com abertura de malha de dois milímetros e incubados com carbonato de cálcio e/ou ácido clorídrico.

\subsection{Experimento de Incubação}

As amostras de terra foram incubadas com $\mathrm{CaCO}_{3}$ p.a. e $\mathrm{HCl}(1 \mathrm{~mol}$ $\mathrm{L}^{-1}$ ) a fim de se obter uma faixa de $\mathrm{pH}$ variando entre 4,0 e 7,0. Essa faixa de $\mathrm{pH}$ escolhida teve como objetivo aproximar-se da faixa de $\mathrm{pH}$ comumente encontrada nos solos agrícolas. Salam \& Helmke (1998) utilizaram a mesma variação de $\mathrm{pH}$ em estudos de adsorção de cobre. Realizou-se um ensaio prévio de incubação, adicionando-se doses crescentes de $\mathrm{CaCO}_{3} \mathrm{e} \mathrm{HCl}$ às amostras de terra dos solos estudados. As amostras foram mantidas por 90 dias em vasos de barro, mantendose a umidade próximo à capacidade de campo. Semanalmente realizaram-se as leituras de $\mathrm{pH}$, até que o mesmo atingisse o equilíbrio. Baseado nessas informações, calcularam-se as quantidades a serem adicionadas de carbonato de cálcio e ácido clorídrico, a fim de obter a faixa de variação de $\mathrm{pH}$ entre 4,0 e 7,0 (Tabela 1). Após a incubação, as amostras foram secas ao ar e passadas por peneira de $2 \mathrm{~mm}$ e, posteriormente, acondicionadas em sacos plásticos.

\subsection{Caracterização química, física e mineralógica}

Os solos foram caracterizados conforme metodologia preconizada por Camargo et al. (1986), sendo analisados os seguintes atributos:

- Carbono orgânico: oxidação da matéria orgânica com solução de dicromato de potássio em presença de ácido sulfúrico e titulação do excesso de 
Tabela 1. Quantidades de $\mathrm{CaCO}_{3}$ p.a. e $\mathrm{HCl}$ aplicadas para cada $10 \mathrm{~kg}$ de terra.

\begin{tabular}{cccc}
\hline Solo & Profundidade & $\mathrm{HCl}\left(1 \mathrm{~mol} \mathrm{~L}^{-1}\right)$ & $\mathrm{CaCO}_{3}$ \\
\hline & & $\mathrm{mL}$ & $\mathrm{g}$ \\
$\mathrm{TE}$ & $0-0,20 \mathrm{~m}$ & $-1----$ & $20 ; 80 ; 160$ \\
& $0,7-0,9 \mathrm{~m}$ & 800 & $20 ; 80$ \\
$\mathrm{LR}$ & $0-0,20 \mathrm{~m}$ & 800 & $20 ; 80$ \\
& $0,8-1,0 \mathrm{~m}$ & $800 ; 1600$ & 40 \\
& & & $20 ; 80$ \\
$\mathrm{LU}$ & $0-0,20 \mathrm{~m}$ & $800 ; 1600$ & 40 \\
\hline
\end{tabular}

dicromato com sulfato ferroso amoniacal.

- pH em água e $\mathrm{KCl} 1 \mathrm{~mol} \mathrm{~L}^{-1}$, relação solo-solução 1:2,5. Com esses valores calculou-se o $\Delta \mathrm{pH}$, definido como $\mathrm{pH} \mathrm{KCl}-\mathrm{pH} \mathrm{H}_{2} \mathrm{O}$. O valor do $\Delta \mathrm{pH}$ foi utilizado como estimativa da carga líquida dos solos.

- Cátions trocáveis $(\mathrm{Ca}, \mathrm{Mg}, \mathrm{K}$ e $\mathrm{Na})$ : extração dos elementos trocáveis com resina trocadora de íons e posterior leitura no espectofotômetro de absorção atômica (cálcio e magnésio) e fotômetro de chama (potássio e sódio). De posse dos resultados obtidos calcularam-se :
a) Soma de bases (SB) $=\mathrm{Ca}+\mathrm{Mg}+\mathrm{K}+\mathrm{Na}$;
b) $\mathrm{CTC}$ efetiva $\left(\mathrm{CTC}_{\mathrm{e}}\right)=\mathrm{SB}+\mathrm{Al}$;
c) CTC total $\left(\mathrm{CTC}_{\mathrm{t}}\right)=$ CTCefetiva $+\mathrm{H}^{+}$;
d) Retenção de cátions (RC) $=($ CTCefetiva $/ \%$ argila $) * 100$; 
e) Saturação por bases $(\mathrm{V} \%)=(\mathrm{SB} / \mathrm{CTC}$ total $) * 100$;

f) Saturação por alumínio $(\mathrm{m} \%)=(\mathrm{Al} * 100) / \mathrm{CTCefetiva}$.

- Teores totais de óxidos (Al, Fe e $\mathrm{Si}$ ): obtidos após ataque sulfúrico. Com esses resultados calcularam-se : a) índice $\left.\mathrm{ki}=\left(\% \mathrm{SiO}_{2} / 60\right) /\left(\% \mathrm{Al}_{2} \mathrm{O}_{3} / 102\right) ; \mathrm{b}\right)$ índice $\mathrm{kr}=\left(\% \mathrm{SiO}_{2} / 60\right) /\left[\left(\% \mathrm{Al}_{2} \mathrm{O}_{3} / 102\right)+\left(\% \mathrm{Fe}_{2} \mathrm{O}_{3} / 160\right)\right]$.

- Ferro e alumínio livres: em meio tamponado com bicarbonato de sódio, reduziu-se o ferro com ditionito de sódio, sendo ambos os cátions complexados pelo citrato de sódio, permanecendo em solução.

- Ferro e alumínio mal cristalizados ou microcristalinos: obtidos por solubilização de ferro e alumínio amorfos em ácido oxálico e seu sal de amônio.

- Ponto de Efeito Salino Nulo (PESN): utilizou-se o método da titulação com $\mathrm{H}^{+}$e $\mathrm{OH}^{-}$a três diferentes concentrações de $\mathrm{KCl}$, sendo o PESN o valor do pH no ponto de interseç̧ão das curvas de titulação. Foram preparadas soluções de $\mathrm{NaOH}\left(0,002\right.$ e $\left.0,004 \mathrm{~mol} \mathrm{~L}^{-1}\right)$ e $\mathrm{HCl}\left(0,002 ; 0,004 ; 0,006 ; 0,0012 \mathrm{~mol} \mathrm{~L}^{-1}\right)$ em três diferentes concentrações do eletrólito suporte, ou seja, $\mathrm{KCl} 0,001 ; 0,01$ e 0,1 mol $\mathrm{L}^{-1}$. O cloreto de potássio foi o sal escolhido, pois é um eletrólito do tipo indiferente, cujos íons tem raios hidratados semelhantes, capazes de serem adsorvidos de forma não específica (Sposito, 1981). Utilizou-se o equivalente a 4,0 g de TFSE, com posterior adição de $20 \mathrm{~mL}$ das soluções descritas anteriormente. As amostras foram agitadas ocasionalmente por 24 horas. Esse intervalo de tempo foi escolhido, pois garante que, nas amostras com baixo teor de matéria orgânica, o equilíbrio seja atingido, enquanto que as amostras com altos teores de matéria orgânica não tenham sofrido intenso processo de oxirredução, o que pode afetar os valores de $\mathrm{pH}$ em até 0,5 unidade nas concentrações mais diluídas (Siqueira et al., 1990). Realizou-se uma última 
agitação e após 30 minutos fizeram-se as leituras de $\mathrm{pH}$. As determinações foram realizadas em triplicata. Calcularam-se então as quantidades de $\mathrm{H}^{+}$e $\mathrm{OH}^{-}$ adsorvidas em determinado valor de $\mathrm{pH}$, descontando-se o branco, ou seja, a quantidade de ácido ou base exigida para trazer o mesmo volume ao mesmo valor de $\mathrm{pH}$, sem considerar a amostra de terra. O ponto de intersecção das três curvas de titulação corrrespondeu ao valor do PESN.

- Potencial Elétrico Superficial ( $\Psi$ o) : nos solos os íons $\mathrm{H}^{+}$e $\mathrm{OH}^{-}$são os determinadores de potencial e o valor do potencial elétrico, em $\mathrm{mV}$, pode ser obtido, utilizando-se a equação de Nernst :

$\Psi \mathrm{o}=59,1(\mathrm{PCZ}-\mathrm{pH})$

sendo que $\mathrm{PCZ}=$ ponto de carga zero, corresponde ao valor de $\mathrm{pH}$ no qual o somatório de cargas positivas se iguala ao somatório de cargas negativas. Porém, para o cálculo do potencial elétrico superficial foi considerado o valor do PESN, devido a proximidade dos valores de PCZ e PESN.

-Superfície Específica (SE) : método de Heilman et al. (1965), baseado na retenção do eter monoetílico do etilenoglicol (EMEG), com as modificações propostas por Cihacek \& Bremner (1979) e Ratner Zomar et al.(1983). Para realizar a determinação da $\mathrm{SE}$, utilizou-se $0,5 \mathrm{~g}$ de terra seca em estufa a $110^{\circ} \mathrm{C}$ durante 24 horas. Essas amostras, após secas, foram acondicionadas em dessecador contendo $\mathrm{CaCl}_{2}$ e a seguir foi adicionado lentamente, a cada uma delas, $1 \mathrm{~mL}$ de EMEG. Uma bomba de vácuo foi acoplada ao dessecador fornecendo pressão de $0,25 \mathrm{~mm} \mathrm{Hg}$ por um período de 45 minutos. A cada duas horas as amostras foram pesadas e novamente aplicado o vácuo até que atingisse 
uma variação de peso entre as determinações inferior a 0,002 g. As determinações foram realizadas em triplicata, e a SE foi posteriormente calculada como sendo :

$\mathrm{SE}\left(\mathrm{m}^{2} \mathrm{~g}^{-1}\right)=(\mathrm{g}$ EMEG $/ \mathrm{g}$ terra $) / 0,000286$. 6

Com os valores de SE e da carga líquida obtida a partir das curvas de titulação, calculou-se a densidade de cargas $(\sigma)$ :

$$
\sigma=\text { Carga Líquida } / \mathrm{SE}
$$

- Análise granulométrica: realizada pelo método do densímetro. Foram tomados $20 \mathrm{~g}$ de terra e adicionaram-se $100 \mathrm{~mL}$ da solução dispersante. Para elaboração da solução dispersante, dissolveram-se 20 g de hidróxido de sódio em 5 litros de água destilada e adicionaram-se $50 \mathrm{~g}$ de hexametafosfato de sódio, agitando, com agitador magnético, até completa dissolução do reagente. A suspensão (solo + dispersante) foi agitada por $16 \mathrm{~h}$ em agitador rotatório a 30 rpm. Transferiu-se a suspensão para uma proveta, onde completou-se o volume de $1 \mathrm{~L}$ com água destilada. A amostra foi agitada com agitador manual por $40 \mathrm{~s} \mathrm{e}$, em seguida, iniciou-se a contagem do tempo de sedimentação. Após 40 segundos, introduziu-se o densímetro na suspensão e realizou-se a primeira leitura, correspondente às frações argila + silte. Após $2 \mathrm{~h}$, realizou-se a segunda leitura, correspondente à fração argila. Por diferença, calcularam-se as quantidades de silte e areia.

- Argila dispersa em água : Foram tomados $10 \mathrm{~g}$ de terra fina seca ao ar e agitou-se, juntamente com água destilada, durante dezesseis horas em agitador rotativo a $30 \mathrm{rpm}$. Determinou-se o tempo de sedimentação e retirou-se uma alíquota, de maneira semelhante a utilizada para análise granulométrica. 
- Umidade na Capacidade de Campo : obtida por meio da aplicação de tensão de $0,3 \mathrm{MPa}$ às amostras deformadas de terra, previamente saturadas com água. Essa determinação teve como objetivo calcular a quantidade de água a ser adicionada no ensaio de incubação do solo com carbonato de cálcio e ácido clorídrico.

-Análise mineralógica qualitativa realizada nas amostras de argila previamente tratadas para eliminação da matéria orgânica e óxidos de ferro, com auxílio de difração de raios $\mathrm{X}$, nas amostras saturadas com magnésio, glicoladas, e nas saturadas com potássio e submetidas às temperaturas de 25,350 e $550^{\circ} \mathrm{C}$.

-Análise mineralógica quantitativa : na fração argila deferrificada, após duas extrações com ditionito-citrato-bicarbonato de sódio, foram quantificadas as quantidades de caulinita e gibsita por meio da análise térmica diferencial (ATD). As amostra de argila deferrificada, isentas de matéria orgânica e saturadas com magnésio foram misturadas com $\mathrm{Al}_{2} \mathrm{O}_{3}$ calcinado na proporção de $1: 3$

\subsection{Curvas e isotermas de adsorção de cobre}

Etapa 1 : Foram tomados o correspondente a 2,00 g de TFSE, em triplicata, das amostras de terra (testemunha), ou seja, com valor de $\mathrm{pH}$ correspondente ao original dos solos. Adicionaram-se $20 \mathrm{~mL}$ de solução $0,0025 \mathrm{~mol} \mathrm{~L}^{-1}$ de $\mathrm{Ca}\left(\mathrm{NO}_{3}\right)_{2}$ contendo $\mathrm{Cu}\left(\mathrm{NO}_{3}\right)_{2}$ nas concentrações de $0,5,10,20,50,100,200,300$, 400,600 e $800 \mathrm{mg} \mathrm{L}^{-1}$ de cobre. O nitrato foi escolhido como suporte devido à sua menor habilidade em complexar cátions metálicos (Msaky \& Calvet, 1990; Guilherme \& Anderson, 1998). A relação de solo:solução utilizada de 1:10 baseou-se em dados de literatura (McLaren et al., 1983, Pombo et al., 1986, Yuan et al., 1997). A suspensão foi agitada em agitador horizontal por $24 \mathrm{~h}$ a 
temperatura constante. Esse período de 24 horas foi adotado, pois garante que o equilíbrio seja atingido (Petruzelli et al., 1985). McLaren \& Williams (1981) encontraram que após 16 horas de equilíbrio a adsorção de cobre foi completa, sendo que períodos prolongados, além desse intervalo de tempo, houve uma adsorção de cobre lenta, em níveis inferiores a $10 \%$ do total de cobre adsorvido. Após agitação, foram feitas as determinações de cobre no extrato com auxílio de espectrofotômetro de absorção atômica. Estimou-se a quantidade de cobre adsorvida pelo solo, subtraindo-se o valor determinado em solução da quantidade inicialmente colocada na solução de equilíbrio. A partir dos dados obtidos experimentalmente, construiram-se isotermas de adsorção, plotando-se a quantidade de cobre adsorvido na ordenada e a concentração de equilíbrio na abcissa. A partir da transformação para forma linear das equações de Freundlich e Langmiur foram obtidos seus respectivos parâmetros.

Baseado nesses resultados, calcularam-se os valores de energia livre das reações de adsorção de cobre $\left(\mathrm{J} \mathrm{mol}^{-1}\right)$ como sendo :

$\Delta \mathrm{G}^{\mathrm{o}}=\mathrm{R} \mathrm{T}$ (ln cobre em equilíbrio - ln cobre adicionado) 8

sendo que $\mathrm{R}=8,30 \mathrm{~J} \mathrm{~mol}^{-1} \mathrm{~kg}^{-1}$ e $\mathrm{T}=298 \mathrm{~K}$.

\subsection{Variação do $\mathrm{pH}$}

Etapa 2 : Após o estudo inicial (Etapa 1), determinou-se a concentração de cobre a ser adicionada às amostras incubadas com $\mathrm{CaCO}_{3}$ e/ou $\mathrm{HCl}$ e avaliou-se o efeito da variação do $\mathrm{pH}$ na adsorção, utilizando-se quatro repetições. Por meio de regressões não lineares estimaram-se os valores de adsorção de cobre para cada repetição, nos valores de $\mathrm{pH}$ iguais a 4,0, 5,0 e 6,0 e realizaram-se às comparações entre os solos e profundidades. 
A análise seguiu o esquema fatorial $3 \times 2 \times 3$, ou seja, três solos, duas profundidades e três valores de $\mathrm{pH}$, num delineamento inteiramente casualizado.

\subsection{Análise de regressão}

Considerando-se a natureza heterogênea dos solos e a possibilidade de vários de seus constituintes estarem associados com os mecanismos de adsorção de cobre, realizaram-se análises de regressão e correlações simples e múltiplas entre o cobre adsorvido e os atributos físicos, químicos e mineralógicos e os coeficientes das equações de Langmuir e Freundlich.

\subsection{Análises estatísticas}

As análises estatísticas realizadas no trabalho, de comparação de médias, correlações simples e múltipla e regressões, foram realizadas através do programa estatístico SAS (SAS Institute, 1988). 


\section{RESULTADOS E DISCUSSÃO}

\subsection{Atributos químicos}

Os resultados das análises químicas dos solos estudados estão expressos nas Tabelas 2 e 3. A Terra Roxa Estruturada e o Latossolo Roxo na superfície possuem maiores saturações por bases. Já o Latossolo variação Una e o Latossolo Roxo (subsuperficie) são pobres em cátions, sendo considerados ácricos. Essa característica de baixa fertilidade natural dos Latossolos ocorre devido ao grau de intemperismo avançado e consequente lixiviação de cátions. Quanto a saturação por alumínio, nas amostras superficiais o LU apresentou maior saturação (44\%). No horizonte subsuperficial a saturação de alumínio foi nula para os três solos estudados. Os baixos teores de alumínio, sobretudo em subsuperfície, estão coerentes com as características químicas e o grau de intemperismo desses solos, uma vez que a mineralogia dos solos ácricos é essencialmente oxídica e os valores de $\mathrm{pH}$ são geralmente altos, não proporcionando elevados teores de alumínio em solução.

Com relação aos valores de $\Delta \mathrm{pH}$, nos horizontes superficiais, os três solos estudados apresentaram balanço de cargas negativo, provavelmente pelo efeito da matéria orgânica. Porém, em subsuperfície o Latossolo Roxo e o Latossolo variação Una apresentaram valores de $\mathrm{pH}$ em $\mathrm{KCl} 1 \mathrm{~mol} \mathrm{~L}^{-1}$ superiores ao $\mathrm{pH}$ em $\mathrm{H}_{2} \mathrm{O}$, mostrando o predomínio de cargas positivas. Essa característica de reversão no balanço de cargas pode ocorrer nos solos ácricos, sobretudo em subsuperfície, pela predominância da fração oxídica nesses horizontes. 


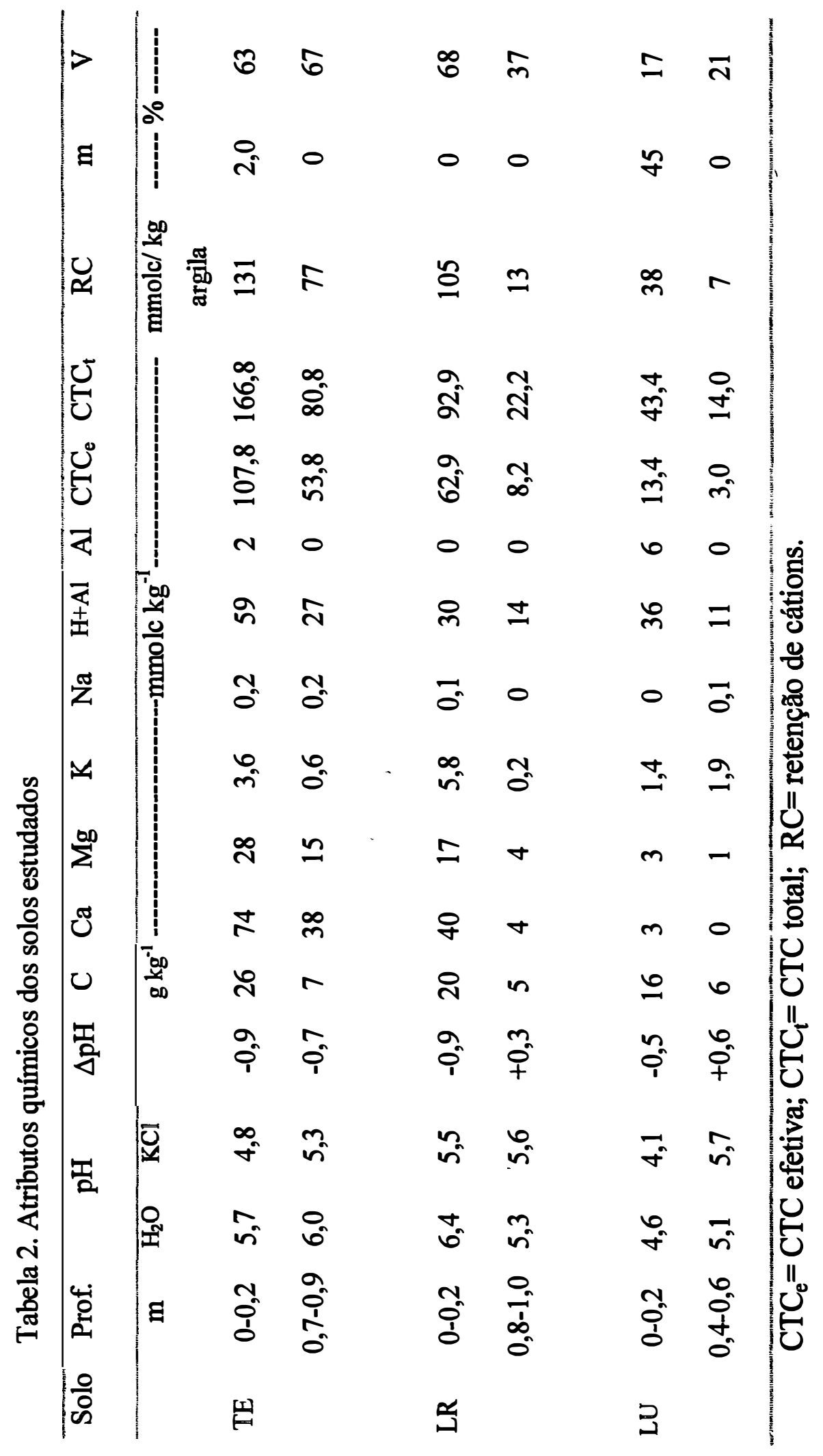


Tabela 3. Teores de óxidos (totais, livre e mal cristalizados) e índices ki e kr.

\begin{tabular}{|c|c|c|c|c|c|c|c|c|c|c|c|}
\hline Solo & Prof. & $\mathrm{Fe}_{\mathrm{t}}$ & $\mathrm{Fe}_{\mathrm{d}}$ & $\mathrm{Fe}_{\mathrm{o}}$ & $\mathrm{Al}_{\mathrm{t}}$ & $\overline{A l_{d}}$ & $\mathrm{Al}_{\mathrm{o}}$ & $\mathrm{Si}_{\mathrm{t}}$ & $\mathrm{MnO}$ & $\mathrm{ki}$ & $\mathbf{k r}$ \\
\hline & $\mathrm{m}$ & ----. & & & $-\mathrm{g}$ & & & & ------ & & \\
\hline \multirow[t]{2}{*}{$\mathrm{TE}$} & $0-0,2$ & 270 & 150 & 12 & 167 & 23 & 8 & 186 & 0,36 & 1,89 & 0,93 \\
\hline & $0,7-0,9$ & 284 & 150 & 14 & 195 & 21 & 7 & 20 & 0,15 & 1,74 & 0,90 \\
\hline \multirow[t]{2}{*}{ LR } & $0-0,2$ & 320 & 164 & 13 & 195 & 26 & 10 & 107 & 0,20 & 0,93 & 0,46 \\
\hline & $0,8-1,0$ & 341 & 185 & 9 & 195 & 21 & 7 & 100 & 0,14 & 0,87 & 0,41 \\
\hline
\end{tabular}

$\begin{array}{llllllllllll}\text { LU } & 0-0,2 & 66 & 39 & 2 & 91 & 22 & 6 & 54 & 0,02 & 0,98 & 0,69\end{array}$ $\begin{array}{lllllllllll}0,4-0,6 & 96 & 43 & 2 & 125 & 31 & 8 & 71 & 0,02 & 0,97 & 0,65\end{array}$

$\mathrm{Fe}_{\mathrm{t}}=$ óxido de ferro total; $\mathrm{Fe}_{\mathrm{d}}=$ óxido de ferro "livre"; $\mathrm{Fe}_{\mathrm{o}}=$ óxido de ferro amorfo; $\mathrm{Al}_{\mathrm{t}}=$ óxido de alumínio total; $\mathrm{Al}_{\mathrm{d}}=$ óxido de alumínio "livre"; $\mathrm{Al}_{\mathrm{o}}=$ óxido de alumínio amorfo; $\mathrm{Si}_{\mathrm{t}}=$ silício total.

Os óxidos de ferro, presentes na fração mineral desses solos, são considerados os principais materiais na geração de cargas positivas nos solos com carga variável (Yu, 1997). Essas observações sugerem a importância da matéria orgânica na geração de cargas negativas nos horizontes superficiais dos solos ácricos. Resultados semelhantes foram obtidos por Alleoni \& Camargo (1994b), que observaram menores valores de PESN e balanço de cargas negativo nos horizontes superficiais dos solos estudados. A Terra Roxa Estruturada, por sua vez, apresentou balanço negativo de cargas ao longo de todo seu perfil, servindo assim como comparação em relação aos Latossolos.

Os baixos valores de retenção de cátions obtidos para as amostras de terra dos Latossolos, notadamente nos horizontes subsuperficiais, onde há menor 
influência da matéria orgânica, reforçam a característica de solos bastante intemperizados. A Terra Roxa Estruturada apresentou maiores valores de RC, em ambos horizontes.

$\mathrm{O}$ índice ki, como esperado, teve seus maiores valores na $\mathrm{TE}$ em relação aos Latossolos, devido ao menor grau de intemperismo do primeiro solo (Tabela 3). Segundo Resende \& Santana (1988), os solos podem ser classificados segundo seus valores de ki e lr como :

$\mathrm{TE}$ : caulinítico não sesquióxidico $(\mathrm{ki}>0,75 \mathrm{e} \mathrm{kr}<0,75)$;

LR : caulinítico sesquióxidico ( $\mathrm{ki}>0,75$ e kr $\leq 0,75)$;

LU : gibsítico sesquióxidico ( $\mathrm{ki} \leq 0,75$ e kr $\leq 0,75)$

Os teores totais de óxido de ferro e alumínio foram superiores no Latossolo Roxo (Tabela 3). Em média, $50 \%$ do óxido de ferro total estava na forma livre, para os três solos, independentemente do teor total. Já a porcentagem de óxido de alumínio livre correspondeu, em média, a 13\% do total na TE e no LR, porém no LU esse valor foi próximo a $25 \%$ do total.

As quantidades de óxidos de ferro mal cristalizados foram pequenas para os solos estudados. A relação $\mathrm{Fe}_{\mathrm{o}} / \mathrm{Fe}_{\mathrm{d}}$ foi próximo a 0,08 para a $\mathrm{TE}$ e para $\mathrm{o}$ horizonte superficial do LR. Para o LU e no horizonte subsuperficial do LR essa relação foi igual a 0,05. Esses resultados são superiores aos encontrados por Guilherme \& Anderson (1998) que obtiveram, para dois Latossolos (Latossolo Vermelho-Amarelo e Latossolo Vermelho-Escuro), relações entre 0,02 e 0,05. Já os valores de óxidos de alumínio mal cristalizados foram superiores aos óxidos de ferro. Em média, a relação $\mathrm{Al}_{\mathrm{o}} / \mathrm{Al}_{\mathrm{d}}$ foi próxima a 0,30 para os três solos.

Os resultados do ponto de efeito salino nulo (PESN), apresentados na Tabela 4, estão próximos aos valores encontrados na literatura, para solos altamente intemperizados (Alleoni, 1992; Alleoni \& Camargo, 1994b; Guilherme 
Tabela 4 . Ponto de Efeito Salino Nulo e Potencial Elétrico.

\begin{tabular}{cccc}
\hline Solo & Horizonte & PESN & Potencial Elétrico $\left(\Psi_{0}\right)$ \\
\hline \multirow{2}{*}{ TE } & Superficie & $3,65 \mathrm{c}^{*}$ & $\mathrm{mV}$ \\
& Profundidade & $3,60 \mathrm{~d}$ & $-121,2$ \\
& & & $-141,8$ \\
LR & Superficie & $3,60 \mathrm{~d}$ & $-165,5$ \\
& Profundidade & $5,65 \mathrm{~b}$ & 20,7 \\
& & & $-70,9$ \\
\multirow{2}{*}{ LU } & Superficie & $3,40 \mathrm{e}$ & 56,2 \\
& Profundidade & $6,05 \mathrm{a}$ & \\
\hline
\end{tabular}

* As letras referem-se ao teste de Tukey $(\alpha=5 \%)$.

\& Anderson, 1998). Guilherme \& Anderson (1998) encontraram valores de PESN nos horizontes A e B de dois solos oxídicos próximos a 4,3 e 6,2 respectivamente. Os valores de PESN se correlacionaram com os teores de carbono $(r=-0,68)$ e com a composição mineralógica dos solos, expressa pelos índices $\mathrm{ki}$ e $\mathrm{kr}(\mathrm{r}=-0,47$ e $\mathrm{r}=-\mathbf{0}, 46)$. Os horizontes subsuperficiais dos Latossolos apresentaram os maiores valores de PESN, devido à predominância da fração mineral em profundidade. Os óxidos de ferro e alumínio possuem altos valores de PESN, próximos a 8,0 e a matéria orgânica tem seu PESN igual a 2 (Sparks, 1995). Portanto, apesar dos baixos valores de matéria orgânica dos Latossolos, há significativo efeito nos atributos eletroquímicos dos horizontes superficiais desses solos. Para a TE, apesar do teor de carbono no horizonte subsuperficial ser próximo ao dos Latossolos, o valor do PESN foi significativamente menor, devido à suas características mineralógicas. Para os horizontes superficiais, a TE apresentou maior valor de PESN, seguido do LR e do LU. Possivelmente, devido a predominância de óxidos na fração mineralógica do LR e do LU, esses óxidos, 
sobretudo os de alumínio, podem estar promovendo o recobrimento das partículas do solo, alterando assim os valores do PESN (Yu, 1997).

Quanto ao potencial elétrico dos solos $\left(\Psi_{0}\right)$, quanto mais próximo o $\mathrm{pH}$ da solução do PESN, menor será seu valor. Portanto, nos horizontes superficiais, devido ao efeito da matéria orgânica e os menores valores do PESN, encontraram-se os maiores valores de $\Psi_{0}$, com exceção da TE, que apresentou potencial elétrico, em módulo, maior no horizonte B. Para a TE, em ambos os horizontes, o $\mathrm{pH}$ do solo foi superior aos valores do PESN, conferindo potenciais elétricos negativos. Para os Latossolos, houve predomínio de cargas negativas em superfície, porém, em subsuperfície os valores de $\mathrm{pH}$ foram inferiores ao PESN, resultando potenciais elétricos positivos nessa profundidade. O LR em superfície apresentou maior potencial elétrico nessa profundidade, pois seu $\mathrm{pH}$ encontra-se mais distante do PESN. Porém, nos horizontes subsuperficiais, a diferença na magnitude de cargas entre os solos foi marcante. Em profundidade, a TE apresentou balanço de cargas negativo e potencial elétrico maior (em módulo), devido ao seu menor PESN em relação aos Latossolos. Isso se deve à predominância da caulinita na fração mineral ( $57 \%$ da fração argila deferrificada), que por sua vez possui valor do PESN inferior ao dos óxidos (Alleoni, 1994c). Já os Latossolos apresentaram balanço de cargas positivo, com valores de potencial elétrico menores (em módulo), devido à proximidade do $\mathrm{pH}$ do solo do PESN. O comportamento de reversão no balanço de cargas nos horizontes subsuperficiais, característica dos solo ácricos, geralmente ocorre em profundidades superiores a $0,5 \mathrm{~m}$, pois nesta condição o efeito da matéria orgânica é menos pronunciado (Uehara, 1988). A predominância da fração mineral, composta principalmente por óxidos de ferro e alumínio, é responsável pelo balanço de cargas positivas nos horizontes subsuperficiais dos Latossolos. Segundo Yu (1997) os óxidos de ferro são os principais responsáveis pela geração de cargas positivas nos solos com 
carga variável. Ainda, os óxidos de alumínio geralmente apresentam valores de PESN maiores do que o PESN do solo, podendo gerar cargas positivas devido à protonação de sua superfície.

\subsection{Experimento de incubação com $\mathrm{CaCO}_{3}$ e $\mathrm{HCl}$}

Os valores de $\mathrm{pH}$ obtidos em $\mathrm{CaCl}_{2} 0,01 \mathrm{~mol} \mathrm{~L}^{-1}$, após a incubação das amostras por três meses com carbonato de cálcio e ácido clorídrico estão apresentados na Tabela 5. Com isso, obteve-se a variação de pH desejada, com o objetivo de avaliar o efeito do $\mathrm{pH}$ na adsorção de cobre.

Tabela 5. Valores de $\mathrm{pH}\left(\mathrm{CaCl}_{2}\right)$ obtidos após adição de $\mathrm{CaCO}_{3}$ e $\mathrm{HCl}$.

\begin{tabular}{ccc}
\hline Solo & \multicolumn{2}{c}{$\mathrm{pH}$ final } \\
TE & Superficie & Profundidade \\
& 3,8 & 2,7 \\
& 4,7 & 3,5 \\
& $4,8^{*}$ & $6,1^{*}$ \\
& 7,2 & 6,6 \\
\hline LR & $4,2^{*}$ & 3,0 \\
& 5,4 & $4,9 *$ \\
& 6,1 & 6,1 \\
& 7,4 & 6,8 \\
\hline LU & 3,0 & 2,9 \\
& $4,4^{*}$ & 3,8 \\
& 5,6 & $5,9 *$ \\
& 7,3 & 6,6
\end{tabular}

* Referem-se aos valores de $\mathrm{pH}$ das amostras que não receberam $\mathrm{HCl}$ ou $\mathrm{CaCO}_{3}$ (testemunhas). 


\subsection{Atributos físicos}

Os resultados obtidos nas análises físicas encontram-se na Tabela 6.

Tabela 6. Atributos físicos dos solos estudados

\begin{tabular}{|c|c|c|c|c|c|c|c|}
\hline Solo & Profundidade & Areia & Silte & Argila & $\overline{\mathrm{ADA}}$ & $\mathrm{U}_{\mathrm{cc}}$ & S.E. \\
\hline & m & --------- & $----\operatorname{g~k}$ & |----. & ------- & $\%$ & $m^{2} g^{-1}$ \\
\hline \multirow[t]{2}{*}{ TE } & $0-0,2$ & 60 & 120 & 820 & 420 & 30 & $134,1(a)^{*}$ \\
\hline & $0,7-0,9$ & 80 & 220 & 700 & 90 & 31 & 151,3 (a) \\
\hline \multirow[t]{2}{*}{ LR } & $0-0,2$ & 170 & 230 & 600 & 340 & 25 & 64,7 (b) \\
\hline & $0,8-1,0$ & 130 & 230 & 640 & 20 & 27 & 75,5 (b) \\
\hline \multirow[t]{2}{*}{ LU } & $0-0,2$ & 610 & 40 & 350 & 180 & 13 & 64,7 (b) \\
\hline & $0,4-0,6$ & 510 & 40 & 450 & 0 & 19 & $53,2(b)$ \\
\hline
\end{tabular}

Quanto à textura, baseado na classificação de Brady (1989), a TE e o LR se enquadram na classe argila, enquanto o LU foi classificado como francoargiloso.

Os valores de argila dispersa em água (ADA) foram baixos e correlacionaram-se com os valores de carbono $(\mathrm{r}=0,98)$ e $\Delta \mathrm{pH}(\mathrm{r}=0,80)$, sendo significativamente reduzidos em profundidade, devido ao menores teores de matéria orgânica e aos valores de $\Delta \mathrm{pH}$ mais próximos a zero, o que favoreceu a redução na repulsão entre as partículas de argila. Resultados semelhantes foram obtidos por Alleoni \& Camargo (1994a) que, estudando Latossolos ácricos, observaram redução na quantidade de argila dispersa em água nos horizontes 
subsuperficiais, devido principalmente ao balanço de cargas, potencial elétrico e $\Delta \mathrm{pH}$. Ainda, a presença de alumínio em condições de acidez, pode favorecer a floculação das partículas de argila, notadamente no horizonte superficial do LU. Essa característica de valores reduzidos de ADA, comum nos solos ácricos, pode apresentar importância no manejo desses solos, uma vez que está relacionada com a ocorrência do fenômeno de encrostamento superficial.

A quantidade de água retida na capacidade de campo $\left(\mathrm{U}_{\mathrm{cc}}\right)$ foi menor para o LU. Deve-se ressaltar que essa determinação foi realizada com o objetivo de calcular a quantidade de água a ser adicionada no ensaio de incubação.

Os resultados de superfície específica (SE) estão coerentes com os valores encontrados na literatura, para solos intemperizados (Aleoni \& Camargo, 1994a, 1995; Guilherme \& Anderson, 1998). Os baixos valores de SE encontrados nos solos ácricos estão relacionado à predominância de minerais cauliníticos e oxídicos na fração argila desses solos (Alleoni \& Camargo, 1994a). Corroborando essa informação, observou-se correlação significativa entre SE e os índices ki e kr $(r=0,55$ e 0,54 , respectivamente), evidenciando assim a influência da mineralogia nos valores de SE. A SE foi superior para a TE, sendo que o LR e o LU não diferiram estatisticamente (Tabela 6). Também não houve diferenças entre os horizontes para o mesmo solo. Possivelmente, devido aos baixos conteúdos de matéria orgânica presentes nos solos estudados, seu efeito não foi marcante, uma vez que não houve correlação com os valores de SE.

A carga líquida nos horizontes superficiais foi negativa, enquanto nos horizontes subsuperficiais os Latossolos apresentaram carga líquida positiva, pois os valores do $\mathrm{pH}$ do solo nessa profundidade foram inferiores aos respectivos valores do PESN (Tabela 7). Os valores de densidade de cargas nos horizontes superficiais foram próximos para os três solos estudados, porém, em subsuperficie, a TE apresentou densidade de cargas superior aos Latossolos. Já os Latossolos, devido à proximidade do $\mathrm{pH}$ em relação ao PESN em subsuperfície, 
Tabela 7. Resultados de carga elétrica líquida e densidade de cargas.

\begin{tabular}{cccc}
\hline Solo & Amostra & Carga líquida & $\begin{array}{c}\text { Densidade de } \\
\text { Cargas }\end{array}$ \\
\hline \multirow{2}{*}{ TE } & Superficie & -25 & $-1,86$ \\
& Profundidade & -35 & $-2,31$ \\
& & & \\
LR & Superficie & -14 & $-2,16$ \\
& Profundidade & +2 & $+0,26$ \\
& & & $-1,85$ \\
LU & Superficie & -12 & $+1,12$ \\
\hline
\end{tabular}

sobretudo no LR, apresentaram menores valores de densidade de carga nessa profundidade.

4.4 Análise mineralógica e análise térmica diferencial

A caulinita e a gibsita foram os minerais predominantes na análise mineralógica. Foram detectados picos de vermiculita com hidroxila entre camadas na TE e LR e picos de anatásio, que não sofre ataque do ditionito e é extremamente resistente a tratamentos térmicos em temperaturas entre 350 e $550^{\circ} \mathrm{C}$. A presença de minerais interestratificados parece não ter afetado significativamente as características dos solos, pois os valores de densidade de cargas e CTC permaneceram baixos. As quantidades de caulinita e gibsita da fração argila deferrificada, quantificadas por meio da análise térmica diferencial (ATD) estão na Tabela 8. Houve predomínio de caulinita (argila 1:1) e gibsita 
Tabela 8. Composição mineralógica quantitativa dos horizontes $\mathrm{B}$ dos solos

\begin{tabular}{ccc}
\hline Solo & Caulinita & Gibsita \\
\hline & 570 & 100 \\
TE & 410 & 410 \\
LR & 370 & 320 \\
\hline
\end{tabular}

(hidróxido de alumínio), sendo que, para os Latossolo Roxo e Latossolo variação Una, a presença de gibsita foi mais acentuada (410 e $320 \mathrm{mg} \mathrm{kg} \mathrm{kg}^{-1}$ respectivamente). Isso tem implicações na magnitude das cargas elétricas nesses solos, sobretudo nos horizontes subsuperficiais, onde há redução nos teores de matéria orgânica.

4.5 Curvas e isotermas de adsorção (Etapa 1)

\subsubsection{Curvas de adsorção}

Os resultados obtidos no ensaio de adsorção de cobre nas amostras de terra correspondente ao $\mathrm{pH}$ original dos solos (testemunhas) estão expressos nas Figuras 5, 6 e 7. Os valores encontrados que originaram as curvas de adsorção encontram-se no Apêndice Al. 


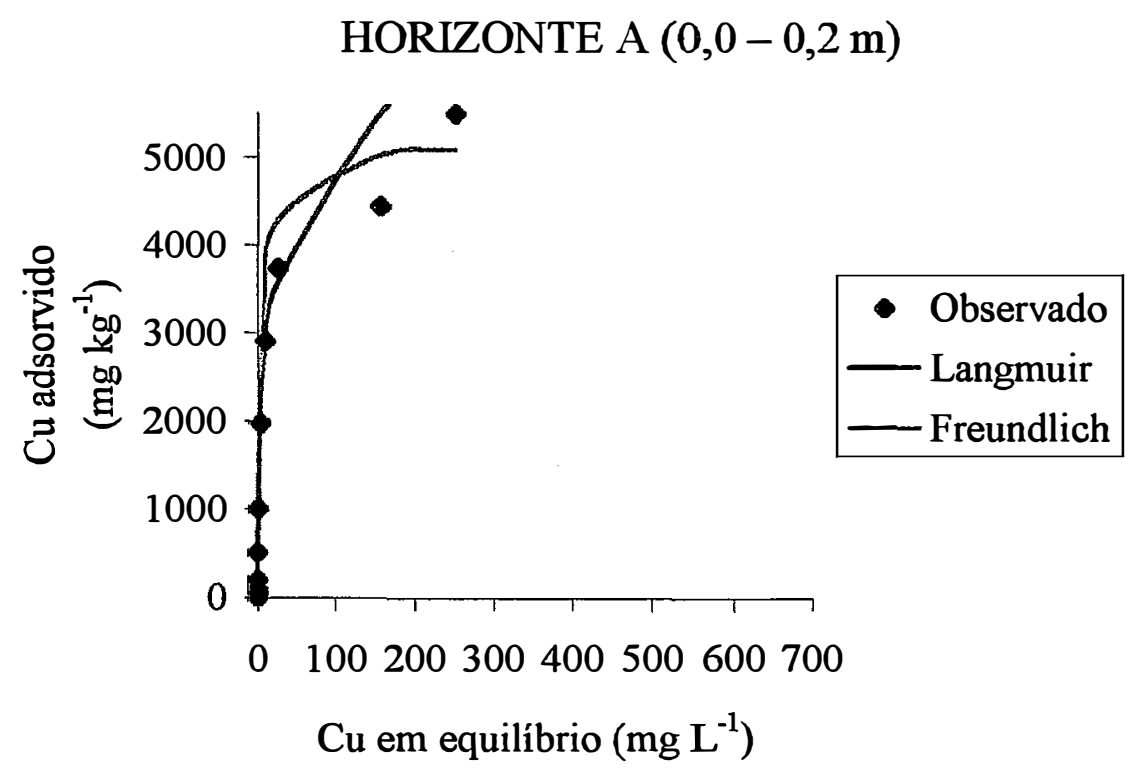

HORIZONTE B $(0,7-0,9 \mathrm{~m})$

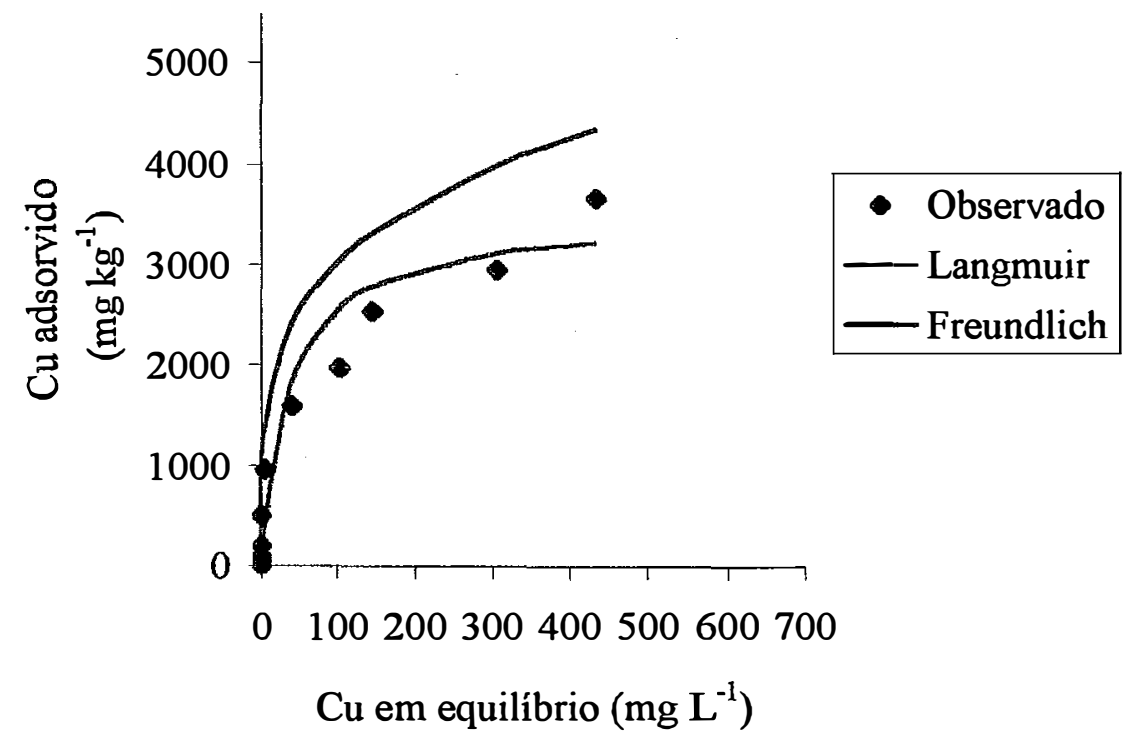

Figura 5. Curvas de adsorção de cobre nos horizontes A e B da Terra Roxa Estruturada. 


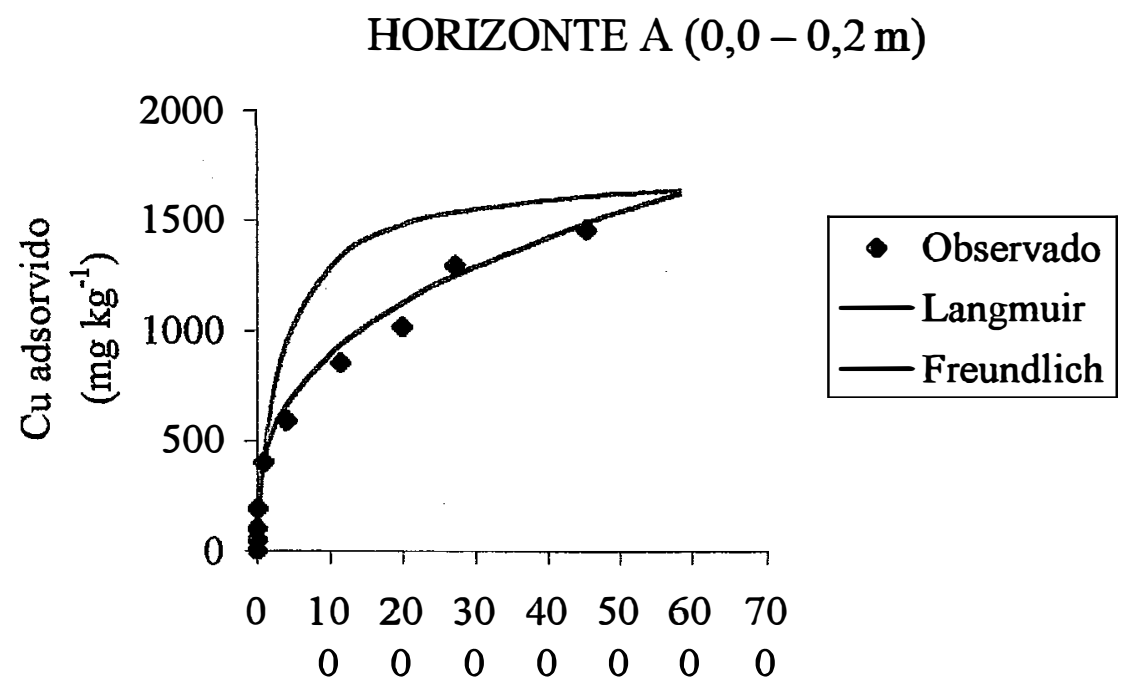

$\mathrm{Cu}$ em equilíbrio $\left(\mathrm{mg} \mathrm{L}^{-1}\right)$

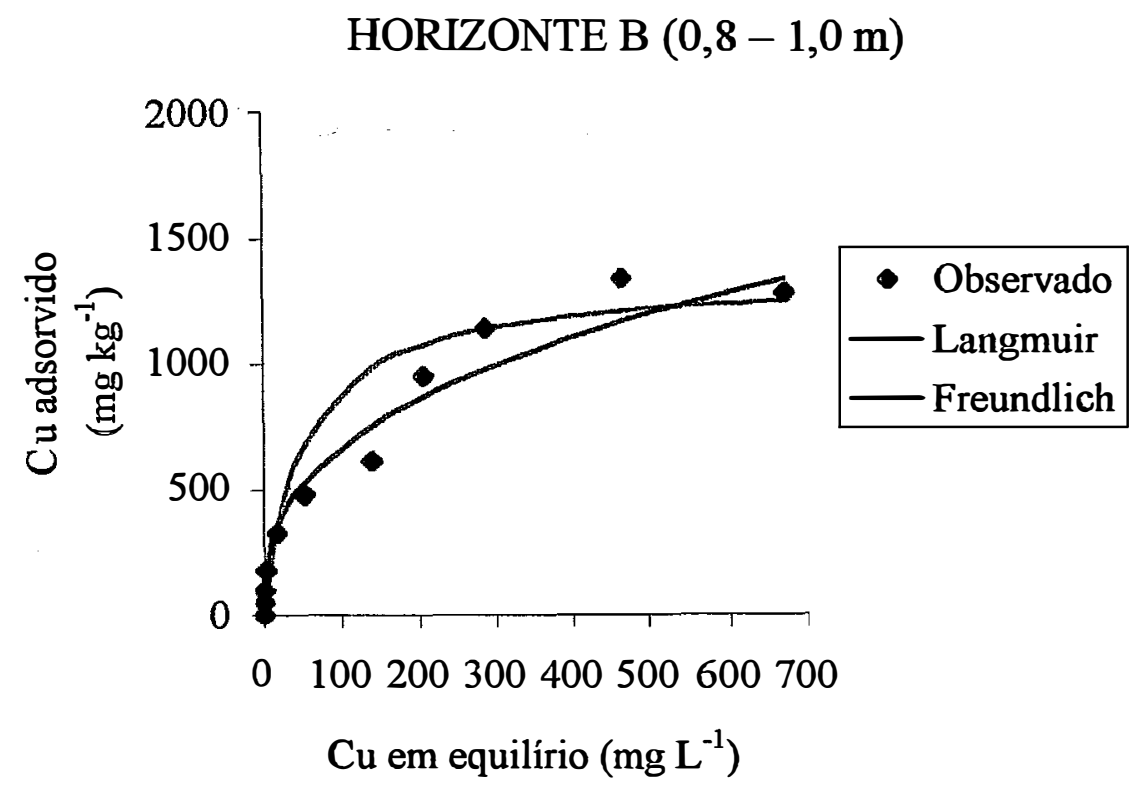

Figura 6. Curvas de adsorção de cobre nos horizontes A e B do Latossolo Roxo. 

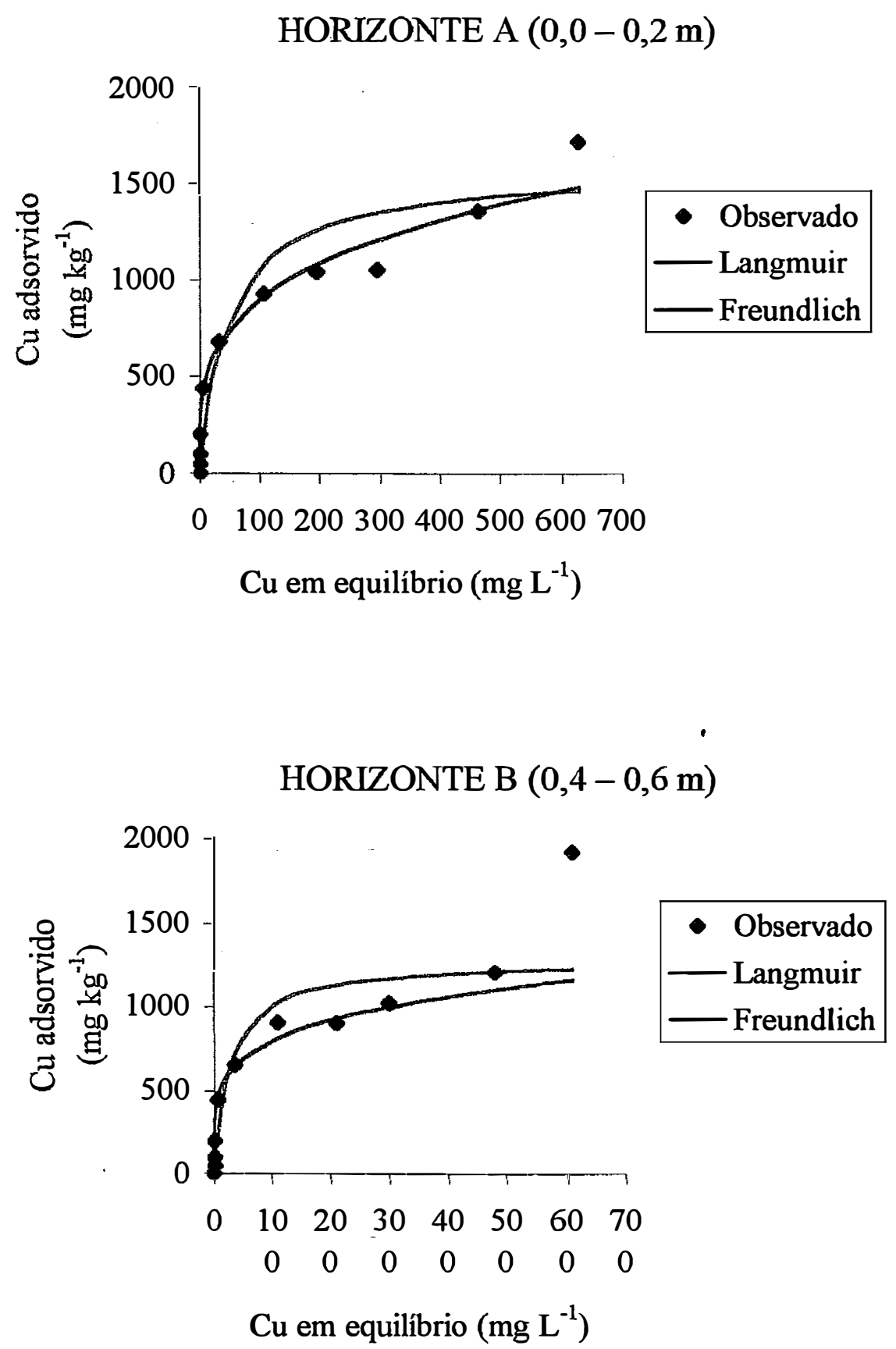

Figura 7. Curvas de adsorção de cobre nos horizontes A e B do Latossolo variação Una 
As quantidades de cobre adsorvidas aumentaram com o aumento da dose adicionada. Nota-se que nas menores quantidades de cobre adicionadas ao solo, foram encontradas as menores concentrações do metal na solução de equilíbrio. Nas concentrações mais baixas de cobre, ou seja, até $20 \mathrm{mg} \mathrm{kg}^{-1}$, para os três solos estudados houve a adsorção de quase toda quantidade adicionada. $\mathrm{Na} \mathrm{TE}$, a adsorção de cobre foi próxima a $98 \%$ até as concentrações de $100 \mathrm{mg} \mathrm{kg}^{-1}$ de cobre. Petruzzelli et al. (1985) notaram que, em baixas concentrações, o cobre tem alta afinidade com as superfícies de adsorção do solo, podendo ser completamente adsorvido. Nesse mesmo estudo, utilizando doses de cobre entre 1 e $10 \mathrm{mg} \mathrm{kg}^{-1}$, a adsorção do metal alcançou a saturação. Considerando a dose máxima de cobre estudada, ou seja $800 \mathrm{mg} \mathrm{kg}^{-1}$, a TE adsorveu maior quantidade do metal, aproximadamente $60 \%$ do total adicionado, enquanto para os Latossolos essa porcentagem foi ao redor de $20 \%$.

Pela inclinação nas curvas de adsorção nota-se que o incremento na adsorção de cobre foi maior nas doses mais baixas do metal, porém a medida que as doses adicionadas aumentaram, o incremento na adsorção foi menos acentuado. Isso pode ter ocorrido, principalmente, pela saturação dos sítios de adsorção. Com o aumento na concentração do metal, mais sítios das superfícies de adsorção do solo são preenchidos e se torna mais difícil para o cobre encontrar sítios disponíveis (Petruzzelli et al., 1985).

Baseado nos resultados das curvas de adsorção de cobre, aplicaram-se os modelos de Freundlich e Langmuir, descritos anteriormente, obtendo-se os seus respectivos parâmetros (Tabela 9).

\subsubsection{Os parâmetros de Langmuir e Freundlich}

Os resultados de adsorção de cobre, para as doses utilizadas, ajustaram-se a ambos os modelos. Os maiores valores de adsorção máxima foram encontrados 
na TE em relação aos Latossolos, sendo que houve diferença entre os horizontes nesse solo.

Tabela 9. Parâmetros obtidos dos modelos de Freundlich e Langmuir.

\begin{tabular}{|c|c|c|c|c|c|}
\hline \multirow[t]{2}{*}{ Solo } & \multirow[t]{2}{*}{ Horizonte } & \multicolumn{2}{|c|}{ Freundlich } & \multicolumn{2}{|c|}{ Langmuir } \\
\hline & & $\mathrm{K}$ & $\mathrm{n}$ & b & $\bar{K}$ \\
\hline \multirow[t]{4}{*}{$\mathrm{TE}$} & Superficie & $1.592,04$ & 0,25 & $5.199,94$ & 0,174 \\
\hline & & $(r=0,99)$ & & $(r=0,99)$ & \\
\hline & Profundidade & 950,65 & 0,25 & $3.505,61$ & 0,026 \\
\hline & & $(r=0,99)$ & & $(r=0,97)$ & \\
\hline \multirow[t]{4}{*}{ LR } & Superficie & 187,87 & 0,34 & $1.733,35$ & 0,029 \\
\hline & & $(r=0,97)$ & & $(r=0,92)$ & \\
\hline & Profundidade & 123,73 & 0,37 & $1.344,51$ & 0,019 \\
\hline & & $(\mathrm{r}=0,99)$ & & $(r=0,96)$ & \\
\hline \multirow[t]{4}{*}{ LU } & Superficie & 255,14 & 0,27 & $1.583,17$ & 0,020 \\
\hline & & $(r=0,98)$ & & $(r=0,95)$ & \\
\hline & Profundidade & 312,25 & 0,20 & $1.268,44$ & 0,037 \\
\hline & & $(\mathrm{r}=0,90)$ & & $(r=0,85)$ & \\
\hline
\end{tabular}

No horizonte superficial da TE, a adsorção máxima foi superior ao horizonte subsuperficial, possivelmente devido ao efeito da matéria orgânica. Resultados semelhantes foram obtidos por Pombo \& Klamt (1986) estudando dois solos (Terra Roxa Estruturada e Podzólico Vermelho-Amarelo) do Rio Grande do Sul. Nesse trabalho, os pesquisadores encontraram os maiores valores de adsorção de cobre na TE e ainda, mais acentuadamente, no horizonte 
superficial. Para os Latossolos, apesar dos menores teores de argila, CTC e óxidos de $\mathrm{Fe}$ e $\mathrm{Al}$ no $\mathrm{LU}$, os valores de adsorção máxima foram próximos ao encontrados para o LR. Isso pode ter ocorrido principalmente pela maior porcentagem de $\mathrm{Al}$ livre em relação ao total no LU, quando comparado a LR (25 \% do total no LU e 13\% do total no LR) (Msaky \& Calvet, 1990).

Os valores dos parâmetros obtidos estão coerentes com os encontrados por Buchter et al. (1989). Esses pesquisadores, estudando onze solos e quinze elementos, observaram que a constante " $n$ " do modelo de Freundlich para o cobre teve seus valores entre 0,47 e 1,420 (média $=0,76$ ), enquanto a constante " $K$ " variou entre 54 e 6.353 (média $=317$ ). $O$ cobre apresentou os maiores valores das constantes do modelo de Freundlich em relação aos demais elementos, indicando a forte retenção do metal e elevada estabilidade. Ainda, os valores da constante " $n$ " tiveram coeficiente de variação próximo a $43 \%$ para o cobre, sendo a maior variação encontrada em relação aos demais elementos estudados.

Observou-se alta correlação entre os parâmetros obtidos das equações de Freundlich e Langmuir e os resultados de adsorção de cobre nos solos estudados (Tabela 9). Concordando com os resultados obtidos, Petruzzelli et al. (1985) encontraram coeficientes de correlação para o modelo de Lagmuir próximos a 0,99. Esses autores observaram que, para o cobre, o modelo de Langmuir se ajustou melhor, enquanto o modelo de Freundlich se mostrou mais adequado para o elemento cádmio. Pombo \& Klamt (1986) trabalhando com doses de cobre entre 0,5 e $34,4 \mathrm{mg} \mathrm{kg}^{-1}$,obtiveram coeficientes de determinação, para o modelo de Langmuir em dois solos, iguais a 0,83 e 0,99, sendo que os maiores valores de adsorção máxima foram encontrados nos horizontes superficiais da TE. Atanassova \& Okazaki (1997), estudando solos com diferentes composições mineralógicas e propriedades físico-químicas, encontraram coeficientes de correlação próximos a 0,96 e 0,99 para as equações de Langmuir e Freundlich, respectivamente, sendo que foram encontrados os maiores valores de adsorção 
máxima nos solos com maior conteúdo de matéria orgânica e óxidos de ferro livres. Yuan \& Lavkulich (1997) encontraram alta correlação entre adsorção de cobre e o parâmetro " $\mathrm{K}$ " do modelo de Freundlich $\left(\mathrm{R}^{2}=0,97\right.$ a 0,99$)$ para diversas amostras de solo. Portanto, pode-se concluir que as informações sugeridas pelos modelos de adsorção são comparáveis e podem ser empregadas para os solos estudados, sobretudo para estimar o comportamento do cobre no sistema.

\subsubsection{Correlações entre os parâmetros e os atributos dos solos}

Os coeficientes de correlação simples entre os parâmetros dos modelos de Langmuir e Freundlich e os atributos do solo estão apresentados no Apêndice A2. Considerando o nível de probabilidade igual a 5\%, a adsorção máxima, ou seja parâmetro "b" do modelo de Langmuir, correlacionou-se mais acentuadamente com o índice ki $(r=0,96)$, CTCtotal $(r=0,89)$,CTCefetiva $(r=0,88)$, óxidos de manganês $(r=0,88)$ e com a S.E. $(r=0,87)$. Ainda, houve correlação com índice $k r$ $(r=0,82)$. Já a constante de afinidade ("K") correlacionou-se com a CTC total $(r=0,83)$, com a CTC efetiva $(r=0,79)$ e com o índice $k i(r=0,83)$. No modelo de Freundlich, o parâmetro empírico " $\mathrm{K}$ " teve maior correlação com o índice ki $(r=0,97)$. Houve correlação estatisticamente significativa também com a S.E. $(r=0,85)$, CTC total $(r=0,83)$, CTC efetiva $(r=0,82)$ e com o índice $k r(r=0,87)$, enquanto que, para o parâmetro "n" não houve correlação simples significativa com nenhum dos atributos dos solos.

Esses resultados demonstram a influência das cargas elétricas do solo nas reações de adsorção do cobre, uma vez que a CTC dos solos foi o principal fator que as influenciou. Resultados semelhantes foram obtidos por Msaky \& Calvet (1990), que observaram maior adsorção de cobre nos solos que possuíam $\mathrm{pH}$ mais distante de seu ponto de carga zero. Basta \& Tabatabai (1992) mostraram que, 
dentre vários metais estudados, a adsorção de cobre foi significativamente correlacionada com a CTC do solo. Alva \& Obreza (1994) também observaram que, para diversos solos estudados, a maior adsorção de cobre ocorreu naqueles que apresentavam maior valor de CTC. Deve-se ressaltar que, embora os fenômenos de sorção de cobre envolvam reações de adsorção específica, as reações de troca iônica podem ocorrer concomitantemente (Guilherme \& Anderson, 1998), sugerindo, portanto, a importância da capacidade de retenção de cátions em ambos os processos. Porém, discordando desses resultados, Sadiq (1981), estudando vinte e sete solos minerais, com características distintas e CTC variando entre 20 - 710 mmol $_{\mathrm{c}} \mathrm{kg}^{-1}$, não encontrou correlação entre a adsorção de cobre e CTC (coeficiente de correlação $=-0,11$, após um dia de agitação das amostras).

As características mineralógicas dos solos, expressas por seus respectivos índices ki e kr demonstraram ter influenciado a adsorção do metal. Por meio da regressão múltipla, observou-se que os índices ki e kr correlacionaram-se principalmente com a CTC efetiva dos solos, apresentando coeficientes de correlação iguais a 0,78 e 0,55 , respectivamente. Por exemplo, a TE, que apresenta maior valor de ki, $\mathrm{kr}$ e consequentemente maior CTC, apresentou maior capacidade de adsorção de cobre em relação aos Latossolos. Portanto, ambos os parâmetros, ou seja, CTC e características mineralógicas se relacionam, afetando a adsorção do metal. A superfície específica, também influenciada pelas características mineralógicas, mostrou ter influenciado a adsorção de cobre, uma vez que as reações físico-químicas processam-se, em grande parte, na superficie dos colóides. Esse resultado difere dos encontrados por Sadiq (1983), que não encontrou correlação entre adsorção de cobre e superfície específica nos solos estudados, obtendo coeficiente de correlação igual a 0,08. Observa-se também que os óxidos de manganês, apesar de presentes em baixas quantidades nos solos estudados, se correlacionaram com a adsorção máxima de cobre. Esses resultados 
estão coerentes com os encontrados por McLaren \& Crawford (1973) e Fu et al. (1991).

Com relação à matéria orgânica, os resultados diferem dos de McLaren \& Crawford (1973), pois, embora tenha ocorrido maior adsorção de cobre no horizonte superficial da TE, essa adsorção de cobre não se correlacionou diretamente com os valores de matéria orgânica, uma vez que seus teores, principalmente para os Latossolos, em profundidade, foram muito baixos, não explicando assim a quantidade do elemento adsorvido nessas condições. Essa mesma conclusão foi obtida por Alva \& Obreza (1994), uma vez que, em solos arenosos, a adsorção de cobre foi maior nos solos com menor conteúdo de matéria orgânica. Cavallaro \& McBride (1984) concluíram que, em baixos valores de $\mathrm{pH}$, os óxidos de ferro e alumínio têm maior efeito na adsorção de cobre do que a matéria orgânica, especialmente nos horizontes subsuperficiais. Sadiq (1981), estudando solos com conteúdos de matéria orgânica entre 2,2 e 42 $\mathrm{g} \mathrm{kg}^{-1}$, não obteve correlação significativa entre a adsorção de cobre e matéria orgânica (coeficiente de correlação $=0,12$ ). Por outro lado, há relatos na literatura de correlações positivas entre teores de matéria orgânica e valores de cobre adsorvido. Em solos com características particulares, como os solos calcáreos, a matéria orgânica foi o principal fator responsável pela adsorção de cobre, apresentando coeficiente de correlação próximo a 0,70 (Singh et al., 1993). Portanto, para os solos estudados nesse trabalho, o teor de matéria orgânica, embora afete a adsorção de cobre, não foi capaz de explicar sua adsorção quando utilizado como característica isolada. Porém, deve-se ressaltar o efeito indireto da matéria orgânica, uma vez que apresenta significativa correlação com a CTC dos solos $(r=0,80)$ e, portanto, influencia suas características adsortivas.

Os resultados de adsorção de cobre não se correlacionaram com os teores de argila dos solos, uma vez que o LU, apesar de seu menor conteúdo de argila, apresentou adsorção de cobre semelhante à do LR. Esse resultado difere do 
encontrado por Mattiazzo-Prezzotto (1994), que propôs que o conteúdo de argila fosse utilizado como parâmetro para prever o comportamento de metais no solo. Porém, deve-se salientar que os resultados obtidos no presente estudo se basearam nas informações de três solos com dois tipos de textura e sem apresentar gradiente textural e, portanto, podem sofrer alterações se considerarmos maior número de solos, como enfocado por Mattiazo-Prezzotto (1994). Pombø \& Klamt (1986) também encontraram correlação significativa entre adsorção de cobre e teor de argila do solo. Os pesquisadores encontraram maior adsorção de cobre no horizonte B de um Podzólico, devido a seu maior conteúdo de argila, em relação ao horizonte superficial.

Deve-se ressaltar que a adsorção de cobre não pode ser caracterizada por uma única constante, uma vez que os atributos do solo estão relacionados, afetando as características adsortivas do solo.

Por meio de regressões múltiplas foram selecionados os atributos dos solos que tinham maior efeito sobre os parâmetros. Os coeficientes de determinação entre os atributos do solo e os parâmetros dos modelos de adsorção encontram-se no Apêndice A3. As equações obtidas ao nível $\alpha=0,05$ foram :

\section{a.) Langmuir}

Adsorção máxima (b) $=15,83$ (CTCefetiva) +11140 (ki) - $14376(\mathrm{kr})-$ 6,14 (argila) - 168,06 (Ferro oxalato) $+2857,30$

$$
\mathrm{R}^{2}=0,96
$$

Constante de afinidade $(\mathrm{K})=-0,0014($ CTCefetiva $)-0,77(\mathbf{k i})+1,33(\mathrm{kr})$ $+0,0013$ (argila) $+0,0078$ (́arbono) $-0,688$

$$
\mathrm{R}^{2}=0,89
$$


b) Freundlich

Constante $\mathrm{K}=-5,62$ (CTCefetiva) $-1959,08(\mathrm{ki})+5006,86(\mathrm{kr})+4,61$ (argila) $+28,21$ (carbono) $+0,018$ (superfície específica) $-3269,31$

$\mathrm{R}^{2}=0,90$

Constante $\mathrm{n}=-0,21(\mathrm{kr})-0,001($ ferro total $)+0,003$ (ferro livre $)-0,0006$ (aluminio total) $+0,41$

$$
\mathrm{R}^{2}=\mathbf{0 , 8 1}
$$

A CTC do solos, os índices ki e kr, além dos teores de argila e carbono apresentam coeficiente de determinação entre 0,80 e 0,96 , sendo os principais fatores que explicam a adsorção de cobre nos solos estudados na análise conjunta.

Apesar dos baixos conteúdos de óxidos de ferro mal cristalizados, estes correlacionaram-se com a adsorção máxima de cobre. Resultados semelhantes foram obtidos por Okazaki et al. (1986), que observaram maior adsorção de cobre nos óxidos de ferro e alumínio com baixa cristalinidade em relação aos bem critalizados. Os óxidos de ferro total e livre e alumínio total influenciaram o parâmetro "n" do modelo de Freundlich, demostrando a importância desses componentes nas reações de adsorção de cobre. Os resultados obtidos estão de acordo com diversos autores que relatam a importância dos óxidos de ferro (Msaky \& Calvet, 1990; Bibak, 1994), porém diferem dos encontrados por Saha et al.(1995) que concluíram, para catorze Alfissolos, que os atributos do solo envolvidos na regressão múltipla para os parâmetros " $b$ " (adsorção máxima do modelo de Langmuir), "K" e " $n$ " do modelo de Freundlich, foram principalmente o pH do solo e o carbono orgânico, apresentando coeficientes de determinação para equação de regressão iguais a 0,$83 ; 0,86$ e 0,62 , respectivamente. Nota-se que as constantes " $\mathrm{K}$ " de ambos os modelos, que indicam a afinidade do metal pelos sítios de adsorção, correlacionaram-se com os mesmos atributos, ou seja, 
CTC efetiva, índices ki e kr, argila e carbono. Esses atributos foram responsáveis por grande parte da variação nas constantes de afinidade, apresentando coeficiente de determinação próximo a 0,90.

Com os resultados obtidos e as informações presentes na literatura, podese observar que, dependendo das características dos solos estudados, os efeitos de determinado atributo do solo influenciam as reações de adsorção de cobre em diferentes intensidades. Para os solos tropicais altamente intemperizados, como os solos ácricos, sugere-se que a CTC e as características mineralógicas (índices ki, kr e óxidos de $\mathrm{Fe}$ e Alf foram os atributos do solo que mais bem se correlacionaram com os parâmetros obtidos. A importância do balanço de cargas do solo na adsorção do metal é reportada por diversos autores na literatura, sobretudo nos solos com características de cargas variáveis. Porém, os demais atributos destacados anteriormente estão correlacionados e influenciam no balanço de cargas do solo.

\subsection{Energia livre das reações de cobre $\left(\Delta \mathrm{G}_{0}\right)$}

Os resultados de $\Delta \mathrm{G}_{\mathrm{o}}$ estão apresentados na Figura 8. Os resultados que originaram as curvas encontram-se no Apêndice A4.

Nas doses de cobre variando entre 5 a $800 \mathrm{mg} \mathrm{kg}^{-1}$, os valores de $\Delta \mathrm{G}^{0}$ diminuíram com o aumento na concentração do metal. Para o mesmo solo, o horizonte superficial apresentou maiores valores $\Delta \mathrm{G}_{\mathrm{o}}$ em relação ao horizonte subsuperficial, exceto para o LU que, nas doses 10 e $20 \mathrm{mg} \mathrm{kg}^{-1}$ apresentou maior valor de energia livre em profundidade. Esses resultados concordam com as informações de literatura que, em baixas concentrações, o cobre forma ligações de alta estabilidade com a superfície dos colóides (Sparks, 1995) e afinidade do elemento pela matéria orgânica. Ainda, a medida que os sítios de adsorção vão se 
TE
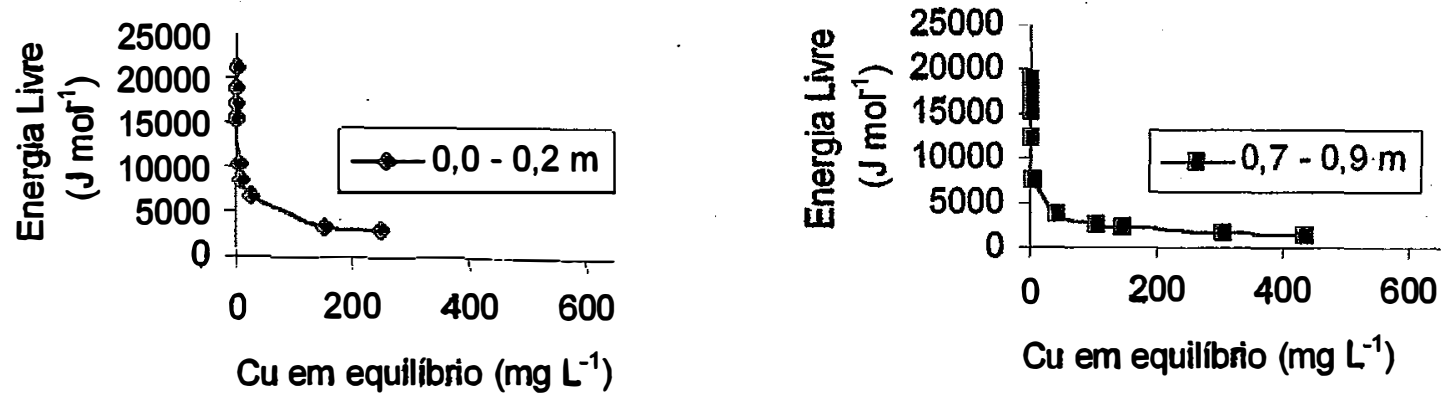

$\mathbf{L R}$
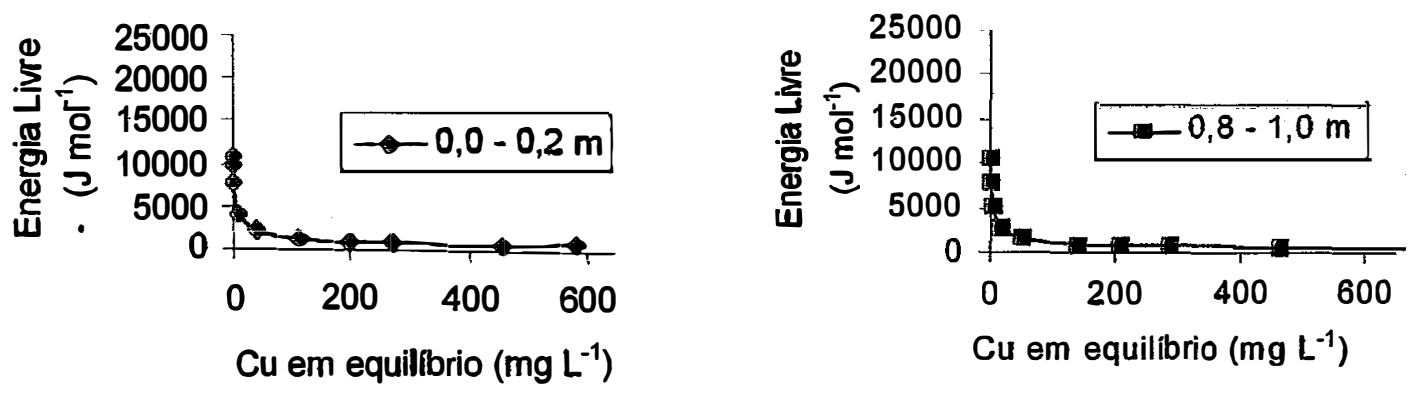

LU
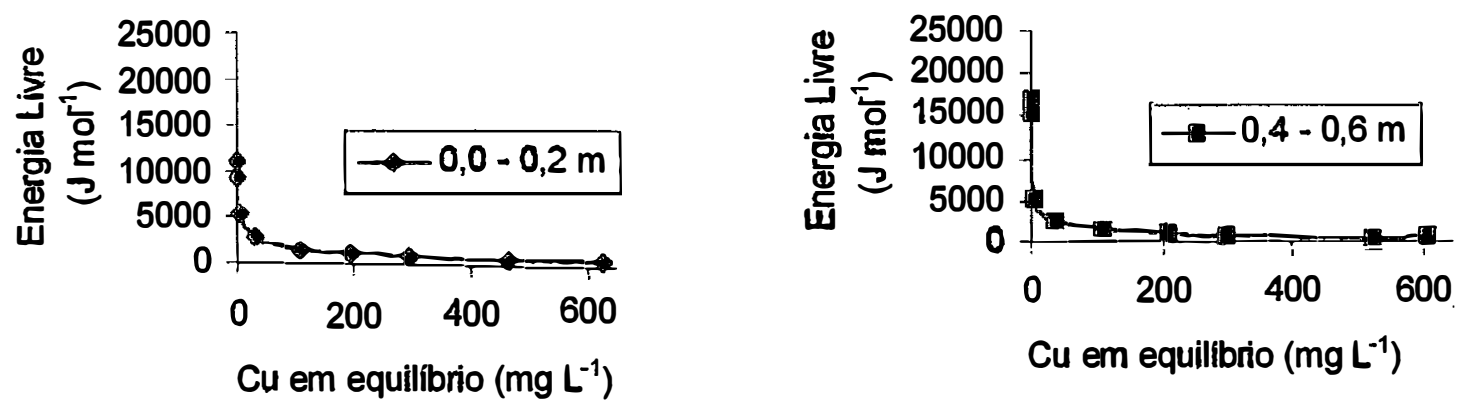

Figura 8. Valores de energia livre (em módulo) das reações de adsorção de cobre. 
saturando, diminui a capacidade do solo em reter o metal (Petruzzelli et al., 1985). No horizonte subsuperficial do LU, devido à predominância da fração mineral, principalmente gibsita, a afinidade do complexo de troca pode ter sido superior a baixas concentrações do elemento, do que os horizontes superficiais. Em média, a TE apresentou maiores valores de $\Delta G_{0}$, devido sua textura e conteúdos de óxidos de ferro e alumínio. Já os Latossolos não diferiram entre si. Para os três solos estudados, pode se considerar que as reações de adsorção são espontâneas, uma vez que a energia livre teve sinal negativo em todas as concentrações do elemento. Esses resultados foram semelhantes aos encontrados por Alleoni \& Camargo (1998) para adsorção de boro. Os autores observaram valores de $\Delta G_{o}$ negativos para as reações de adsorção de boro nos solos estudados, sendo que os maiores valores foram encontrados em superfície, principalmente nos solos argilosos.

4.7 Efeito da variação do $\mathrm{pH}$ na adsorção de cobre (Etapa 2)

Fundamentado nos resultados do ensaio inicial (Etapa 1), a dose de $100 \mathrm{mg}$ $\mathrm{kg}^{-1}$ de cobre foi escolhida para avaliar o efeito da variação do $\mathrm{pH}$ do solo na adsorção do metal. Adotou-se essa dose de cobre, pois concentrações de cobre inferiores resultaram em quase cem por cento na adsorção do metal, notadamente na TE. Sabe-se que, nessa concentração e nos valores de $\mathrm{pH}$ estudados, não há precipitação do elemento (Gomes et al., 1997). A dose de $100 \mathrm{mg} \mathrm{kg}^{-1}$ de cobre foi adotada no trabalho de Brümmer \& Herms (1983), que estudaram o efeito do $\mathrm{pH}$ do solo na mobilidade do metal. Nessa etapa, foram utilizadas as amostras de terra incubadas com $\mathrm{CaCO}_{3} \mathrm{e} \mathrm{HCl}$, cuja metodologia foi descrita anteriormente.

Os resultados obtidos encontram-se na Figura 9. Os dados que originaram as curvas se encontram detalhados no Apêndice A5. 


\section{Superficie}

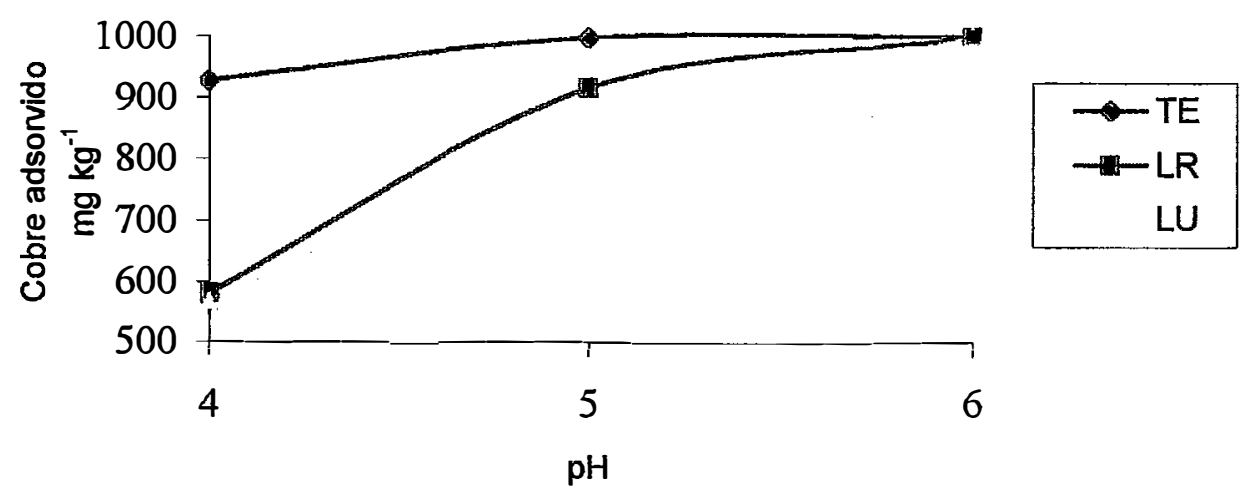

\section{Profundidade}

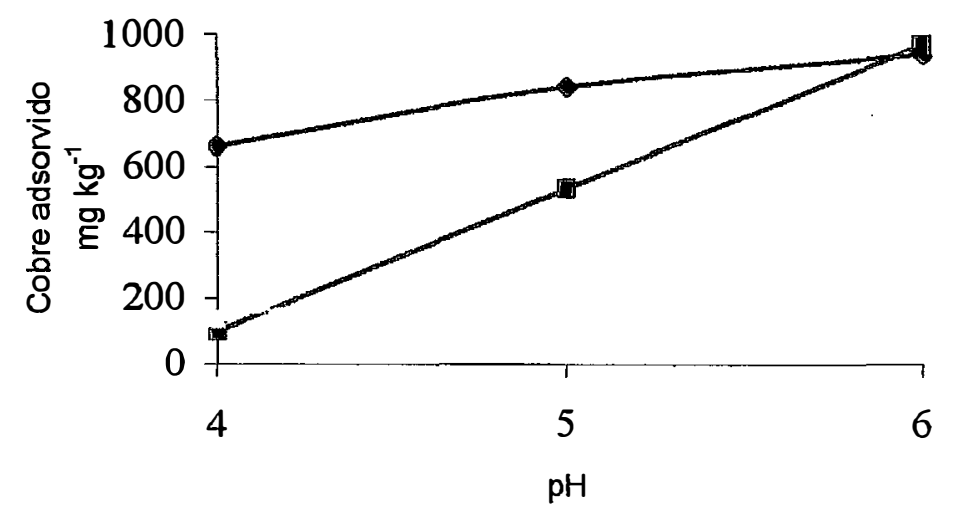

Figura 9. Adsorção de cobre em diferentes valores de $\mathrm{pH}$, após adição de $100 \mathrm{mg} \mathrm{kg}^{-1}$ do elemento.

Houve efeito da interação (solo ${ }^{*}$ profundidade $* \mathrm{pH}$ ) na adsorção de cobre, pois a probabilidade associada ao valor $\mathrm{F}$ foi altamente significativa (Apêndice A5). Considerando cada solo individualmente, houve diferenças na adsorção de cobre entre os horizontes superficial e subsuperficial. Nos horizontes superficiais, houve maior adsorção do metal, para os três solos. Esses resultados 
estão coerentes com os encontrados na literatura e sustentam o conceito da afinidade do cobre pela matéria orgânica. Os mesmos resultados foram observados por Guilherme \& Anderson (1997), utilizando Latossolos com características semelhantes às deste estudo. Esses autores encontraram maior adsorção de cobre nos horizontes A desses solos. Ainda, nos horizontes superficiais, devido à sua maior CTC, houve maior adsorção do metal. Pombo \& Klamt (1986) encontraram maior adsorção de cobre nos horizontes superficiais dos solos, devido ao maior conteúdo de matéria orgânica e CTC. Observa-se que, considerando os horizontes superficial e subsuperficial, a adsorção de cobre segue a distribuição dos conteúdos de matéria orgânica e CTC (Kuo \& Baker, 1980). Porém, dependendo do conteúdo e o tipo de matéria orgânica, a influência do $\mathrm{pH}$ na concentração de cobre em solução é modificada (Brümmer \& Herms, 1983). Em solos com baixo conteúdo de matéria orgânica, a concentração de cobre em solução sofre ligeiro aumento com a elevação do $\mathrm{pH}$ do solo de condições neutras para alcalinas. Já em solos com maior conteúdo de matéria orgânica, o mesmo comportamento ocorre, porém em menor intensidade (Brümmer \& Herms, 1983).

Para um mesmo solo, após o aumento do $\mathrm{pH}$, houve correspondente aumento na adsorção de cobre, exceto para o horizonte superficial da TE, no qual não houve diferença na adsorção de cobre nos valores de $\mathrm{pH} 5$ e 6 . Os resultados obtidos nesse experimento são semelhantes aos encontrados por diversos autores (Duquete \& Hendershot, 1990; Msaky \& Calvet, 1990; Basta \& Tabatabai, 1992; Alva \& Obreza 1994; Pombo, 1997). Duquete \& Hendershot (1990) encontraram os maiores valores de adsorção de cobre em seis solos estudados, quando o pH foi igual ou superior a 5,0, sendo que, para valores inferiores, houve acentuado decréscimo na adsorção do metal. Para pH igual a 5,0, os autores encontraram que $90-100 \%$ da quantidade do cobre aplicado estava adsorvido. Possivelmente, o mesmo deve ter ocorrido para a TE deste trabalho, uma vez que nos valores de pH 5,0 e 6,0 a quantidade adsorvida de cobre foi semelhante. Kuo \& Baker 
(1980) encontraram os maiores valores de adsorção de cobre e, consequentemente, menor concentração de equilíbrio, quando o $\mathrm{pH}$ foi próximo a 6,0. Para uma faixa de $\mathrm{pH}$ entre 4,4 e 6,3, Pombo (1997) encontrou correspondente aumento na adsorção de cobre com o aumento do $\mathrm{pH}$, devido principalmente às cargas dependentes do $\mathrm{pH}$ dos argilominerais, óxidos hidratados e matéria orgânica.

Os resultados obtidos demonstram que a adsorção de cobre ocorre mesmo quando o pH da solução encontra-se abaixo do PESN. Se considerarmos os horizontes subsuperficiais dos Latossolos, onde há predomínio de cargas positivas, a adsorção de cobre foi significativa. No valor de $\mathrm{pH}$ igual a 5,0, o LR adsorveu, nos horizontes A e B, respectivamente, 91 e $53 \%$ do total de cobre adicionado, enquanto para o LU as quantidades adsorvidas foram iguais a $86 \mathrm{e}$ $32 \%$. Com isso, observa-se que não apenas mecanismos de adsorção eletrostática estão envolvidos, uma vez que, nessas condições, há repulsão entre as cargas positivas da superficie dos colóides e o cobre. Sugere-se que mecanismos de adsorção específica são os responsáveis pelas reações de adsorção. Comportamento semelhante foi evidenciado por Kuo \& Baker (1980), que estudaram o efeito da variação do $\mathrm{pH}$ na adsorção de cobre, considerando valores de $\mathrm{pH}$ abaixo do ponto de carga zero dos solos estudados.

$\mathrm{O}$ aumento na adsorção de cobre com o aumento do $\mathrm{pH}$ pode ser explicado pelo efeito em diversos fatores, dentre eles, no aumento na CTC do solo (Duquette \& Hendershot, 1990). Com o aumento do $\mathrm{pH}$ pode haver o deslocamento do equilíbrio das reações de complexação e variação na especiação do metal (Msaky \& Calvet, 1990). Em baixos valores de $\mathrm{pH}$, em solos com elevados teores de alumínio, esse íon pode competir pelos sítos de troca. Portanto, com o aumento do $\mathrm{pH}$ pode haver correspondente aumento na afinidade dos solos pela adsorção de cobre (Zhu \& Alva, 1993). Porém, elevando-se o pH para valores superiores a 6,0, o comportamento do metal pode ser alterado. Brümmer 
\& Herms (1983) observaram que, em solos com elevado conteúdo de matéria orgânica, valores de $\mathrm{pH}$ superiores a 6,0 ou 7,0 podem favorecer a formação de complexos orgânicos solúveis com cobre e, consequentemente, aumentar a concentração do metal na solução. Corroborando com essas informações, McLaren et al. (1983) observaram que a adsorção de cobre diminuiu em valores de $\mathrm{pH}$ inferiores a 4,5 e superiores a 6,5. Segundo os autores, a diminuição na adsorção de cobre nos valores de $\mathrm{pH}$ mais elevados foi devido ao aumento na solubilidade da matéria orgânica, resultando na formação de complexos solúveis com o cobre, porém não indicando que houve correspondente aumento na disponibilidade do metal. Ainda, Davis (1984) observou que a adsorção de cobre foi aumentada em valores de $\mathrm{pH}$ entre 4,5 e 6,4. Porém, para a faixa de $\mathrm{pH}$ estudada, com o aumento do $\mathrm{pH}$ não houve aumento na concentração de cobre em solução, seguido de redução na sua adsorção. Abd-Elfattah (1981), estudando onze solos, ao pH natural e saturados com cálció $\mathrm{pH} 7,0$, notou que a saturação com cálcio aumentou a quantidade de cobre adsorvida e também a afinidade do solo em retê-lo. Esse comportamento foi representado da seguinte forma, sendo que $\mathrm{Ca}^{2+}$ e $^{2+}$ representam espécies hidratadas e $\mathrm{M}$, espécie desidratada :

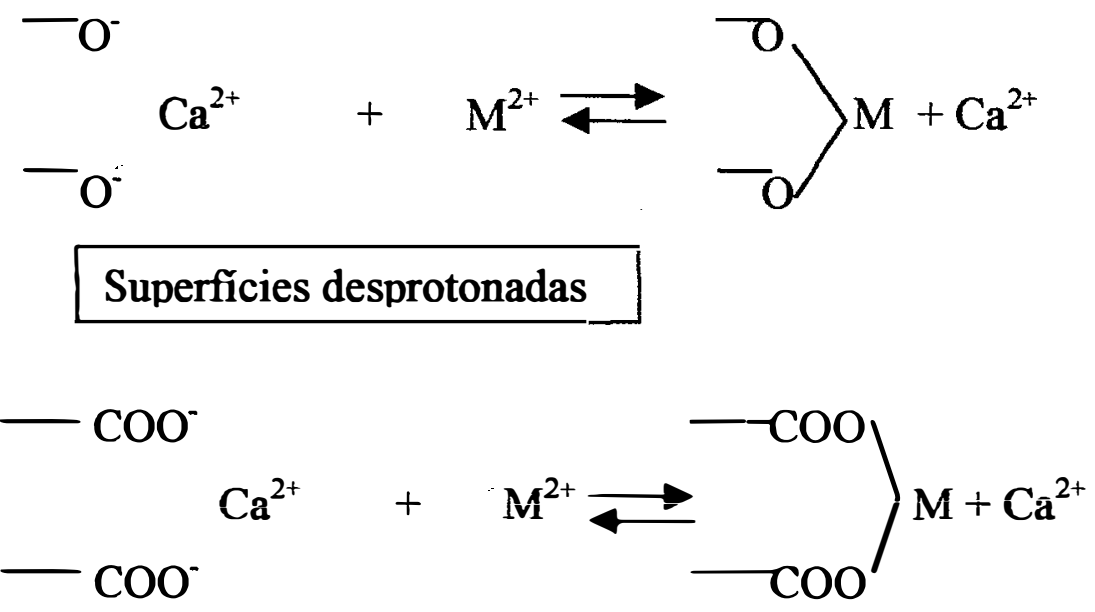

Grupos funcionais da matéria orgânica 
Reações semelhantes podem ter ocorrido nos solos estudados no presente trabalho, uma vez que a elevação do $\mathrm{pH}$ foi realizada utilizando-se carbonato de cálcio. Além do efeito direto do cálcio no deslocamento dos íons $\mathrm{H}^{+}$há, concomitantemente, a desprotonação das superficies dos óxidos, sílica e grupos funcionais da matéria orgânica, resultando na geração de sítios com elevada seletividade pelo cobre (Abd-Elfattah, 1981). Essas conclusões podem ser importantes, pois têm implicações nos efeitos de práticas de manejo, tais como a calagem, na retenção e disponibilidade de cobre nos solos. Discordando dessas informações, Petruzzelli et al. (1985) notaram que a medida que se aumentou a força iônica da solução $\left(0,005 \mathrm{~mol} \mathrm{~L}^{-1}\right.$ para $0,05 \mathrm{~mol} \mathrm{~L}^{-1}$ de $\left.\mathrm{CaCl}_{2}\right)$, a adsorção de cobre foi diminuída, devido principalmente ao efeito competitivo do cálcio e formação de complexos estáveis com o íon $\mathrm{Cl}^{-}$. Boon (1987), estudando a adsorção de cobre em um solo com $\mathrm{pH}$ igual a 4,7 e textura arenosa, observou que na presença de $0,1 \mathrm{~mol} \mathrm{~L}^{-1}$ de $\mathrm{CaCl}_{2}$, a adsorção do metal foi diminuída, porém em menor intensidade do que esperado, sugerindo que, apesar da elevada concentração de cálcio em solução e saturação da CTC com esse elemento, o cobre foi adsorvido em sítios específicos, que tinham preferência pelo metal.

Entre os três solos estudados, considerando os três valores de $\mathrm{pH}$, não houve diferenças na adsorção de cobre nos horizontes superficiais. Em valores de pH elevado, a concentração de cobre em solução é reduzida, sendo que as diferenças entre solos de classes texturais e conteúdos de argila diferentes tende a ser minimizada (Brümmer \& Herms, 1983). Embora a TE tenha adsorvido mais cobre em determinado $\mathrm{pH}$, quando consideramos os três valores de $\mathrm{pH}$ estudados, a quantidade total adsorvida no horizonte superficial não diferiu estatisticamente dos Latossolos. Porém nos horizontes subsuperficiais, a adsorção de cobre na TE não diferiu estatisticamente do LR, mas foi maior do que no LU. Com relação ao $\mathrm{pH}$, considerando seu valor igual a 4,0, a TE apresentou adsorção em superficie e em subsuperficie superior aos Latossolos, que por sua vez não diferiram entre si. 
Ao pH 6,0, os horizontes superficiais dos três solos não apresentaram diferenças, porém, em subsuperfície, o LR apresentou maiores valores de adsorção, seguido da TE e do LU. Com relação aos Latossolos, os resultados obtidos diferem dos encontrados por McKenzie (1980), pois apesar do maior conteúdo de goetita no LU, as quantidades de cobre adsorvidas foram semelhantes para ambos os solos.

$\mathrm{O}$ balanço de cargas provavelmente foi o principal fator que contribuiu no aumento da adsorção de cobre com o aumento do pH. Resultados semelhantes foram obtidos por Kuo \& Baker (1983), que concluíram que a CTC do solo foi um importante fator que regulou a adsorção de cobre no solo. Buchter et al. (1989) observaram alta correlação entre pH e CTC dos solos com a adsorção de cobre. Considerando as cáracterísticas mineralógicas dos solos estudados, com possibilidade de reversão no balanço de cargas e os elevados valores do PESN, sobretudo em subsuperfície, o aumento do $\mathrm{pH}$ proporcionou geração de cargas negativas e consequente aumento na capacidade adsortiva do solo (Msaky \& Calvet, 1990). Salam \& Helmke (1990) observaram que a atividade de cobre em solução foi diminuída com o aumento do $\mathrm{pH}$, dentro de uma faixa de variação de 4,0 a 7,0, devido principalmente à geração de cargas negativas no solo, o que resultou em aumento na adsorção e complexação do metal.

Dependendo das características dos solos, tais como $\mathrm{pH}$, mineralogia, conteúdos de argila e matéria orgânica, esses atributos influenciam de maneira diferenciada a adsorção de cobre. Para compreender os mecanismos de adsorção do metal é necessário considerar a relação entre as diversas propriedades do solo. 


\section{CONCLUSÕES}

Baseado nos resultados, pode-se concluir que :

A Terra Roxa Estruturada apresentou maior capacidade de adsorção de cobre, se comparada com o Latossolo Roxo e Latossolo variação Una, porém elevando-se o $\mathrm{pH}$ desses solos para valores próximos a 6,0 as quantidades adsorvidas do elemento pelos solos são semelhantes, sendo que os horizontes superficiais adsorveram maiores quantidades de cobre em relação aos horizontes superficiais, evidenciando a influência da matéria orgânica na reação de adsorção do metal.

O balanço de cargas do solo, influenciado pelos teores de matéria orgânica e argila, e as características mineralógicas, principalmente óxidos e hidróxidos de ferro e alumínio, foram os fatores mais importantes nas reações de adsorção para os solos ácricos. 


\section{REFERÊNCIAS BIBLIOGRÁFICAS}

ABD-ELFATTAH, A.; WADA, K. Adsorption of lead, copper, zinc, cobalt and cadmium by soils that differ in cation-exchange materials. Journal of Soil Science, v.32, p.271-283, 1981 .

ALLEONI, L.R.F. Atributos eletroquímicos de solos ácricos do norte paulista. Piracicaba, 1992. 123p. Dissertação (Mestrado) - Escola Superior de Agricultura “Luiz de Queiroz", Universidade de São Paụlo.

ALLEONI, L.R.F. Adsorção de boro em Podzólicos e latossolos Paulistas. Piracicaba, 1996. 127p. Tese (Doutorado) - Escola Superior de Agricultura "Luiz de Queiroz", Universidade de São Paulo.

ALLEONI, L.R.F.; CAMARGO, O.A. Atributos físicos de Latossolos ácricos do norte paulista. Scientia Agricola, v.51, p. 321-326, 1994a.

ALLEONI, L.R.F.; CAMARGO, O.A. Pontos de efeito salino nulo de Latossolos ácricos. Revista Brasileira de Ciência do Solo, v.18, p. 175-180, 1994 b.

ALLEONI, L.R.F.; CAMARGO, O.A. Solos ácricos : atributos e manejo. Boletim Informativo da Sociedade Brasileira de Ciência do Solo, v.20, p. 9-17, 1995. 
ALLEONI, L.R.F.; CAMARGO, O.A. Energia livre das reações de adsorção de boro em solos. Revista de Agricultura, v.73, p.319-330, 1998.

ALVA, A.K.; OBREZA, T.A. Reactions of copper and sulfate in sandy soils under citrus grove an uncultivated condictions. Journal of Soil Science, v.158, p.56-64, 1994.

AMARAL SOBRINHO, N. M. B. Metais pesados em solos brasileiros. In : ALVAREZ, V. H.; FONTES, L.E.F.; FONTES, M. P. (Ed.) 0 solo nos grandes domínios morfoclimáticos do Brasil. Viçosa: Socidade Brasileira de Ciência do Solo. 1996, p. 837 - 853.

AMARAL SOBRINHO, N.M.B.; VELLOSO, A.C.X.; OLIVEIRA, C. DE. Solubilidade de metais pesados em solo ratado com resíduo siderúrgico. Revista Brasileira de Ciência do Solo, v.21, p.9-21, 1997.

ATANASSOVA, I.; OKAZAKI, M. Adsorption-desorption characteristics of high levels of copper in soil clay fractions. Water Air and Soil Pollution, v.98, p.213-228, 1997.

BARROW, N.J.; BOWDEN, J.W.; POSNER, A.M.; QUIRK, J.P. Describing the adsorption of copper, zinc and lead on a variable change mineral surface. Australian Journal of Soil Research, v.19, p.309-321, 1981.

BARROW, N.J. Reactions of anions and cations with variable-charge soils. Advances in Agronomy, v.38, p.183-229, 1985. 
BASTA, N.T.; TABATABAI, M.A. Effect of cropping systems on adsorption of metals by soils : III. Competitive adsorption. Soil Science Society of America Journal, v.153, p.331-336, 1992.

BIBAK, A. Cobalt, copper and manganese adsorption by aluminium and iron oxides and humic acid. Communications in Soil Science and Plant Analysis, v.25, p.3229$3239,1994$.

BLEAM, W.F.; McBRIDE, M.B. The chemistry of adsorbed $\mathrm{Cu}$ (II) and $\mathrm{Mn}$ (II) in aqueous titanium dioxide suspensions. Journal of Colloid Interface Science, v.110, p.335-346, 1986.

BOO, J.A. Adsorcion de cobre em un suelo franco-arenoso de sabana. Agronomia Tropical, v.26, p.367-382, 1987.

BORAH, D.K.; RATTAN, R.K.; BANERJEE, N.K. Effect of soil organic matter on the adsorption of $\mathrm{Zn}, \mathrm{Cu}$ and $\mathrm{Mn}$ in soils. Journal of Indian Society of Soil Science, v.40, p.277-282, 1992.

BOURG, A.C.M.; SCHINDLER, P.W. Effect of ethylendiamine-tetraacetic acid on the adsorption of copper (II) at amorphous silica. Inorganic and Nuclear Chemistry Letters, v.15, p.225-229, 1979.

BOWMAN, R.S.; ESSINGTON, M.E.; O'CONNOR, G.A. Soil adsorption of Ni: influence of soil solution composition. Soil Science Society of America Journal, v.45, p.860-865, 1981 . 
BRADY, N.C. Natureza e propriedade dos solos. Rio de Janeiro: Freitas Bastos, 1989. 898p.

BRIDGES, E.M. Toxic metals in amenity soil. Soil Use and Management, v.5, p.91$100,1989$.

BRÜMMER, G.; TILLER, K.G.; HERMS, V.; CLAYTON, P.M. Adsorption-desorption and/or precipitation-dissolution process of zinc in soils. Geoderma, v.31, p.337$357,1983$.

BUCHTER, B.; DAVIDOFF, B.; AMACHER, M.C.; HINZ, C.; ISKANDAR, I.K.; SELIM, H.M. Correlation of Freundlich Kd e $\mathrm{n}$ retention parameters with soils and elements. Soil Science, v. 148, p.370-379, 1989.

BURAU, R.F. Sorption of heavy metals by lhydrous M.O. Geochimica et Cosmochimica Acta, v.37, p.1277-1293, 1973.

CAMARGO, O. A. Complexos de metais pesados com substâncis húmicas e matéria orgânica : estabilidade das ligações. In: ENCONTRO BRASILEIRO DE SUBSTÂNCIAS HÚMICAS, 2., São Carlos, 1997. Anais. São Carlos:EMBRAPA, CNPDIA, 1997. p. 72-73.

CAMARGO, O.A.; VALADARES, J.M.A.S.; DECHEN, A.R. Efeitos do pH e da incubação na extração do manganês, zinco, cobre e ferro do solo. Revista Brasileira de Ciência do Solo, v.6, p.83-88, 1982. 
CAMARGO, O.A.; MONIZ, A.C.; JORGE, J.A.; VALADARES, J.M.A.S. Métodos de análise química, mineralógica e física de solos do IAC. Campinas: IAC, 1986. $94 \mathrm{p}$.

CAVALLARO, N.; McBRIDE, M.B. Zinc and copper sorption and fixation by an acid soil clay: effect of selective dissolution. Soil Science Society of America Journal, v.48, p.1050-1054, 1984.

CIHACEK, J.L.; BREMNER, J.M. A simplified ethylene glycolmonoethyl procedure for assesment of soil surface area. Soil Science Society of America Journal, v.43, p.821-822, 1979.

CLARK, C.J.; McBRIDE, M.B. Chemisorption of $\mathrm{Cu}$ (II) and Co (II) on allophane and inogolite. Clays and Clay Minerals, v.32, p.300-310, 1984.

COTTON, F.A.; WILKINSON, G. Advanced inorganic chemistry. New York: Interscience, 1972. $1145 \mathrm{p}$.

COUTINHO, E.L.M.; GROVE, J.H. Distribuição de cobre, manganês e zinco em frações do solo (compact disc). In: CONGRESSO BRASILEIRO DE CIÊNCIA DO SOLO, 26., Rio de Janeiro, 1997. Anais. Rio de Janeiro:EMBRAPA, CNPS; SBCS, 1997.

COX, D.P. The distribution of copper in common rocks and ore deposits. In: NRIGU, J.O. (Ed.) Copper in the environment. Part I: Ecological cycling. New York:John Wiley, 1979. p.19-41. 
DAVIES, J.A.; LECKIE, J.O. Effect of adsorbed complexing ligands on trace metal uptake by hydrous oxides. Environmental Science Technology, v.12, p.1309-1315, 1978.

DAVIS, J.A. Complexation of trace metals by adsorbed natural organic matter. Geochimica et Cosmochimica Acta, v. 48, p.679-691, 1984.

DUQUETTE, M.; HENDERSHOT, W.H. Copper an zinc on some B horizons of Quebec soils. Communications in Soil Science and Plant Analysis, v.21, p.377394, 1990.

ELLIOT, H.A.; HUANG, C.P. The effect of complex formation on the adsorption characteristics of heavy metals. Environmental International, v.2, p.145-155, 1979.

ELLIS, B.G.; KNEZEK, B.D. Adsorptions reactions of micronutrients in soils. In: DINAUER, R.C. Micronutrients in agriculture. Madison: ASA;SSSA, 1977. $566 \mathrm{p}$.

EL SAYED, M.H.; BURAU, R.G.; BABCOCK, K.L. Thermodnamic of copper (II)calcium exchange on bentonite clay. Soil Science Society of America Proceedings, v.34, p.397-400, 1970.

FAO. Soil map of the world. Wageningem: ISRIC, 1989. 138p. (FAO.UNESCO. Technical Paper, 20).

FERREIRA, M.E.; CRUZ, M.C.P. Micronutrientes na agricultura. Piracicaba:POTAFOS; CNPq, 1991.734p. 
FORBES, E.A.; POSNER, A.M.; QUIRK, J.P. The specific adsorption of divalent Cd, $\mathrm{Co}, \mathrm{Cu}, \mathrm{Pb}$, and $\mathrm{Zn}$ on goethite. Journal of Soil Science, v.27, p.154-166, 1976.

FU, G.; ALLEN, H.E.; COWAN, C.E. Adsorption of cadmium and copper by manganese oxide. Soil Science, v.152, p.72-81, 1991.

GARCIA-MIRAGAYA, J.; PAGE, A.L. Influence of ionic strenght and inorganic complex formation on the sorption of trace amounts of $\mathrm{Cd}$ by montmorilonite. Soil Science Society of America Journal, v.40, p.658-663, 1976.

GOMES, P.C.; FONTES, M.P.F.; COSTA, L.M.; MENDONÇA E.S. Extração fracionada de metais em Latossolo Vermelho-Amarelo. Revista Brasileira de Ciência do Solo, v.21, p.543-551, 1997.

GUILHERME, L.R.G.; LIMA, J.M.; ANDERSON, S.J. Efeito do fósforo na adsorção de cobre em horizontes A e B de latossolos do estado de Minas Gerais. In : CONGRESSO BRASILEIRO DE CIÊNCIA DO SOLO, 25., Viçosa, 1995. Anais. Viçosa: UFV;SBCS, 1995. p. 316-318.

GUILHERME, L.R.G.; ANDERSON, S.J. Cinética de dessorção de $\mathrm{Cu}$ em latossolos : efeito do tempo de contato durante a adsorção (compact disc). In: CONGRESSO BRASILEIRO DE CIÊNCIA DO SOLO, 26., Rio de Janeiro, 1997. Anais. Rio de Janeiro:EMBRAPA, CNPS;SBCS, 1997.

GUILHERME, L.R.G.; ANDERSON, S.J. Copper sorption kinetics and sorption hysteresis in two oxide-rich soils (Oxisols). In: VENNE, E.A. (Ed). Adsorption of metals by geomedia : variables, mechanisms and model applications. Academic Press, San Diego: 1998. cap.9, p. 209-228. 
HEILMAN, M.D.; CARTER, D.L.; GONZALES, C.L. The ethylene glycol monoethyl ether technique for determining soil surface area. Soil Science, v.100, p.409-413, 1965.

HEM, J.D. Reactions of metal ions at surfaces of hydrous iron oxide. Geochimica et Cosmochimica Acta, v.41, p.527-538, 1977.

HOLGREM, G.G.S.; MEYER, M.W.; CHANEY, R.L.; DANIELS, R.B. Cd, Pb, Zn, Cu and $\mathrm{Ni}$ in agricultural soils of the United States of America. Journal of Environmental Quality, v.22, p.335-348, 1993.

JENNE, E.A. Iron element sorption by sediments and soils - sites and process. In: CHAPEL, W.; PETERSON, K. (Ed.) Symposium on molybdenum in the environment. New York: Marcel-Dekker, 1976. v.2, p.425-553.

JOHNSON, L.J.; CHU, C.H. Mineralogical characterization of selected soils from northeastern United States. Pennsylvania State University, 1983.4 48. (Agricultural Experimental Station Bulletin, 847)

KERNDORFF, H.; SCHNITZER, M. Sorption of metals on humic acid. Analytica Chimica Acta, v. 44, p. 1701-1708, 1980.

KING, L.D. Soil heavy metals. In: ALVAREZ, V. H.; FONTES, L. E. F.; FONTES, M. P. (Ed.) O solo nos grandes domínios morfoclimáticos do Brasil. Viçosa: SBCS, 1996. p. 823 - 836 . 
KINNIBURGH, D.G.; JACKSON, M.L.; SYERS, J.K. Adsorption of alkaline earth, transition, and heavy iron and aluminum. Soil Science Society of America Journal, v.40, p. 796-799, 1976.

KRAUSKOPF, K.B. Geochemistry of micronutrients. In: MORVEDT, J.J. (Ed) Micronutrients in agriculture. Madison, Soil Science Society of America, 1972. p.7-40.

KORTE, N.E.; SKOPP, J.; FULLER, W.H.; NIEBLA, E.E.; ALESII, B.A. Trace element movement in soils. Influence of soil physical and chemical properties. Soil Science, v.122, p.350-359, 1976.

KUO, S.; BAKER, A.S. Sorption of copper, zinc and cadmium by some acid soils. Soil Science Society of America Journal, v.44, p.969-974, 1980.

MARTINI, G.; BASSETTI, V.; OTTAVIANI, M.F. Mobility and adsorption of copper complexes on aluminas: an ESR study. Journal of Chemical Physics, v.77, p.311$317,1980$.

MSAKY, J.J.; CALVET, R. Adsorption behavior of copper and zinc in soils: influence of $\mathrm{pH}$ on adsorption characteristics. Soil Science, v.150, p.513-522, 1990.

MATOS, A.T.; FONTES, M.P.F.; JORDÃO, C.P.; COSTA, L.M. Mobilidade e formas de retenção de metais pesados em latossolo vermelho-amarelo. Revista brasileira de Ciência do Solo, v.20, p.379-386, 1996. 
MATTIAZZO-PREZZOTO, M.E. Comportamento de cobre, cádmio, crômio, níquel e zinco adicionados a solos de clima tropical em diferentes valores de $\mathrm{pH}$. Piracicaba, 1994. 197p. Tese (Livre Docência) - Escola Superior de Agricultura "Luiz de Queiroz”, Universidade de São Paulo.

MATTIGOD, S.V.; PAGE, A.L. Assessment of metal pollution in soil. In: Applied Environmental geochemistry. Academic Press, London: 1983. cap.12, p.355-394.

McBRIDE, M.B. Exchange and hydration properties of $\mathrm{Cu}^{2+}$ on mixed-ion $\mathrm{Na}^{+}-\mathrm{Cu}^{2+}$ smectites. Soil Science Society of America Journal, v.40, p.452-456, 1976.

McBRIDE, M.B. Interpretation of the variability selectivity coefficients for exchange between ions of unequal charge on smectites. Clays and Clay Minerals, v.28, p.255-261, 1980.

McBRIDE, M.B. Forms and distributions of copper in solid and solution phase of soil. In: LONERAGAN, J.F.; ROBSON, A.D.; GRAHAM, R.D. (Ed.) Copper in soils and plants. New York: Academic Press, 1981. p.25-46.

McBRIDE, M.B. Sorption of copper (II) on aluminum hydroxide as affected by phosphate. Soil Science Society of America Journal, v.49, p.843-846, 1985.

McBRIDE, M.B. Reactions controlling heavy metal solubility in soils. Advances in Soil Science, v.10, p.1-56, 1989.

McBRIDE, M.; SAUVÉ, S.; HENDERSHOT, W. Solubility control of $\mathrm{Cu}, \mathrm{Zn}, \mathrm{Cd}$ e $\mathrm{Pb}$ in contamined soils. European Journal of Soil Science, v.48, p.337-346, 1997. 
McKENZIE, R.M. The adsoption of lead and other heavy metals on oxides of manganese and iron. Australian Journal of Soil Research, v.18, p.61-73, 1980.

McLAREN, R.G.; CRAWFORD, D.V. Studies on soil copper II. The specific adsorption of copper by soils. Journal of Soil Science, v.24, p.443-452, 1973.

McLAREN, R.G.; SWIFT, R.S.; WILLIAMS, J.G. The adsorption of copper by soil materials at low equilibrium concentration. Journal of Soil Science, v.32, p.247$256,1981$.

McLAREN, R.G.; WILLIAMS, J.G.; SWIFT, R.S. The adsorption of copper by soil samples from Scotland at low equilibrium solution concentrations. Geoderma, v.31, p.97-106, 1983.

MSAKY, J.J.; CALVET, R. Adsoprtion behavior of copper and zinc in soils : Influence of $\mathrm{pH}$ on adsorptios characteristics. Soil Science, v.150, p.513-522, 1990.

OKAZAKI, M.; TAKAMIDOH, K.; YAMANE, I. Adsorption of heavy metal cations on hydrated oxides and oxides of iron and aluminum with different crupta limities. Soil Science and Plant Nutrition, v.32, p.523-533, 1986.

OLIVEIRA, J.B.; PRADO, H. do. Carta pedológica semi-detalhada do Estado de São Paulo : Guaíra; projeto cartográfico IGC. Campinas:IAC, 1991. Escala 1:100.000.

PADMANABHAM,M. Comparative study of adsorption-desorption behaviour of copper (II), zinc (II), cobalt (II) e lead (II) at the goethite solution interface. Australian Journal of Soil Research, v.21, p.515-525, 1983. 
PETRONIO, B.M.; D’ORAZIO,D.; PETRUZZELLI, G.; GENNARO, M.C.; VANNI, A.; LIBERATORI, A. Characterization of the liquid phase of sewage sludge. Effects on copper (II) adsorption by soil. Environmental Technology, v.17, p.439-444, 1996.

PETRUZZELLI, G.; GUIDI, G.; LUBRANO, L. Ionic strength effect on heavy metal adsorption by soil. Communications in Soil Science and Plant Analysis, v.16, p.971-986, 1985.

PEZZAROSSA, B.; MALORGIO, F.; LUBRANO, L.; TOGNONI, F.; PETRUZZELLI, G. Phosphate fertilizer as a source of heavy metals in protectes cultivation. Communications in Soil Science and Plant Analysis, v.21, p.737-751, 1990.

POMBO, L.C.A. Sorção competitiva de $\mathrm{Zn}, \mathrm{Cu}, \mathrm{Cr}$, Ni e Fe a um solo TBd do Estado do Rio Grande do Sul (compact disc). In: CONGRESSO BRASILEIRO DE CIÊNCIA DO SOLO, 26., Rio de Janeiro, 1997. Anais. Rio de Janeiro: EMBRAPA,CNPS; SBCS, 1997.

POMBO, L.C.A.; KLAMT, E. Adsorção de zinco e cobre de dois solos do Estado do Rio Grande do Sul. Revista Brasileira de Ciência do Solo, v.10, p.191-194, 1986.

PRADO, H.do. Os solos do Estado de São Paulo : mapas pedológicos. Piracicaba: S.N., 1997, 205p.

RATNER-ZOMAR, Y.; BANIN, A.; CHEN, Y. Oven drying as a pretreatment for surface area determinations of soils and clays. Soil Science Society of America Journal, v.47, p.1056-1058, 1983. 
RESENDE, M.; SANTANA, D.P. Uso das relações ki e kr na estimativa da mineralogia para classificação dos latossolos. In: REUNIÃO DE CLASSIFICAÇÃO, CORRELAÇÃO DE SOLOS E INTERPRETAÇÃO DE APTIDÃO AGRÍCOLA, 3, Rio de Janeiro, 1988. Anais. Rio de Janeiro: EMBRAPA,SNLCS, 1988. p.225-232. (EMBRAPA, SNLCS. Documentos, 12)

SADIQ, M. The adsorption characteristics of soil and sorption of copper, manganese e zinc. Communications in Soil Science and Plant Analysis, v.12, p.631-642, 1981.

SAHA, J.K.; MANDAL, B.; MANDAL, L.N. Adsorption of copper in Alfisols in relation to soil properties. Journal of Indian Society of Soil Science, v.43, p.196199, 1995.

SALAM, A.K.; HELMKE, P.A. The pH dependence of free ionic activies and total dissolved concentrations of copper and cadmium in soil solution. Geoderma, v.83, p.281-291, 1998.

SANDERS, J.R. The effect of $\mathrm{pH}$ upon the copper and cupric ion concentrations in soil solutions. Journal of Soil Science, v.33, p.679-689, 1982.

SAS INSTITUTE. SAS user's guide: release 6.03 . Cary, 1988. 1028 p.

SCHINDLER, P.W.; LIECHTI, P.; WESTALL, J.C. Adsorption of copper, cadmium and lead from aqueous solution at the kaolinite/water interface. Netherlands Journal of Agriculture Science, v.35, p. 219-230, 1987 
SCHNITZER, M.; SKINNER, S.I.M. Organo-metalic interactions in soils. 5. Stability constants fo $\mathrm{Cu}^{++}, \mathrm{Fe}^{++}, \mathrm{Zn}^{++}$-fulvic acid complexes. Soil Science, v.102, p.361-365, 1966.

SCHULTHESS, C.P.; HUANG, C.P. Adsorption of heavy metals by silicon and aluminum oxide surfaces on clay minerals. Soil Science Society of America Journal, v.54, p.679-688, 1990.

SINGH, M. Retention of added copper by two soils as affected by organic matter, $\mathrm{CaCO}_{3}$ and exchangeable ions. Geoderma, v.5, p.219-227, 1971.

SINGH, R.R.; PRASAD, B.; CHOUDHARY, S.N. Kinetics of copper adsorption in calcareous soils. Journal of Indian Society of Soil Science, v.41, p.482-485, 1993.

SIQUEIRA, C.; LEAL, J.R.; VELLOSO, A.C.X.; SANTOS, G.A. Eletroquímica de solos tropicais de carga variável : I. Influência da matéria orgânica no tempo de equilíbrio para determinação das curvas de titulação potenciométrica. Revista Brasileira de Ciência do Solo, v.14, p.7-1 1, 1990.

SPARKS, D.L. Environmental soil chemistry. San Diego:California, 1995. cap.5, p.99-139: Sorption phenomena on soils.

SPOSITO, G. The operational definition of zero point of charge in soils. Soil Science Society of America Journal, v.45, p.292-297, 1981.

STEVENSON, F.J.; FITCH, A. Reactions with organic-matter. In: LONERAGAN, F.J.; ROBSON, A.D.; GRAHAN, R.D. (Ed.) Copper in soils and plants. Sydney: Academic Press, 1981. p.69-96. 
STUMM, W.; MORGAN. Aquatic chemistry. New York: John Willey, 1981. 47p.

TAGA, M.; TANAKA, S.; FUKUSHIMA, M. Evaluation of copper (II)-binding ability of humic acids in peat using sulphoprophyl C-25 cation exchanger. Analytica Chimica Acta, v.244, p.281-287, 1991.

TEMMINGHOFF, E.J.M.; VAN DER ZEE, S.E.A.T.M.; KEIZER, M.G. The influence of $\mathrm{pH}$ on the desorption and speciation of copper in a sandy soil. Journal of Soil Science, v.158, p.398-407, 1994.

UEHARA, G. Acric properties and their significance to soil classification. In: INTERNATIONAL SOIL CLASSIFICATION WORKSHOP, 8., Rio de Janeiro, 1986. Proceedings. Rio de Janeiro : EMBRAPA,SNLCS, 1988. p. 19-22.

VALADARES, J.A.M.S. Cobre em solos do Estado de São Paulo. I. Cobre total. Bragantia, v.34, p.125-132, 1975.

WANG, Z.; STUMM,W. Heavy metal complexation by surfaces and humic acids: brief discourse on assessment by acidimetric titration. Netherland Journal of Agricultural Science, v.35, p.231-240, 1987.

YU, T.R. Chemistry of variable charge soils. New York: Oxford University Press, 1997. 505p.

YUAN, G.; LAVKULICH, L.M. Sorption behavior of copper, zinc and cadmium im response to stimulated changes in soil properties. Communications in Soil Science and Plant Analysis, v.28, p.571-587, 1997. 
ZHU, B.; ALVA, A.K. Diferential adsorption of trace metals by soils as influenced by exchangeable cations and ionic strength. Soil Science, v.155, p.61-66, 1993. 
APÊNDICES 
A1 : Curvas de adsorção de cobre nas amostras de terra com $\mathrm{pH}$ original dos solos.

\section{Terra Roxa Estruturada}

\begin{tabular}{|c|c|c|c|c|}
\hline \multirow{3}{*}{$\begin{array}{c}\text { Cobre } \\
\text { adicionado } \\
\mathrm{mg} \mathrm{kg}^{-1}\end{array}$} & \multicolumn{2}{|c|}{$\begin{array}{l}\text { Concentração de equilíbrio } \\
\text { (CE) }\end{array}$} & \multicolumn{2}{|c|}{ Quantidade adsorvida } \\
\hline & \multicolumn{2}{|c|}{ - } & \multicolumn{2}{|c|}{ - } \\
\hline & $0,0-0,2 \mathrm{~m}$ & $0,7-0,9 \mathrm{~m}$ & $0,0-0,2 \mathrm{~m}$ & $0,7-0,9 \mathrm{~m}$ \\
\hline 0 & 0 & 0 & 0 & 0 \\
\hline 5 & 0,01 & 0,01 & 49,9 & 49,9 \\
\hline 10 & 0,01 & 0,01 & 99,9 & 99,9 \\
\hline 20 & 0,01 & 0,01 & 199,9 & 199,9 \\
\hline 50 & 0,01 & 0,34 & 499,9 & 496,6 \\
\hline 100 & 0,2 & 4,32 & 998,3 & 956,9 \\
\hline 200 & 3,3 & 41,0 & 1967,0 & 1590,0 \\
\hline 300 & 9,9 & 103,0 & 2901,0 & 1970,0 \\
\hline 400 & 27,0 & 146,3 & 3730,0 & 2536,7 \\
\hline 600 & 156,7 & 304,7 & 4433,3 & 2953,3 \\
\hline 800 & 251,3 & 434,0 & 5486,7 & 3660,0 \\
\hline
\end{tabular}

Obs: Os valores de CE e adsorção referem-se à média de três repetições 


\section{Latossolo Roxo}

\begin{tabular}{ccccc}
\hline $\begin{array}{c}\text { Cobre } \\
\text { adicionado }\end{array}$ & \multicolumn{2}{c}{ Concentração de equilíbrio } & \multicolumn{2}{c}{ Quantidade adsorvida } \\
\hline $\mathrm{mg} \mathrm{kg}^{-1}$ & - (CE) & & \\
& $0,0-0,2 \mathrm{~m}$ & $0,8-1,0 \mathrm{~m}$ & $0,0-0,2 \mathrm{~m}$ & $0,8-1,0 \mathrm{~m}$ \\
0 & 0 & 0 & 0 & 0 \\
5 & 0,1 & 0,07 & 49,4 & 49,3 \\
10 & 0,2 & 0,42 & 98,2 & 95,8 \\
20 & 0,8 & 2,5 & 191,6 & 175,3 \\
50 & 9,9 & 17,5 & 401,0 & 325,0 \\
100 & 40,9 & 52,1 & 591,3 & 478,7 \\
200 & 114,7 & 138,8 & 853,3 & 611,7 \\
300 & 198,3 & 205,2 & 1016,7 & 948,7 \\
400 & 270,3 & 286,0 & 1296,7 & 1140,0 \\
600 & 454,0 & 466,0 & 1460,0 & 1340,0 \\
800 & 583,3 & 672,0 & 2166,7 & 1280,0
\end{tabular}

Obs: Os valores de CE e adsorção referem-se a média de três repetições 


\section{Latossolo variação Una}

\begin{tabular}{|c|c|c|c|c|}
\hline \multirow{3}{*}{$\begin{array}{c}\text { Cobre } \\
\text { adicionado } \\
\mathrm{mg} \mathrm{kg}^{-1}\end{array}$} & \multicolumn{2}{|c|}{$\begin{array}{l}\text { Concentração de equilíbrio } \\
\text { (CE) }\end{array}$} & \multicolumn{2}{|c|}{ Quantidade adsorvida } \\
\hline & \multicolumn{2}{|c|}{ - } & \multicolumn{2}{|c|}{ 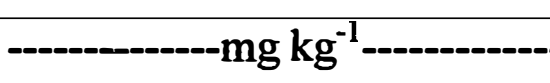 } \\
\hline & $0,0-0,2 \mathrm{~m}$ & $0,4-0,6 \mathrm{~m}$ & $0,0-0,2 \mathrm{~m}$ & $0,4-0,6 \mathrm{~m}$ \\
\hline 0 & 0 & 0 & 0 & 0 \\
\hline 5 & 0,11 & 0,01 & 48,9 & 49,9 \\
\hline 10 & 0,11 & 0,01 & 98,9 & 99,9 \\
\hline 20 & 0,4 & 0,04 & 195,7 & 199,6 \\
\hline 50 & 6,0 & 5,8 & 440,3 & 442,3 \\
\hline 100 & 31,9 & 34,8 & 680,7 & 652,3 \\
\hline 200 & 107,0 & 109,8 & 930,0 & 901,7 \\
\hline 300 & 195,5 & 210,2 & 1045,0 & 898,3 \\
\hline 400 & 294,7 & 298,0 & 1053,3 & 1020,0 \\
\hline 600 & 464,0 & 480,0 & 1360,0 & 1200,0 \\
\hline 800 & 628,0 & 608,7 & 1720,0 & 1913,3 \\
\hline
\end{tabular}

Obs: Os valores de CE e adsorção referem-se a média de três repetições 
A2 : Coeficientes de correlação simples entre os atributos do solo e os parâmetros dos modelos de Langmuir e Freundlich.

\begin{tabular}{|c|c|c|c|c|}
\hline & \multicolumn{2}{|c|}{ Freundlich } & \multicolumn{2}{|c|}{ Langmuir } \\
\hline & $\mathbf{K}$ & $\mathbf{n}$ & $\mathbf{b}$ & $\mathbf{K}$ \\
\hline $\mathrm{pH} \mathrm{H}_{2} \mathrm{O}$ & 0,28 & 0,25 & 0,37 & 0,17 \\
\hline $\mathrm{pH} \mathrm{KCl}$ & $-0,25$ & 0,17 & $-0,27$ & $-0,17$ \\
\hline Carbono & 0,51 & $-0,01$ & 0,57 & 0,70 \\
\hline Retenção de cátions & 0,62 & $-0,01$ & 0,78 & 0,67 \\
\hline CTC efetiva & 0,82 & $-0,09$ & 0,88 & 0,79 \\
\hline CTC total & 0,83 & $-0,12$ & $-0,89$ & 0,83 \\
\hline M\% & $-0,18$ & $-0,07$ & $-0,18$ & $-0,16$ \\
\hline V\% & 0,53 & 0,19 & 0,63 & 0,37 \\
\hline $\mathrm{Fe}_{\mathrm{t}}$ & 0,19 & 0,64 & 0,30 & 0,14 \\
\hline $\mathrm{Fe}_{\mathrm{d}}$ & 0,22 & 0,65 & 0,34 & 0,18 \\
\hline $\mathrm{Fe}_{\mathrm{o}}$ & 0,47 & 0,34 & 0,58 & 0,29 \\
\hline $\mathrm{Al}_{\mathrm{t}}$ & 0,17 & 0,51 & 0,27 & 0,06 \\
\hline $\mathrm{Al}_{\mathrm{d}}$ & $-0,24$ & $-0,45$ & $-0,34$ & $-0,03$ \\
\hline $\mathrm{Al}_{\mathrm{o}}$ & $-0,02$ & 0,17 & 0,03 & $-0,52$ \\
\hline $\mathrm{MnO}$ & 0,74 & 0,14 & 0,82 & 0,80 \\
\hline $\mathrm{Si}$ & 0,46 & 0,13 & 0,49 & 0,83 \\
\hline $\mathrm{Ki}$ & 0,97 & $-0,46$ & 0,96 & 0,71 \\
\hline $\mathrm{Kr}$ & 0,87 & $-0,74$ & 0,82 & 0,60 \\
\hline
\end{tabular}




\begin{tabular}{lcccc}
\hline & \multicolumn{2}{c}{ Freundlich } & \multicolumn{2}{c}{ Langmuir } \\
& K & $\mathbf{n}$ & b & K \\
PESN & $-0,41$ & $-0,03$ & $-0,51$ & $-0,24$ \\
Potencial elétrico & $-0,44$ & $-0,13$ & $-0,55$ & $-0,25$ \\
Argila & 0,73 & 0,11 & 0,79 & 0,64 \\
ADA & 0,53 & 0,07 & 0,61 & 0,68 \\
Superficie específica & 0,85 & $-0,24$ & 0,87 & 0,50 \\
\hline
\end{tabular}


A3 : Coeficientes de correlação múltipla dos atributos do solo utilizados nas regressões múltiplas.

\begin{tabular}{llll}
\hline \multicolumn{2}{c}{ Langmuir } & \multicolumn{2}{c}{ Freundlich } \\
\hline \multicolumn{1}{c}{ Parâmetro $\mathrm{b}$} & \multicolumn{1}{c}{ Parâmetro $\mathrm{K}$} & Parâmetro $\mathrm{n}$ & \multicolumn{1}{c}{ Parâmetro $\mathrm{K}$} \\
CTCef. $=0,86$ & CTCef. $=0,75$ & $\mathbf{k r}=-0,70$ & CTCef. $=0,78$ \\
$\mathbf{k i}=0,94$ & $\mathbf{k i}=0,67$ & $\mathrm{Fe}_{\mathrm{t}}=0,60$ & $\mathbf{k i}=0,92$ \\
$\mathbf{k r}=0,80$ & $\mathbf{k r}=0,56$ & $\mathrm{Fe}_{\mathrm{d}}=0,61$ & $\mathbf{k r}=0,83$ \\
Argila $=0,77$ & Argila $=0,61$ & $\mathrm{Al}_{\mathrm{t}}=0,48$ & Argila $=0,70$ \\
$\mathrm{Fe}_{\mathbf{o}}=0,57$ & Carbono $=0,67$ & & Carbono $=0,48$ \\
& & & S.E. $=0,49$ \\
\hline
\end{tabular}


A4 : Energia livre das reações de cobre $\left(\mathrm{J} \mathrm{mol}^{-1}\right)$

\begin{tabular}{ccccccc}
\hline $\begin{array}{c}\text { Cobre } \\
\text { adicionado }\end{array}$ & \multicolumn{2}{c}{ TE } & \multicolumn{3}{c}{ LR } \\
\hline$\left(\mathrm{mg} \mathrm{kg}^{-1}\right)$ & $0,0-0,2 \mathrm{~m}$ & $0,7-0,9 \mathrm{~m}$ & $0,0-0,2 \mathrm{~m}$ & $0,8-1,0 \mathrm{~m}$ & $0,0-0,2 \mathrm{~m}$ & $0,4-0,6 \mathrm{~m}$ \\
5 & ---- & ---- & $-10.805,7$ & $-10.678,9$ & ---- &.--- \\
10 & ---- & ---- & $-9.892,2$ & $-7.840,9$ & $-11.080,8$ & $-17.085,6$ \\
20 & ---- & $-18.800,1$ & $-7.840,9$ & $-5.176,5$ & $-9.478,1$ & $-15.371,2$ \\
50 & $-21.066,4$ & $-12.320,2$ & $-4.005,6$ & $-2.596,6$ & $-5.258,0$ & $-5.342,4$ \\
100 & $-15.725,2$ & $-7.774,1$ & $-2.213,3$ & $-1.611,1$ & $-2.823,4$ & $-2.613,2$ \\
200 & $-10.151,8$ & $-3919,71$ & $-1.375,9$ & $-902,9$ & $-1.547,1$ & $-1.482,4$ \\
300 & $-8.437,4$ & $-2.644,2$ & $-1.023,6$ & $-939,8$ & $-1.059,2$ & $-880,2$ \\
400 & $-6.667,4$ & $-2.487,2$ & $-969,1$ & $-829,8$ & $-755,9$ & $-728,1$ \\
600 & $-3.321,3$ & $-1.676,3$ & $-689,7$ & $-625,1$ & $-635,8$ & $-331,9$ \\
800 & $-2.863,8$ & $-1.512,7$ & $-781,2$ & $-431,3$ & $-598,7$ & $-676,1$ \\
\hline
\end{tabular}

$\mathrm{TE}=$ Terra Roxa Estruturada, $\mathrm{LR}=$ Latossolo Roxo, $\mathrm{LU}=$ Latossolo variação Una. 
A5 : Adsorção de cobre $\left(\mathrm{mg} \mathrm{kg}^{-1}\right)$ nas amostras de terra com incubadas com carbonato de cálcio e ácido clorídrico, após a adição de $100 \mathrm{mg} \mathrm{kg}^{-1}$ de cobre.

\begin{tabular}{ccccccc}
\hline pH & \multicolumn{2}{c}{ TE } & \multicolumn{2}{c}{ LR } & \multicolumn{2}{c}{ LU } \\
\hline & Superficie & Profundidade & Superficie & Profundidade & Superficie & Profundidade \\
4 & 928,2 & 661,1 & 580 & 99,4 & 567,1 & 137,3 \\
5 & 997,0 & 838,9 & 915,4 & 533,0 & 859,9 & 323,5 \\
6 & 999,3 & 940,0 & 996,6 & 967,7 & 997,2 & 676,6 \\
\hline
\end{tabular}

Análise da variância com aplicação do Teste $\mathrm{F}$

\begin{tabular}{lcccc}
\hline Causas de Variação & G.L. & S.Q. & F & $\alpha$ \\
\hline Solos (S) & 2 & 1144507,54 & 4522,44 & 0,0001 \\
Profundidade (Prof) & 1 & 1576185,33 & 12456,38 & 0,0001 \\
pH (pH) & 2 & 2277445,84 & 8999,17 & 0,0001 \\
S*Prof & 2 & 214633,25 & 848,11 & 0,0001 \\
S*pH $^{*}$ & 4 & 464246,85 & 917,22 & 0,0001 \\
Prof*pH & 2 & 232703,78 & 919,51 & 0,0001 \\
S*Prof*pH $^{*}$ Resíduo & 4 & 82852,11 & 163,36 & 0,0001 \\
\hline Total & 54 & 6832,97 & & \\
\hline
\end{tabular}

